\title{
Computerized genetic map of Bacillus subtilis
}

\author{
Véronique Biaudet, Franck Samson, Constantin Anagnostopoulos, \\ S. Dusko Ehrlich and Philippe Bessières
}

\author{
Author for correspondence: Véronique Biaudet. Tel: +331346525 32. Fax: + 33134652521 . \\ e-mail : biaudet@, biotec.jouy.inra.fr
}

Génétique Microbienne, Institut National de Recherche Agronomique, Domaine de Vilvert, 78352 Jouy-en-Josas cedex, France

Keywords: Bacillus subtilis, genetic map, database

\section{Introduction}

Bacillus subtilis is a Gram-positive soil organism endowed with an interesting developmental programme, which includes acquisition of competence for transformation with exogenous DNA, sporulation and germination, and is taxonomically closely related to various bacilli used for production of numerous industrial enzymes. It is wellcharacterized genetically and physiologically, due to a number of studies carried out in the past few decades [714], and is thus an excellent model organism for Grampositive bacteria, in particular those that have relatively $\mathrm{A}+\mathrm{T}$-rich genomes, such as lactic acid bacteria, clostridia or mycoplasmas. Present and future work with B. subtilis includes systematic characterization of its genes, carried out within a consortium of European laboratories, in coordination with a number of laboratories from Japan $[382,540]$.

The accumulation of large quantities of data by the European and Japanese laboratories prompted us to develop a new software package to facilitate their organization and management. We therefore developed a database, on an Oracle relational system, dedicated to the analysis of bacterial genomes, which we called Micado (MICrobial Advanced Database Organization). It is designed to cross-reference or link heterogeneous information such as nucleotide sequences and the associated features, bibliographic references, genetic map data and properties of mutant strains. The sequence information comes from primary entries in EMBL and GenBank, and a non-redundant controlled set of $B$. subtilis sequences from SubtiList [488], a database cleaner than nonspecialized databases.

Micado is endowed with a user-friendly query interface through a WorldWide Web networked hypermedia server on the Internet (its address is http://locus.jouy.inra.fr). It gives an international multiplatform and accountless access to the database. Searching sequences and genes is based on annotations such as features, descriptions or bibliography. It makes use of selection menus and clickable images to obtain information about genes by selecting gene names on genetic or physical map graphical representations. Interactive requests on the database allow users to scale a gene and its region at the sequence level, thus providing fine details on map contents. Printingquality outputs exist for interactively displayed regions, and for documents in this paper and future updates.

A program has been written to draw the B. subtilis genetic map automatically (Fig. 1) and present the global organization of the loci and their order on the chromosome in a compact and readable form. It is independent of the variable number of genes in each degree, an indispensable feature considering the permanent increase of uncovered genes in the last few years, and its foreseeable continuation. We cross genetic map information and sequence data inside Micado for control and addition of new genes. Organization of sequences in large contigs, coming from the sequencing groups or SubtiList database, allowed us to check for wrongly located genes on the genetic map, and to modify orientation information for some contigs and loci. Also, aligning genes on sequences showed inaccuracies in position measurement, and gave us an opportunity to remedy them. The present version of the $B$. subtilis genetic map is the first in which a table and graphical representation were automatically generated by a computer program.

The genetic map and the information reported on Table 1 were derived, with revision and updating, from the sixth edition [23] of a series of revised versions of the B. subtilis 168 chromosome map, starting with that of Henner \& Hoch in 1980 [287, 288, 580, 581, 582, 23]. The linear vertical form adopted in the last edition has also been used in this version. The map is, as usual, divided in degrees of a circle starting from the origin of chromosome replication. The size of the $B$. subtilis genome has been estimated as approximately $4.2 \mathrm{Mb}$ from the data of the physical map of Amjad et al. [21] and $4 \cdot 188 \mathrm{Mb}$ from that of Itaya \& Tanaka [330]. A degree, therefore, corresponds to about $11.6 \mathrm{~kb}$. The number of genes placed on the present map is $1089 ; 410$ more genes have therefore been 

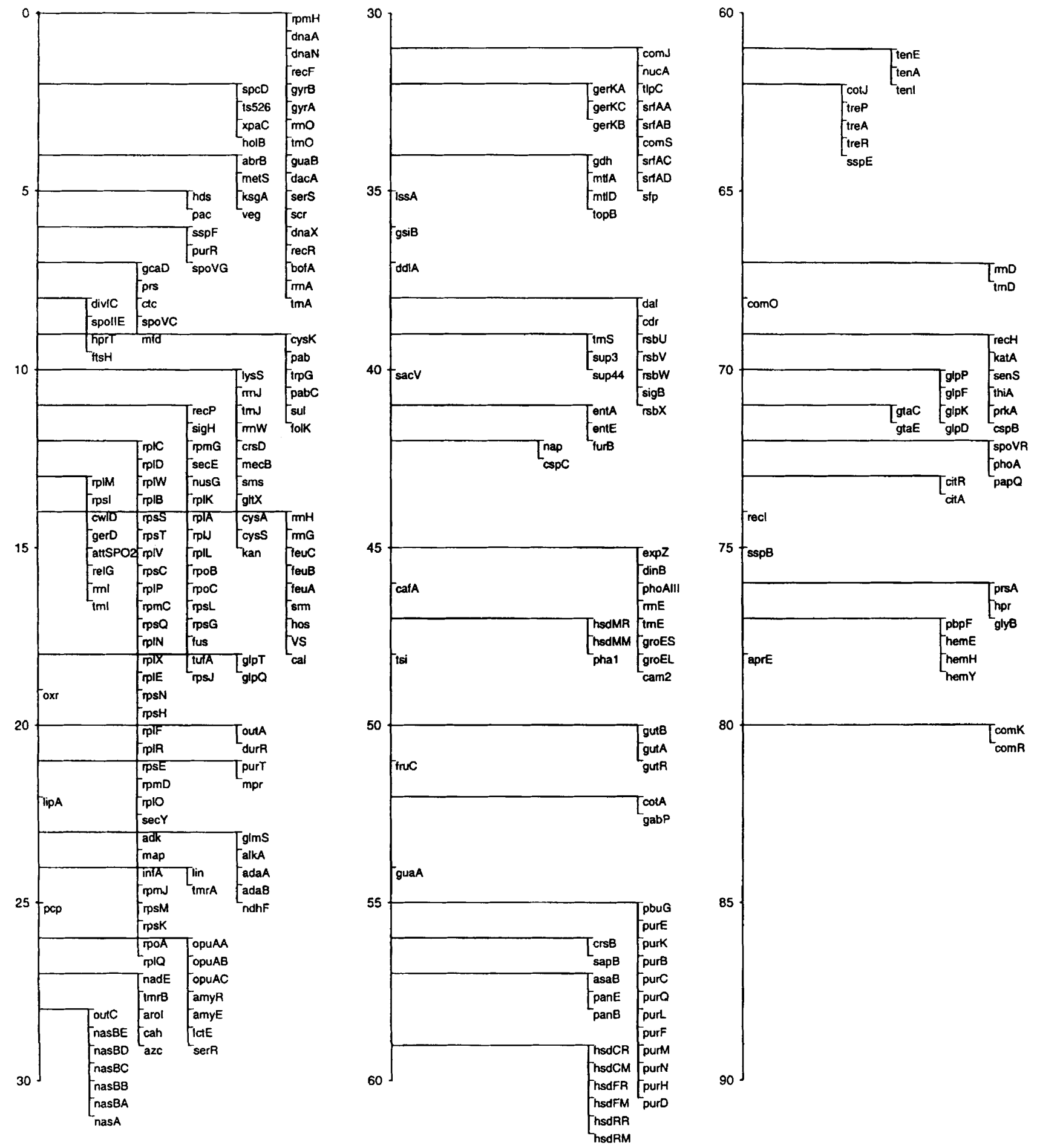

Fig. 1. B. subtilis genetic map

added since the last edition. The reader is referred to the introduction of the last edition [23] as regards accuracy of map position of a gene, distance between genes and nomenclature. Gene position and distances are of course now sufficiently accurate in the already-sequenced areas. In Table 1, besides the usual information (gene symbol, map position, function, references), we added the symbols formerly or alternatively used by authors. For updates of the $B$. subtilis genetic map, we regularly search the literature and the network for novel information. The current map includes published data up to 1 May 1996. In the particular cases where no publication has been found, the bibliography reports references from the sequence databases (the annotation 'Direct submission to EMBL/ 


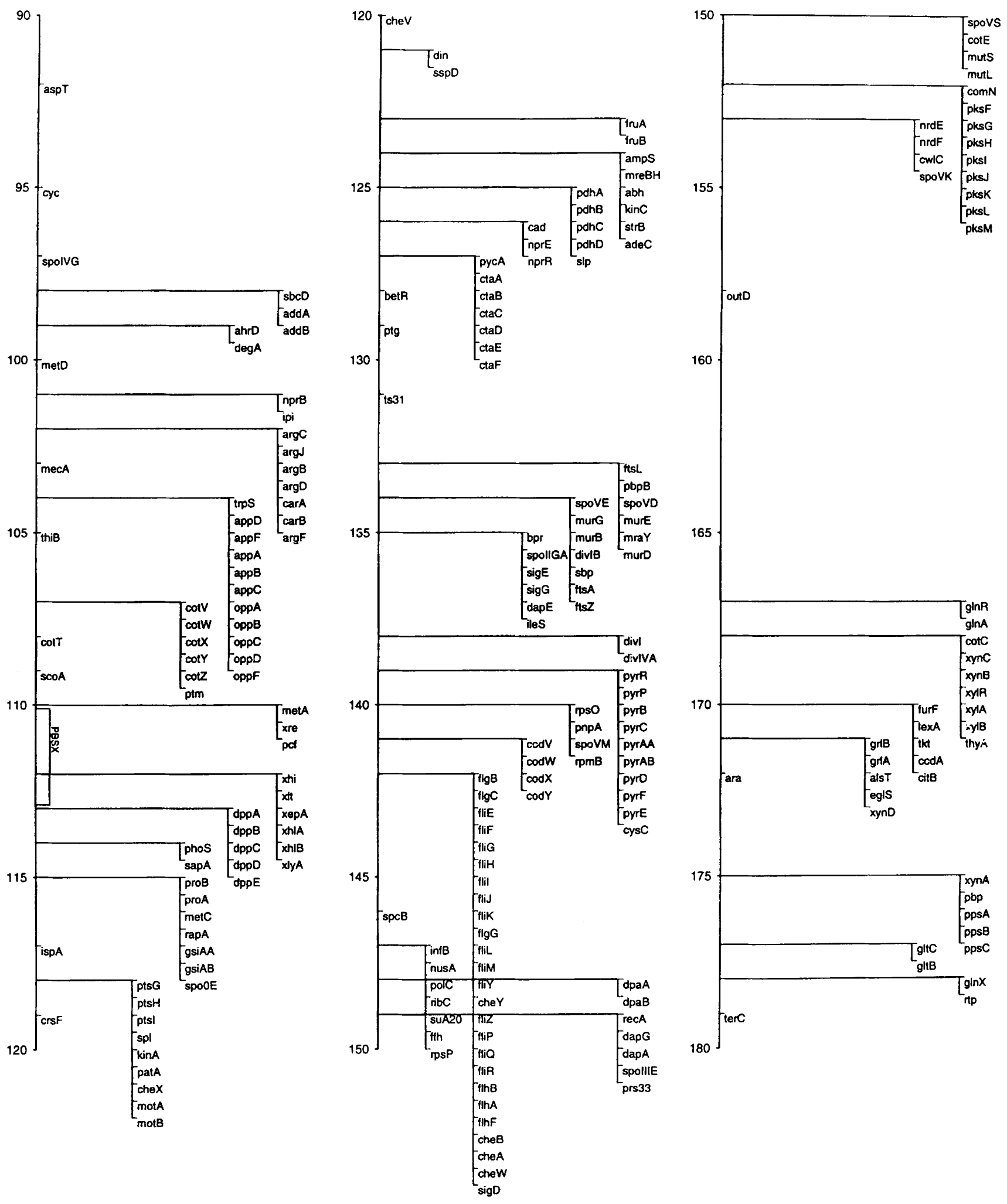

Fig. 1. B. subtilis genetic map (cont.) 

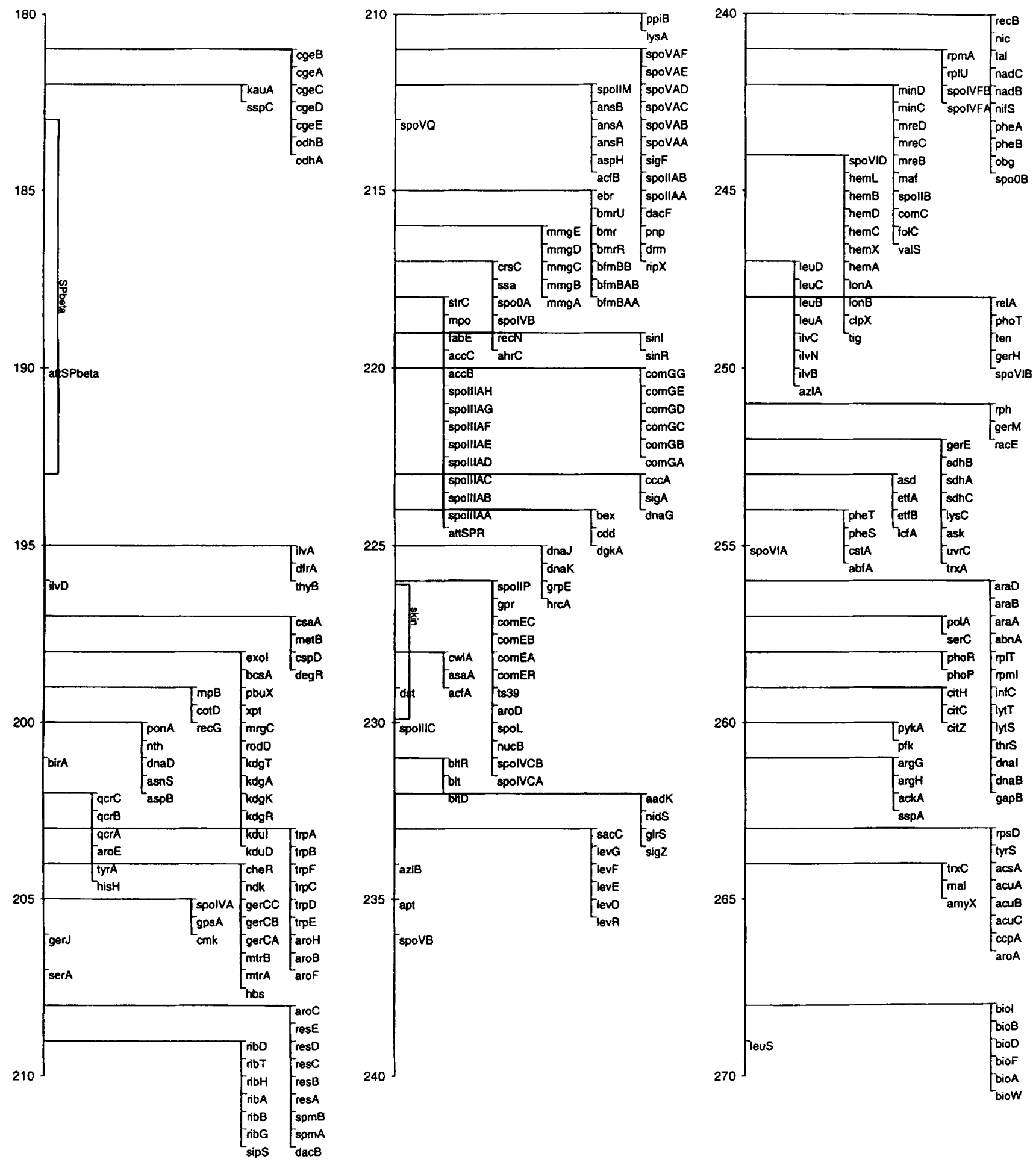

Fig. 1. B. subtilis genetic map (cont.) 

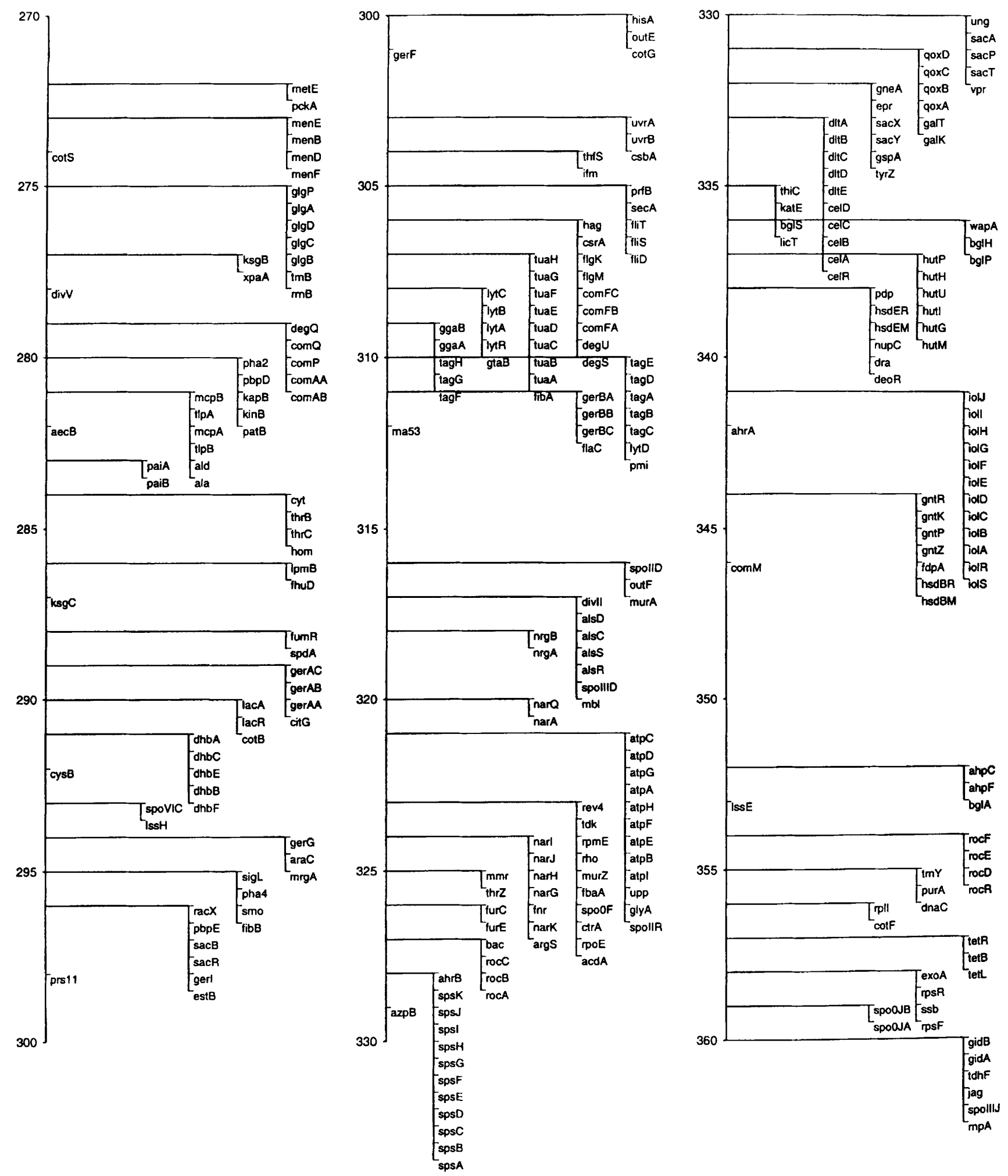

Fig. 1. B. subtilis genetic map (cont.) 
Table 1. Genes of $B$. subtilis

Map positions are given in degrees: NM, not mapped; UC, map position not fully defined. References: *, locus sequenced; \#, locus cloned.

\begin{tabular}{|c|c|c|c|}
\hline $\begin{array}{l}\text { Gene } \\
\text { symbol }\end{array}$ & $\begin{array}{l}\text { Map } \\
\text { position }\end{array}$ & $\begin{array}{l}\text { Functions, products, phenotypes, other characteristics, former or } \\
\text { alternative symbols }\end{array}$ & Reference \\
\hline $\operatorname{aadK}$ & 232 & Aminoglycoside 6-adenylyltransferase & $527^{*}, 546$ \\
\hline$a b f A$ & 254 & $\alpha-\mathrm{L}$-Arabinofuranosidase Streptomyces lividans homologue & $825^{*}$ \\
\hline$a b b$ & 124 & Homologous to the $a b r B$ gene, gene $y l x T$ & $367 *, 824$ \\
\hline$a b n A$ & 256 & $\begin{array}{l}\text { Gene involved in the utilization of arabinan and arabinose; Aspergillus niger } \\
\text { arabinase homologue }\end{array}$ & $825^{*}$ \\
\hline$a b r A$ & & See $r e v-4$ & \\
\hline$a b r B$ & 4 & Transition state regulatory protein controlling a variety of genes; $c p s X$ & $563^{*}$ \\
\hline $\operatorname{acc} B$ & 218 & Biotin carboxyl carrier protein & $437^{*}$ \\
\hline $\operatorname{acc} C$ & 218 & Biotin carboxylase subunit of acetyl-CoA carboxylase & $437^{*}$ \\
\hline $\operatorname{acd} A$ & 323 & Acyl-CoA dehydrogenase & $228^{*}$ \\
\hline ace $A$ & & See $p d h A$ & \\
\hline$a c e B$ & & See $p d h B$ & \\
\hline ace $C$ & & See $p d b C$ & \\
\hline ace $D$ & & See $p d h D$ & \\
\hline $\operatorname{acf} A$ & 228 & $\begin{array}{l}\text { Resistance to acriflavin, ethidium bromide and distamycin; sensitivity to } \\
\text { streptomycin }\end{array}$ & 326 \\
\hline $\operatorname{acf} B$ & 212 & Same phenotype as acf $A$ & 688 \\
\hline ack $A$ & 261 & Acetate kinase & $245^{*}$ \\
\hline $\operatorname{acs} A$ & 263 & Acetyl-CoA synthetase & $246^{*}, 247$ \\
\hline acu $A$ & 263 & Acetoin dehydrogenase & $246^{*}, 247$ \\
\hline$a c u B$ & 263 & Acetoin dehydrogenase & $246^{*}, 247$ \\
\hline$a c u C$ & 263 & Acetoin dehydrogenase & $246^{*}, 247$ \\
\hline $\operatorname{ada} A$ & 23 & $\begin{array}{l}\text { Adaptive response to alkylating agents; methylphosphotriester-DNA } \\
\text { methyltransferase }\end{array}$ & $483^{*}, 484^{*}, 485$ \\
\hline$a d a B$ & 23 & $O^{6}$-Methylguanine-DNA methyltransferase & $483^{*}, 484^{*}, 485$ \\
\hline add $A$ & 98 & $\begin{array}{l}\text { Subunit of ATP-dependent deoxyribonuclease; equivalent to E. coli RecBCD } \\
\text { enzyme; now considered an allele of this locus; helicase }\end{array}$ & $\begin{array}{l}253,373 \#, 374^{*} \\
681^{*}\end{array}$ \\
\hline addB & 98 & $\begin{array}{l}\text { Subunit of ATP-dependent deoxyribonuclease; mutants show increased stability for } \\
\text { some plasmids }\end{array}$ & $\begin{array}{l}253,373 \#, 374 * \\
681^{*}\end{array}$ \\
\hline ade & & See ade $C$ & \\
\hline adeC & 124 & Adenine deaminase; ade & $529,530 *, 824$ \\
\hline adk & 12 & Adenylate kinase & $505^{*}$ \\
\hline $\operatorname{aec} A$ & & See $l y s C$ & \\
\hline $\operatorname{aec} B$ & 282 & Aminoethylcysteine resistance & 452 \\
\hline$a b p C$ & 352 & Probable alkyl hydroperoxide reductase; $n d b$ & $541,873^{*}$ \\
\hline$a b p F$ & 352 & Probable alkyl hydroperoxide reductase & 541 \\
\hline$a b r A$ & 342 & Arginine hydroxamate resistance & 489 \\
\hline$a b r B$ & 328 & Arginine hydroxamate resistance & 489 \\
\hline$a b r C$ & 217 & Arginine hydroxamate resistance & $707 \#$ \\
\hline$a b r D$ & 99 & Arginine hydroxamate resistance & 41 \\
\hline ala & 281 & Alanine requirement & 452 \\
\hline ald & 281 & L-Alanine dehydrogenase; spoVN & $649,691 *, 769$ \\
\hline alk $A$ & 23 & 3-Methyladenine DNA glycosylase & $486^{*}$ \\
\hline $\operatorname{als} A$ & & See $c c p A$ & \\
\hline als $C$ & 317 & Regulator homologous to the lys $\mathrm{R}$ family & $616^{*}$ \\
\hline als $D$ & 317 & Acetolactate decarboxylase & $616^{*}$ \\
\hline als $\mathrm{R}$ & 317 & Constitutive acetolactate synthase & $616 *, 866,869$ \\
\hline als $S$ & 317 & Structural gene for acetolactate synthase & $616^{*}$ \\
\hline als $T$ & 171 & Alanine sodium symport protein $\mathrm{T}$ & $630^{*}$ \\
\hline$a m p S$ & 124 & AmpS protein & $824 *$ \\
\hline amy $A$ & & See $a m y E$ & \\
\hline
\end{tabular}


Table 1 (cont.)

\begin{tabular}{|c|c|c|c|}
\hline $\begin{array}{l}\text { Gene } \\
\text { symbol }\end{array}$ & $\begin{array}{c}\text { Map } \\
\text { position }\end{array}$ & $\begin{array}{l}\text { Functions, products, phenotypes, other characteristics, former or } \\
\text { alternative symbols }\end{array}$ & Reference \\
\hline$a m y B$ & & See $\operatorname{deg} Q$ & \\
\hline$a m y E$ & 26 & Amylase structural gene; amy $A$ & $839^{*}, 840^{*}$ \\
\hline amyH & & See $a m y R$ & \\
\hline amyR & 26 & Control of amylase synthesis; gra, amyH & $521 *, 839 *, 865$ \\
\hline$a m y X$ & 264 & Starch-degrading enzyme; pullulanase & $393 *$ \\
\hline ans $A$ & 212 & L-Asparaginase & $745^{*}$ \\
\hline ans $B$ & 212 & L-Aspartase & $745^{*}$ \\
\hline ans $R$ & 212 & Repressor of the ans operon & $747^{*}$ \\
\hline$a p p A$ & 104 & Oligopeptide permease system & $368^{*}$ \\
\hline$a p p B$ & 104 & Oligopeptide permease system & $368^{*}$ \\
\hline$a p p C$ & 104 & Oligopeptide permease system & $368^{*}$ \\
\hline$a p p D$ & 104 & Oligopeptide permease system; probable ATP-binding protein & $368^{*}$ \\
\hline$a p p F$ & 104 & Oligopeptide permease system; probable ATP-binding protein & $368^{*}$ \\
\hline$a p r$ & & See aprE & \\
\hline $\operatorname{apr} A$ & & See $a p r E$ & \\
\hline aprE & 78 & Structural gene for subtilisin; apr $A$, apr, sprE & $525,721 *$ \\
\hline$a p t$ & 235 & Adenine phosphoribosyl transferase & 659 \\
\hline ara & 172 & Arabinose utilization & 558 \\
\hline $\operatorname{ara} A$ & 256 & Arabinose utilization; L-arabinose isomerase & $641 \#, 825^{*}$ \\
\hline $\operatorname{araB}$ & 256 & Arabinose utilization; L-ribulokinase & $641 \#, 825^{*}$ \\
\hline $\operatorname{araC}$ & 294 & Arabinose utilization regulation & 640 \\
\hline $\operatorname{araD}$ & 256 & Arabinose utilization; L-ribulose-5-phosphate 4-epimerase & $641 \#, 825^{*}$ \\
\hline $\arg A$ & & See $\operatorname{argJ}$ & \\
\hline $\arg B$ & 102 & $\begin{array}{l}\text { Arginine requirement; identified by complementation of corresponding locus in } E \text {. } \\
\text { coli }\end{array}$ & $490 \#, 531$ \\
\hline $\arg C$ & 102 & $\begin{array}{l}\text { Arginine requirement; identified by complementation of corresponding locus in } E \text {. } \\
\text { coli }\end{array}$ & $531,708^{*}, 709^{*}$ \\
\hline $\arg D$ & 102 & $\begin{array}{l}\text { Arginine requirement; identified by complementation of corresponding locus in } E \text {. } \\
\text { coli }\end{array}$ & $490 \#, 531$ \\
\hline $\arg E$ & & See $\arg J$ & \\
\hline $\operatorname{argF}$ & 102 & $\begin{array}{l}\text { Ornithine carbamoyltransferase; identified by complementation of corresponding } \\
\text { locus in E. coli; formerly } \arg C\end{array}$ & $490,491 \#, 531$ \\
\hline $\arg G$ & 261 & $\begin{array}{l}\text { Arginine requirement; identified by complementation of corresponding locus in } E \text {. } \\
\text { coli }\end{array}$ & $39,393 *, 490$ \\
\hline $\operatorname{argH}$ & 261 & $\begin{array}{l}\text { Arginine requirement; identified by complementation of corresponding locus in } E \text {. } \\
\text { coli }\end{array}$ & $39,393 *, 490$ \\
\hline $\arg J$ & 102 & $\begin{array}{l}\text { The product of this gene combines both the activities of the } \arg A \text { (amino acid } \\
\text { acetyl transferase) and } \arg E \text { (acetylornithine deacetylase) gene products of } E \text {. coli; } \\
\arg A, \arg E\end{array}$ & 531 \\
\hline $\arg S$ & 324 & Arginyl-tRNA synthetase & $609 *$ \\
\hline $\operatorname{aro} A$ & 263 & 3-Deoxy-D-arabinoheptulosonic-7-phosphate synthase; chorismate mutase isozyme 3 & $61 *, 302$ \\
\hline $\operatorname{aroB}$ & 203 & Dehydroquinate synthase & $292,429 \#$ \\
\hline $\operatorname{aroC}$ & 208 & Dehydroquinate dehydratase & $717^{*}, 805 \#$ \\
\hline aroD & 226 & Shikimate dehydrogenase & $302,715 \#$ \\
\hline aroE & 202 & 3-Enolpyruvylshikimate-5-phosphate synthase & $290^{*}$ \\
\hline aroF & 203 & Chorismate synthase & $292^{*}, 302$ \\
\hline aroH & 203 & Chorismate mutase isozymes 1 and 2 & $238,292 *$ \\
\hline aroI & 27 & Shikimate kinase & $506^{*}, 552 \#$ \\
\hline aroJ & & See $b i s H$ & \\
\hline $\operatorname{asa} A$ & 228 & Arsenate resistance & 2 \\
\hline$a s a B$ & 57 & Arsenate resistance (derived from B. subtilis W23) & 3 \\
\hline asd & 149 & $\begin{array}{l}\text { Aspartate semialdehyde dehydrogenase; problem of gene symbol redundance; see } \\
\text { other asd at } 253^{\circ}\end{array}$ & $112^{*}$ \\
\hline
\end{tabular}


Table 1 (cont.)

\begin{tabular}{|c|c|c|c|}
\hline $\begin{array}{l}\text { Gene } \\
\text { symbol }\end{array}$ & $\begin{array}{c}\text { Map } \\
\text { position }\end{array}$ & $\begin{array}{l}\text { Functions, products, phenotypes, other characteristics, former or } \\
\text { alternative symbols }\end{array}$ & Reference \\
\hline asd & 253 & $\begin{array}{l}\text { Bacteroides ovatus arabinosidase homologue; problem of gene symbol redundance; } \\
\text { see other asd at } 149^{\circ}\end{array}$ & $825 *$ \\
\hline ask & 252 & Aspartokinase II attenuator & $825 *$ \\
\hline asn $S$ & 200 & Asparaginyl-tRNA synthetase & $80^{*}$ \\
\hline $\operatorname{asp} B$ & 200 & Aspartate aminotransferase & $80^{*}, 301$ \\
\hline aspH & 212 & Aspartase, constitutive & 320 \\
\hline asp $T$ & 92 & Aspartate transport & 817 \\
\hline ath & & See $p u r M$ & \\
\hline $\operatorname{atp} A$ & 321 & ATP synthase subunit $\alpha$ & $652 *$ \\
\hline $\operatorname{atp} B$ & 321 & ATP synthase subunit a & $652 *$ \\
\hline $\operatorname{atp} C$ & 321 & ATP synthase subunit $\varepsilon$ & $652 *$ \\
\hline $\operatorname{atp} D$ & 321 & ATP synthase subunit $\beta$ & $652^{*}$ \\
\hline $\operatorname{atp} E$ & 321 & ATP synthase subunit $\mathrm{c}$ & $652^{*}$ \\
\hline $\operatorname{atp} F$ & 321 & ATP synthase subunit $b$ & $652^{*}$ \\
\hline $\operatorname{atp} G$ & 321 & ATP synthase subunit $\gamma$ & $652 *$ \\
\hline $\operatorname{atpH}$ & 321 & ATP synthase subunit $\delta$ & $652 *$ \\
\hline atpI & 321 & ATP synthase subunit i & $652 *$ \\
\hline att $\mathrm{SPO} 2$ & 13 & Integration site for phage $\mathrm{SPO} 2$ & 700 \\
\hline att $S P R$ & 218 & Integration site for phage SPR & 136 \\
\hline att $S P \beta$ & 190 & Integration site for phage SP $\beta$ and related phages IG1, IG3, and IG4 & 867 \\
\hline $\begin{array}{l}a q c \\
a q i\end{array}$ & 27 & $\begin{array}{l}\text { Resistance to azetidine-2-carboxylic acid; azc } 90 \% \text { co-transformed with aroI } \\
\text { See } \sec A\end{array}$ & 209 \\
\hline aql $A$ & 247 & 4-Azaleucine resistance; derepressed leucine biosynthetic enzymes & $427 \#$ \\
\hline$a q l B$ & 234 & 4-Azaleucine resistance & 806 \\
\hline$a \approx p-12$ & & See polC & \\
\hline$a \approx p B$ & 329 & Resistance to azopyrimidines & 95 \\
\hline bac & 327 & Bacilysin biosynthesis & 299 \\
\hline$b c s A$ & 198 & Bacterial chalcone synthase A & $97^{*}$ \\
\hline bet $\mathrm{R}$ & 128 & Resistance to betacin produced by SP $\beta$ lysogens & 280 \\
\hline bex & 224 & Bacillus Era-complementing segment; an essential small G-protein in E. coli & $343^{*}$ \\
\hline$b f m A$ & & See $p d h A$ & \\
\hline$b f m B$ & & See $b f m B B$ & \\
\hline$b f m B 1 a$ & & See $b f m B A A$ & \\
\hline$b f m B 1 b$ & & See $b f m B A B$ & \\
\hline bfmB2 & & See $b f m B B$ & \\
\hline bfmB $A A$ & 215 & Branched-chain $\alpha$-ketoacid dehydrogenase E1- $\alpha ; b f m B 1 a$ & $67,800^{*}$ \\
\hline$b f m B A B$ & 215 & Branched-chain $\alpha$-ketoacid dehydrogenase $\mathrm{E} 1-\beta ; b f m B 1 b$ & $67,800^{*}$ \\
\hline $\begin{array}{l}b f m B B \\
b g l\end{array}$ & 215 & $\begin{array}{l}\text { Branched-chain 2-oxo-acid dehydrogenase E2 subunit; } b f m B, b f m B 2 \\
\text { See } b g l S\end{array}$ & $5^{*}, 67,800^{*}$ \\
\hline $\operatorname{bgl} A$ & 352 & Phospho- $\beta$-glucosidase & 873* \\
\hline bglC & & See egls & \\
\hline bglH & 336 & $\beta$-Glucosidase & $854^{*}$ \\
\hline bg $l P$ & 336 & $\begin{array}{l}\beta \text {-Glucoside permease; similar to } \beta \text {-glucoside-specific phosphotransferase Enzymes } \\
\text { II }\end{array}$ & $398^{*}$ \\
\hline bglS & 335 & Endo-1,3-1,4- $\beta$-glucanase (lichenase); $b g l$ & $500^{*}, 827$ \\
\hline bio $A$ & 268 & Biotin biosynthesis; DAPA aminotransferase & $393^{*}, 553$ \\
\hline bioB & 268 & Biotin biosynthesis & $393 *, 553$ \\
\hline bioD & 268 & Dethiobiotin synthetase & $393 *$ \\
\hline bioF & 268 & Biotin biosynthesis; 7-XAP synthetase & $393 *$ \\
\hline bioI & 268 & Biotin biosynthesis; cytochrome $\mathrm{P} 450$ protein & $393 *$ \\
\hline biow & 268 & Biotin biosynthesis; pimelyl-CoA synthetase & $393 *$ \\
\hline $\operatorname{bir} A$ & 201 & $\begin{array}{l}\text { Bifunctional biotin operon repressor; biotin acetyl-CoA-carboxylase ligase; } \\
\text { transcription regulator }\end{array}$ & $68^{*}$ \\
\hline
\end{tabular}


Table 1 (cont.)

\begin{tabular}{|c|c|c|c|}
\hline $\begin{array}{l}\text { Gene } \\
\text { symbol }\end{array}$ & $\begin{array}{l}\text { Map } \\
\text { position }\end{array}$ & $\begin{array}{c}\text { Functions, products, phenotypes, other characteristics, former or } \\
\text { alternative symbols }\end{array}$ & Reference \\
\hline blt & 231 & $\begin{array}{l}\text { Multidrug efflux transporter; resistance to acriflavin, ethidium bromide and } \\
\text { distamycin; sensitivity to streptomycin }\end{array}$ & $6^{*}$ \\
\hline blt $D$ & 231 & Transacetylase co-transcribed with blt & $6^{*}$ \\
\hline blt $\mathrm{R}$ & 231 & Transcriptional regulator of $b l t$ & $6^{*}$ \\
\hline $\begin{array}{l}b m r \\
b m r-1 R\end{array}$ & 215 & $\begin{array}{l}\text { Bacterial multidrug resistance; homologous to tet gene of } \mathrm{pBR} 322 \text {; also called } b m r 1 \\
\text { See } b m r \mathrm{R}\end{array}$ & $5^{*}, 519 *$ \\
\hline$b m r \mathrm{R}$ & 215 & Multidrug-efflux transporter regulator; $b m r-1 \mathrm{R}$ & $5 *$ \\
\hline$b m r U$ & 215 & Bacterial multidrug resistance protein $\mathrm{BmrU}$, co-transcribed with $b m r$ & $5^{*}$ \\
\hline $\operatorname{bof} A$ & 0 & Activation of $\sigma^{\mathrm{K}}$ during sporulation & $619 *$ \\
\hline bof $B$ & & See spoIVFA and spoIVFB & \\
\hline$b p f$ & & See $b p r$ & \\
\hline$b p r$ & 135 & Bacillopeptidase $\mathrm{F} ; b p f$ & $\begin{array}{l}168^{*}, 696^{*}, 697^{*} \\
835^{*}\end{array}$ \\
\hline but & NM & 5-Bromouracil tolerance & 56 \\
\hline cad & 126 & Cadaverine synthesis, lysine decarboxylase & $279 *, 824$ \\
\hline $\operatorname{caf} A$ & 46 & Caffeine resistance & 96 \\
\hline $\operatorname{caf} B$ & & See $g y r A$ & \\
\hline$c a b$ & 27 & Cephalosporin C deacetylase & $474 *$ \\
\hline cal & 14 & Chalcomycin resistance & 683 \\
\hline cam-2 & 45 & Chloramphenicol resistance & 26 \\
\hline $\operatorname{car} A$ & 102 & Carbamoylphosphate synthetase subunit $\mathrm{A}$, arginine-specific; cpaA & $142^{*}, 490$ \\
\hline $\operatorname{car} B$ & 102 & Carbamoylphosphate synthetase subunit $\mathrm{B}$, arginine-specific; $c p a B$ & $142^{*}, 490$ \\
\hline cat $A$ & & See $h p r$ & \\
\hline $\operatorname{ccc} A$ & 223 & Gene for cytochrome $c_{550}$ & 793* \\
\hline $\operatorname{ccd} A$ & 170 & Required for cytochrome $c$ synthesis & $665^{*}$ \\
\hline $\operatorname{ccp} A$ & 263 & $\begin{array}{l}\text { Catabolite control protein involved in glucose regulation of several genes; als } A \text { is } \\
\text { allelic to } \operatorname{ccp} A ; \text { graR, als } A\end{array}$ & $247,284 *, 866,869$ \\
\hline cdd & 224 & Deoxycytidine-cytidine deaminase & $716^{*}$ \\
\hline$c d r$ & 38 & Cadmium resistance & 871 \\
\hline $\operatorname{cel} A$ & 333 & Putative cellobiose phosphotransferase Enzyme II & $227^{*}$ \\
\hline$c e l B$ & 333 & Putative cellobiose phosphotransferase Enzyme II & $227^{*}$ \\
\hline celC & 333 & Putative cellobiose phosphotransferase Enzyme III & $227^{*}$ \\
\hline celD & 333 & Putative 6-phospho- $\beta$-glucosidase & $227^{*}$ \\
\hline$c e l \mathrm{R}$ & 333 & cel operon regulator & $227^{*}$ \\
\hline $\operatorname{cge} A$ & 181 & $\begin{array}{l}\text { Operon cge } A B \text { genes controlled by the sporulation regulatory protein GerE; } \\
\text { cge } A A\end{array}$ & $625^{*}$ \\
\hline $\operatorname{cge} A A$ & & See cge $A$ & \\
\hline cge $A B$ & & See cgeB & \\
\hline cgeB & 181 & Operon cge $A B$ genes controlled by the sporulation regulatory protein GerE; cge $A B$ & $625 *$ \\
\hline $\operatorname{cge} B A$ & & See $c g e C$ & \\
\hline $\operatorname{cge} B B$ & & See $c g e D$ & \\
\hline $\operatorname{cgeBC}$ & & See $\operatorname{cge} E$ & \\
\hline $\operatorname{cgeC}$ & 181 & $\begin{array}{l}\text { Operon cge } C D E \text { genes controlled by the sporulation regulatory protein GerE; } \\
\operatorname{cge} B A\end{array}$ & $625 *$ \\
\hline $\operatorname{cge} D$ & 181 & $\begin{array}{l}\text { Operon cge } C D E \text { genes controlled by the sporulation regulatory protein GerE; } \\
\text { cgeBB }\end{array}$ & $625^{*}$ \\
\hline cgeE & 181 & $\begin{array}{l}\text { Operon } c_{g e} C D E \text { genes controlled by the sporulation regulatory protein GerE; } \\
\text { cgeBC }\end{array}$ & $625^{*}$ \\
\hline che $A$ & 142 & $\begin{array}{l}\text { Chemotaxis, histidine kinase chemotactic signal modulator; previous } c b e A \text { is now } \\
\text { fiZ; cheN }\end{array}$ & $\begin{array}{l}52^{*}, 198,360,549 \\
869,871\end{array}$ \\
\hline$c h e B$ & 142 & Chemotaxis; previous $c$ be $B$ is now che $Y$; che $L$ & $\begin{array}{l}359^{*}, 360,549,875 \text {, } \\
876\end{array}$ \\
\hline cheC & & See $f i P$ & \\
\hline
\end{tabular}


Table 1 (cont.)

\begin{tabular}{|c|c|c|c|}
\hline $\begin{array}{l}\text { Gene } \\
\text { symbol }\end{array}$ & $\begin{array}{c}\text { Map } \\
\text { position }\end{array}$ & $\begin{array}{c}\text { Functions, products, phenotypes, other characteristics, former or } \\
\text { alternative symbols }\end{array}$ & Reference \\
\hline$c h e D$ & & See $f i Y$ & \\
\hline cheF & & See $f i J$ & \\
\hline cheL & & See $c h e B$ & \\
\hline$c b e N$ & & See $c h e A$ & \\
\hline$c h e \mathrm{R}$ & 204 & Chemotactic methyltransferase & $292^{*}, 548 \#$ \\
\hline cheV & 120 & Chemotaxis & $195^{*}$ \\
\hline cheW & 142 & Chemotaxis & $\begin{array}{l}260^{*}, 360,549,875 \\
876\end{array}$ \\
\hline $\operatorname{che} X$ & 118 & Chemotaxis & 875 \\
\hline che $Y$ & 142 & Chemotaxis; formerly cheB & $\begin{array}{c}52^{*}, 53,54^{*}, 360 \\
549,875,876\end{array}$ \\
\hline $\operatorname{cis} A$ & & See spoIVCA & \\
\hline$c i s B$ & & See spoIVCB & \\
\hline cit $A$ & 73 & Citrate synthase & $340^{*}, 525$ \\
\hline cit $B$ & 170 & Aconitase & $144^{*}, 630^{*}$ \\
\hline citC & 259 & Isocitrate dehydrogenase & $\begin{array}{l}215,340^{*}, 341 * \\
573 \#\end{array}$ \\
\hline citF & & See $s d b A$ & \\
\hline $\operatorname{cit} G$ & 289 & Fumarate hydratase & $464 *$ \\
\hline citH & 259 & Malate dehydrogenase; $m d h$ & $215,341^{*}$ \\
\hline citK & & See $o d h A$ & \\
\hline cit $L$ & & See $p d h D$ & \\
\hline citM & & See $o d h B$ & \\
\hline $\operatorname{cit} \mathrm{R}$ & 73 & Regulatory protein of the $l y s \mathrm{R}$ family located upstream of cit $A$ & $340 *, 525$ \\
\hline cit $Z$ & 259 & Citrate synthase II & $340^{*}, 341^{*}$ \\
\hline$c l p C$ & & See $m e c B$ & \\
\hline $\operatorname{clp} X$ & 244 & Possible ATP-dependent Clp protease; ATP-binding subunit & $825^{*}, 849$ \\
\hline$c m k$ & 205 & Cytidine monophosphate kinase; $c m p$ & $718^{*}$ \\
\hline$c m p$ & & See $\mathrm{cmk}$ & \\
\hline $\operatorname{cod} V$ & 141 & Similar to XerC and XerD of E. coli & $307 *, 692 *$ \\
\hline $\operatorname{cod} W$ & 141 & Heat-shock protein; similar to $b s l V$ of E. coli; $b s l V$ & $307 *, 692 *$ \\
\hline $\operatorname{cod} X$ & 141 & $\begin{array}{l}\text { Heat-shock protein; similar to } b s l V \text { of E. coli and ClpX ATPase (a regulatory } \\
\text { subunit of the E. coli ClpP protease); bsl } U\end{array}$ & $307 *, 692 *$ \\
\hline $\operatorname{cod} Y$ & 141 & Regulatory gene of the $d p p$ operon & $307^{*}, 692^{*}$ \\
\hline $\operatorname{com} A 1$ & & See $\operatorname{com} A A$ & \\
\hline $\operatorname{com} A 2$ & & See $\operatorname{com} A B$ & \\
\hline $\operatorname{com} A A$ & 279 & $\begin{array}{l}\text { Competence; early block effector signal transduction; } \operatorname{com}-9 \text { may map in } \operatorname{com} A \text { or } \\
\operatorname{com} B ; \operatorname{com} A 1\end{array}$ & $152^{*}, 811^{*}$ \\
\hline $\operatorname{com} A B$ & 279 & Competence; early block; com-9 may map in $\operatorname{com} A$ or $\operatorname{com} B ; \operatorname{com} A 2$ & $152^{*}, 811^{*}$ \\
\hline $\operatorname{com} C$ & 242 & Competence & $152 *$ \\
\hline comE1 & & See $\operatorname{com} E A$ & \\
\hline comE2 & & See $c o m E B$ & \\
\hline comE3 & & See $\operatorname{comEC}$ & \\
\hline comE4 & & See comER & \\
\hline $\operatorname{comE} A$ & 226 & Competence protein; comE1 & $152^{*}, 252^{*}$ \\
\hline $\operatorname{com} E B$ & 226 & Competence protein; comE2 & $152 *, 252 *$ \\
\hline $\mathrm{comEC}$ & 226 & Competence protein; comE3 & $152^{*}, 252^{*}$ \\
\hline comER & 226 & Competence protein; comE4 & $152^{*}, 252^{*}$ \\
\hline comF1 & & See $\operatorname{comF} A$ & \\
\hline $\operatorname{comF2}$ & & See $c o m F B$ & \\
\hline comF3 & & See $\operatorname{comFC}$ & \\
\hline $\operatorname{comFA}$ & 306 & Competence protein; comF1 & $152^{*}, 417^{*}$ \\
\hline $\operatorname{comFB}$ & 306 & Competence protein; $c o m F 2$ & $152^{*}, 417^{*}$ \\
\hline
\end{tabular}


Table 1 (cont.)

\begin{tabular}{|c|c|c|c|}
\hline $\begin{array}{l}\text { Gene } \\
\text { symbol }\end{array}$ & $\underset{\text { position }}{\text { Map }}$ & $\begin{array}{c}\text { Functions, products, phenotypes, other characteristics, former or } \\
\text { alternative symbols }\end{array}$ & Reference \\
\hline $\operatorname{comFC}$ & 306 & Competence protein; $c 0 m F_{3}$ & $152^{*}, 417^{*}$ \\
\hline $\operatorname{com} G 1$ & & See $\operatorname{com} G A$ & \\
\hline $\operatorname{com} G 2$ & & See $c o m G B$ & \\
\hline $\operatorname{com} \mathrm{m}^{3}$ & & See $\operatorname{com} G C$ & \\
\hline $\operatorname{com} G 4$ & & See comGD & \\
\hline $\operatorname{com} G 5$ & & See comGE & \\
\hline comG6 & & See $\operatorname{com} G G$ & \\
\hline $\operatorname{com} G A$ & 220 & Competence; may include com- 71 ; com $G 1$ & $10^{*}, 152^{*}$ \\
\hline $\operatorname{com} G B$ & 220 & Competence; may include com- 71 ; com $G 2$ & $10^{*}, 152^{*}$ \\
\hline $\operatorname{com} G C$ & 220 & Competence; may include $\operatorname{com}-71$; com $G 3$ & $10 *, 152 *$ \\
\hline $\operatorname{com} G D$ & 220 & Competence; may include com- 71 ; com $G 4$ & $10^{*}, 152^{*}$ \\
\hline $\operatorname{comGE}$ & 220 & Competence; may include $c o m-71$; com $G 5$ & $10^{*}, 152^{*}$ \\
\hline $\operatorname{com} G G$ & 220 & Competence; may include $c o m-71$; com $G 6$ & $10^{*}, 152^{*}$ \\
\hline comI & & See $\operatorname{nuc} A$ & \\
\hline comJ & 31 & Competence; encodes an $18 \mathrm{kDa}$ protein that is isolated with the ComI protein; nin & $199 *, 794^{*}$ \\
\hline $\operatorname{comK}$ & 80 & Required for genetic competence; includes com-30 & $152,777^{*}, 779$ \\
\hline comL & & See $\operatorname{srf} A A$ & \\
\hline $\operatorname{com} M$ & 346 & Competence; formerly com-104 & 152,174 \\
\hline $\operatorname{com} N$ & 152 & Competence & 445 \\
\hline $\operatorname{com} O$ & 68 & Competence; formerly com-18 & 445 \\
\hline $\operatorname{com} P$ & 279 & Competence: homologous to sensor class of signal-transduction proteins & $812^{*}$ \\
\hline comQ & 279 & Competence; competence regulatory gene & $492^{*}$ \\
\hline $\operatorname{com} R$ & 80 & Competence; previously com- 44 & $40 \#, 445$ \\
\hline coms & 31 & Required for competence; a small protein $\mathrm{S}$ & $127^{*}, 259$ \\
\hline $\cot A$ & 52 & Spore-coat protein & $65^{*}, 146 \#$ \\
\hline $\cot B$ & 290 & Spore-coat protein & $146 \#, 874$ \\
\hline $\cot C$ & 168 & Spore-coat protein & $146 *, 874$ \\
\hline $\cot D$ & 199 & Spore-coat protein & $146^{*}, 874$ \\
\hline $\cot E$ & 150 & Spore-coat protein; peroxidase & $147,620^{*}, 810,874$ \\
\hline $\cot F$ & 356 & Spore-coat protein & $125^{*}$ \\
\hline $\cot G$ & 300 & Spore-coat protein & $642 *, 711$ \\
\hline $\cot J$ & 62 & $\sigma^{\mathrm{E}}$-controlled operon affecting the polypeptide composition of spore coats & $294 *$ \\
\hline $\cot S$ & 274 & Spore-coat protein & $807^{*}$ \\
\hline $\cot T$ & 108 & Spore-coat protein & $30^{*}$ \\
\hline $\cot V$ & 107 & Spore-coat protein & $872 *$ \\
\hline $\cot W$ & 107 & Spore-coat protein & $872^{*}$ \\
\hline $\cot X$ & 107 & Spore-coat protein & $872^{*}$ \\
\hline $\cot Y$ & 107 & Spore-coat protein & $872 *$ \\
\hline $\cot Z$ & 107 & Spore-coat protein & $872^{*}$ \\
\hline $\operatorname{cpaA}$ & & See $\operatorname{car} A$ & \\
\hline$c p a B$ & & See $c a r B$ & \\
\hline $\operatorname{cps} X$ & & See $a b r B$ & \\
\hline crk & NM & Cytidine kinase & 621 \\
\hline crr & & See $p t s G$ & \\
\hline $\operatorname{crs} A$ & & See $\operatorname{sig} A$ & \\
\hline $\operatorname{crs} B$ & 56 & Requires high glucose for sporulation & 742 \\
\hline $\operatorname{crs} C$ & 217 & Carbon-source-resistant sporulation; maps close to or in $s p o 0 A$ & 742 \\
\hline $\operatorname{crs} D$ & 10 & Carbon-source-resistant sporulation & 742 \\
\hline crsE & & See $r p o B$ & \\
\hline $\operatorname{crs} F$ & 119 & Carbon-source-resistant sporulation & 742 \\
\hline $\operatorname{csa} A$ & 197 & Homologous to $c s a A$ gene from plants & $97 *$ \\
\hline $\operatorname{csb} A$ & 303 & Gene controlled by $\sigma^{\mathrm{B}}$ & $70^{*}, 711$ \\
\hline $\operatorname{csh}$ & NM & Genes controlled by the sporulation regulatory gene spoOH & $296,334^{*}$ \\
\hline
\end{tabular}


Table 1 (cont.)

\begin{tabular}{|c|c|c|c|}
\hline $\begin{array}{l}\text { Gene } \\
\text { symbol }\end{array}$ & $\begin{array}{l}\text { Map } \\
\text { position }\end{array}$ & $\begin{array}{l}\text { Functions, products, phenotypes, other characteristics, former or } \\
\text { alternative symbols }\end{array}$ & Reference \\
\hline $\operatorname{csp} B$ & 69 & Cold-shock protein & $525,823 *$ \\
\hline $\operatorname{csp} C$ & 42 & Cold-shock protein & $501 *$ \\
\hline $\operatorname{csp} D$ & 197 & Cold-shock protein, homologous to $\operatorname{csp} B$ & $97 *$ \\
\hline $\operatorname{csr} A$ & 306 & Carbon storage regulator; homologous to $\operatorname{crs} A$ of $E$. coli & $623,711^{*}$ \\
\hline cst $A$ & 254 & Induced in carbon starvation; homologous to cst $A$ of E. coli & $825^{*}$ \\
\hline $\operatorname{cta} A$ & 127 & Required for expression of cytochrome $a a_{3}$ & $495^{*}$ \\
\hline $\operatorname{ctaB}$ & 127 & Cytochrome- $a$ oxidase assembly factor & $654^{*}$ \\
\hline $\operatorname{ctaC}$ & 127 & Cytochrome- $a a_{3}$ oxidase subunit II & $654^{*}$ \\
\hline $\operatorname{ctaD}$ & 127 & Cytochrome- $a a_{3}$ oxidase subunit I & $654^{*}$ \\
\hline$c t a E$ & 127 & Cytochrome- $a a_{3}$ oxidase subunit III & $654^{*}$ \\
\hline$c t a F$ & 127 & Cytochrome- $a a_{3}$ oxidase subunit IVB & $654^{*}$ \\
\hline ctc & 7 & $\begin{array}{l}\text { Expressed at the end of exponential growth under conditions in which the enzymes } \\
\text { of the tricarboxylic acid cycle are repressed }\end{array}$ & $298,318^{*}, 523^{*}$ \\
\hline $\begin{array}{l}\operatorname{ctr} A \\
\operatorname{cwb} A\end{array}$ & 323 & $\begin{array}{l}\text { CTP synthetase; requirement for cytidine in the absence of ammonium ion; pyrG } \\
\text { See } l y t B\end{array}$ & $621,762 *$ \\
\hline cwlA & 228 & Autolytic amidase; minor autolysin & $187^{*}, 383^{*}, 384$ \\
\hline $\mathrm{cwlB}$ & & See $l y t C$ & \\
\hline $\mathrm{cw} / \mathrm{C}$ & 153 & Cell wall hydrolase & $208,386^{*}$ \\
\hline cwld & 13 & High similarity to a major autolysin of $B$. subtilis $\mathrm{CwlB}$ & $679 *$ \\
\hline cyc & 95 & $\mathrm{D}$-Cycloserine resistance & 210 \\
\hline $\operatorname{cys} A$ & 10 & $\begin{array}{l}\text { Cysteine requirement, serine trans-acetylase; original isolate contained four linked } \\
\text { mutations; } c y s \text { (cysteine sensitivity), cym (cysteine or methionine), bts (hydrogen } \\
\text { sulfide excretion) and } c y s A ; c y s E\end{array}$ & $205^{*}, 346$ \\
\hline$c y s B$ & 292 & Cysteine requirement & 149 \\
\hline cys $C$ & 139 & Cysteine, methionine, sulfite, or sulfide requirement & 861 \\
\hline cys $E$ & & See $c y s A$ & \\
\hline cysK & 9 & Cysteine synthase A & $534 *, 539 *$ \\
\hline cys $S$ & 10 & Cysteinyl-tRNA synthetase & $205,680^{*}$ \\
\hline cyt & 284 & Requires cytidine & 306 \\
\hline $\operatorname{dac} A$ & 0 & D-Alanine carboxypeptidase; vegetative penicillin-binding protein 5 & $83,755^{*}$ \\
\hline dacB & 208 & DD-Carboxypeptidase penicillin-binding protein 5 , operon with $s p m A B$ & $84^{*}, 595,717^{*}$ \\
\hline $\operatorname{dacF}$ & 211 & Putative DD-carboxypeptidase; penicillin-binding protein & $670,833^{*}, 834$ \\
\hline dae & & See $\operatorname{dlt} A$ & \\
\hline dal & 38 & D-Alanine requirement; alanine racemase & $177^{*}$ \\
\hline $\operatorname{dap} A$ & 149 & Dihydrodipicolinate synthase & $112^{*}$ \\
\hline $\operatorname{dap} E$ & $135^{\prime}$ & $N$-Acetyl-LL-diaminopimelic acid deacylase; $l s s B$ & $76,91,193,631$ \\
\hline dap $G$ & 149 & Aspartokinase I; lssD & $112^{*}, 631$ \\
\hline dat & NM & Constitutive $O^{6}$-methylguanine-DNA alkyltransferase & $483^{*}$ \\
\hline$d b p A$ & & See hbs & \\
\hline$d c d$ & NM & Deoxycytidine $5^{\prime}$-monophosphate deaminase & 479 \\
\hline $\operatorname{dci} A A$ & & See $d p p A$ & \\
\hline $\operatorname{dci} A B$ & & See $d p p B$ & \\
\hline$d c i A C$ & & See $d p p C$ & \\
\hline $\operatorname{dci} A D$ & & See $d p p D$ & \\
\hline dciAE & & See $d p p E$ & \\
\hline$d c k$ & NM & Deoxycytidine/deoxyadenosine kinase & 480 \\
\hline$d d d$ & NM & Deoxycytidine kinase & 621 \\
\hline$d d l A$ & 37 & D-Alanyl-D-alanine ligase & 91 \\
\hline$d d s$ & & See $\operatorname{div} I B$ & \\
\hline $\operatorname{deg} A$ & 99 & $\begin{array}{l}\text { Involved in the control of degradation of B. subtilis glutamine 5-phosphoribosyl-1- } \\
\text { pyrophosphate amidotransferase }\end{array}$ & $86,681^{*}$ \\
\hline $\operatorname{deg} Q$ & 279 & Degradative enzyme regulation; sac $Q, a m y B$ & $404,842 *$ \\
\hline $\operatorname{deg} R$ & 197 & Degradative enzyme regulation; $p r t \mathrm{R}$ & $843^{*}$ \\
\hline
\end{tabular}


Table 1 (cont.)

\begin{tabular}{|c|c|c|c|}
\hline $\begin{array}{l}\text { Gene } \\
\text { symbol }\end{array}$ & $\begin{array}{c}\text { Map } \\
\text { position }\end{array}$ & $\begin{array}{l}\text { Functions, products, phenotypes, other charactetistics, former or } \\
\text { alternative symbols }\end{array}$ & Reference \\
\hline $\operatorname{deg} S$ & 306 & Degradative enzyme regulation; part of $\operatorname{sac} U$ & $291 *, 381 *$ \\
\hline $\operatorname{deg} U$ & 306 & Degradative enzyme regulation; part of $s a c U$; iep & $754^{*}$ \\
\hline $\operatorname{deo} A$ & NM & Thymidine phosphorylase & 455 \\
\hline deoR & 338 & Repression of the $d r a-n u p C-p d p$ operon & $663^{*}$ \\
\hline dfr $A$ & 195 & Dihydrofolate reductase; coordinately regulated with thy $B$ & $333^{*}$ \\
\hline$d g k A$ & 224 & Diacylglycerol kinase & 477 \\
\hline$d b b A$ & 291 & $\begin{array}{l}\text { 2,3-Dihydro-2,3-dihydroxybenzoate dehydrogenase; based on similarity to E. coli } \\
\text { EntA }\end{array}$ & $635^{*}$ \\
\hline$d b b B$ & 291 & Isochorismatase; based on similarity to E. coli $\mathrm{EntB}$ & $635^{*}$ \\
\hline$d b b C$ & 291 & Isochorismate synthase; based on similarities to E. coli EntC & $634^{*}, 635^{*}$ \\
\hline$d b b E$ & 291 & 2,3-Dihydroxybenzoate-AMP ligase; based on similarity to E. coli EntE & $635^{*}$ \\
\hline$d b b F$ & 291 & Similat to E. coli EntF & $635^{*}$ \\
\hline $\operatorname{din}$ & 121 & Deoxyribonuclease inhibitor & 596 \\
\hline $\operatorname{din} A$ & & See $u v r B$ & \\
\hline $\operatorname{din} B$ & 45 & DNA-damage-inducible & $113^{*}, 222$ \\
\hline $\operatorname{din} C$ & & See $\operatorname{tag} C$ & \\
\hline $\operatorname{din} \mathrm{R}$ & & See $\operatorname{lex} A$ & \\
\hline$d i v-341$ & & See $\sec A$ & \\
\hline $\operatorname{div} A$ & & See $\operatorname{div} I C$ & \\
\hline $\operatorname{div} B$ & & See div $V$ & \\
\hline $\operatorname{div} C$ & & See divII & \\
\hline $\operatorname{div} D$ & & See divI & \\
\hline $\operatorname{divI}$ & 138 & Temperature-sensitive cell division; divD & 92,773 \\
\hline $\operatorname{divIB}$ & 134 & Deficient in division and sporulation; $d d s$ & $45^{*}, 168^{*}, 269^{*}, 270$ \\
\hline $\operatorname{divIC}$ & 8 & Minicell production; div $A$, divIVC & $410^{*}, 773$ \\
\hline $\operatorname{divII}$ & 317 & Temperature-sensitive cell division; $\operatorname{div} C$ & 773 \\
\hline $\operatorname{div} I V A$ & 138 & Minicell production & 92,613 \\
\hline $\operatorname{divIVB}$ & & See $\min D$ & \\
\hline $\operatorname{div} I V C$ & & See $\operatorname{div} I C$ & \\
\hline $\operatorname{div} V$ & 278 & Temperature-sensitive cell division; $\operatorname{div} B$ & 773 \\
\hline $\operatorname{dlt} A$ & 333 & $\begin{array}{l}\text { D-Alanine esterification of lipoteichoic acid and wall teichoic acid; carrier protein } \\
\text { ligase; dae }\end{array}$ & $225^{*}, 567^{*}$ \\
\hline$d l t B$ & 333 & D-Alanine esterification of lipoteichoic acid and wall teichoic acid & $225^{*}, 567^{*}$ \\
\hline dlt $C$ & 333 & D-Alanine esterification of lipoteichoic acid and wall teichoic acid; carrier protein & $225^{*}, 567^{*}$ \\
\hline dlt $D$ & 333 & D-Alanine esterification of lipoteichoic acid and wall teichoic acid; precursor & $225^{*}, 567^{*}$ \\
\hline dlt $E$ & 333 & Similar to ketoacyl reductase & $225^{*}, 567^{*}$ \\
\hline $\operatorname{dna} A$ & 0 & $\begin{array}{l}\text { DNA synthesis, initiation of chromosome replication; homologous to } d n a A \text { of } E \text {. } \\
\text { coli; previous } d n a A \text { locus is now } n r d A\end{array}$ & $535^{*}$ \\
\hline$d n a B$ & 256 & DNA synthesis; initiation of chromosome replication & $314,537 *$ \\
\hline$d n a C$ & 355 & 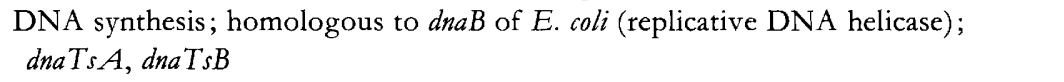 & $266,647^{*}$ \\
\hline$d n a D$ & 200 & DNA synthesis, initiation of chromosome replication & $80^{*}, 350$ \\
\hline$d n a E$ & & See $d n a G$ & \\
\hline$d n a F$ & & See $p o l C$ & \\
\hline$d n a G$ & 223 & $\begin{array}{l}\text { DNA synthesis; homologous to } d n a G \text { of } E \text {. coli (DNA primase); previous } d n a G \text { is } \\
\text { now } d n a N \text {; dnaE }\end{array}$ & $16,801 *$ \\
\hline$d n a H$ & & See $d n a X$ & \\
\hline dnaI & 256 & DNA synthesis & $79,350,537^{*}$ \\
\hline$d n a J$ & 225 & Homologous to dnaJ of E. coli (heat-shock protein) & $815^{*}$ \\
\hline$d n a K$ & 225 & Homologous to dnaK of E. coli (heat-shock protein) & $273^{*}, 814^{*}, 815 \#$ \\
\hline$d n a N$ & 0 & $\begin{array}{l}\text { DNA synthesis, homologous to } d n a N \text { of } E \text {. coli }(\beta \text { subunit of DNA polymerase } \\
\text { III); formerly } d n a G\end{array}$ & $536^{*}$ \\
\hline$d n a P$ & & See polc & \\
\hline
\end{tabular}


Table 1 (cont.)

\begin{tabular}{|c|c|c|c|}
\hline $\begin{array}{l}\text { Gene } \\
\text { symbol }\end{array}$ & $\begin{array}{c}\text { Map } \\
\text { position }\end{array}$ & $\begin{array}{l}\text { Functions, products, phenotypes, other characteristics, former or } \\
\text { alternative symbols }\end{array}$ & Reference \\
\hline $\operatorname{dnaTs} A$ & & See $d n a C$ & \\
\hline $\operatorname{dna} T s B$ & & See $d n a C$ & \\
\hline$d n a X$ & 0 & $\begin{array}{l}\text { DNA synthesis, homologous to } d n a Z X \text { of E. coli }(\tau \text { and } \gamma \text { subunits of DNA } \\
\text { polymerase III); subunit of holoenzyme DNA polymerase III; formerly } d n a H \text { and } \\
\text { dna- } 8132\end{array}$ & $18^{*}, 735^{*}, 738^{*}$ \\
\hline$d p a A$ & 148 & DPA synthetase; the original $d p a-1$ mutation is an allele of $d p a A ; s p o V F A$ & $35,112 *, 133 *, 578$ \\
\hline$d p a B$ & 148 & DPA synthetase; spoVFB & $35,112 *, 133 *, 578$ \\
\hline$d p p A$ & 113 & Dipeptide permease; DNA sequence has five adjacent ORFs; dci $A A$ & $448,449 *, 692$ \\
\hline$d p p B$ & 113 & Dipeptide permease; DNA sequence has five adjacent ORFs; dciAB & $448,449 *, 692$ \\
\hline$d p p C$ & 113 & Dipeptide permease; DNA sequence has five adjacent ORFs; dciAC & $448,449 *, 692$ \\
\hline$d p p D$ & 113 & Dipeptide permease; DNA sequence has five adjacent ORFs; dciAD & $448,449 *, 692$ \\
\hline$d p p E$ & 113 & Dipeptide permease; DNA sequence has five adjacent ORFs; dci $A E$ & $448,449 *, 692$ \\
\hline dra & 338 & Deoxyriboaldolase & $663^{*}, 741$ \\
\hline$d r m$ & 211 & Phosphodeoxyribomutase & 671 \\
\hline dst & 229 & Resistance to distamycin and acriflavin & 688 \\
\hline$d u r R$ & 20 & Duramycin resistance & 514 \\
\hline$e b r$ & 215 & Ethidium bromide resistance; perhaps the same as $b m r$ & $56,137^{*}$ \\
\hline eglS & 171 & Endo-1,4- $\beta$-glucanase (CM-cellulase); bglC, gld & $426^{*}, 630^{*}, 827^{*}$ \\
\hline eno & NM & Enolase & $143^{*}, 411^{*}$ \\
\hline ent $A$ & 41 & EntA enterochelin synthesis & $4^{*}$ \\
\hline entE & 41 & EntE enterochelin synthesis & $4^{*}$ \\
\hline epr & 332 & Minor extracellular protease & $694 *$ \\
\hline est $B$ & 296 & Esterase B defect & $179 *, 297$ \\
\hline $\operatorname{etf} A$ & 253 & $\alpha$ subunits of electron-transfer flavoprotein & $825^{*}$ \\
\hline etf $B$ & 253 & $\beta$ subunits of electron-transfer flavoprotein & $825 *$ \\
\hline eth $A$ & NM & Ethionine resistance & 795 \\
\hline $\operatorname{exo} A$ & 358 & 3'-Exodeoxyribonuclease & $539 *$ \\
\hline exoI & 198 & Homologous to polymerase $\mathrm{N}$-terminal exonuclease & $97 *$ \\
\hline $\exp Z$ & 45 & Nucleotide-binding protein & $140^{*}$ \\
\hline fabE & 218 & Fatty acid biosynthesis; homologous to fabE of E. coli & $437,732 *$ \\
\hline$f b a A$ & 323 & Fructose-bisphosphate aldolase; $t s r$ & $472,473,762^{*}$ \\
\hline$f b a B$ & & See iolJ & \\
\hline$f d p A$ & 344 & Fructose-bisphosphatase & 200 \\
\hline feu $A$ & 14 & Periplasmic iron-binding protein & 846 \\
\hline$f e u B$ & 14 & Component of iron-uptake system & 846 \\
\hline fenC & 14 & Component of iron-uptake system & 846 \\
\hline$f b$ & 147 & Signal-recognition particle; homologous to Ffh of E. coli & $208,310^{*}$ \\
\hline fbuD & 286 & Ferrichrome-binding protein & $265^{*}$ \\
\hline$f i b A$ & 307 & Macrofibre formation; weak linkage to his $A$ & 658 \\
\hline$f i b B$ & 295 & Macrofibre formation & 658 \\
\hline$f a B$ & & See $s i g D$ & \\
\hline $\mathrm{AlaC}$ & 311 & Defect in flagellar synthesis & 586 \\
\hline$f a D$ & & See $\sin \mathrm{R}$ & \\
\hline $\operatorname{fg} B$ & 142 & $\begin{array}{l}\text { Part of che-fla operon; three loci } B, C, G \text {; flagellar genes; homologous to the } \\
\text { corresponding genes of E. coli and Salmonella typhimurium }\end{array}$ & $876^{*}$ \\
\hline $\mathrm{fgC}$ & 142 & $\begin{array}{l}\text { Part of che-fla operon; three loci } B, C, G \text {; flagellar genes; homologous to the } \\
\text { corresponding genes of E. coli and } S . \text { typhimurium }\end{array}$ & $876^{*}$ \\
\hline $\mathrm{fgG}$ & 142 & $\begin{array}{l}\text { Part of che- } f l a \text { operon; three loci } B, C, G \text {; flagellar genes; homologous to the } \\
\text { corresponding genes of E. coli and S. typbimuritum }\end{array}$ & $14^{*}, 876$ \\
\hline $\operatorname{fgK}$ & 306 & Flagellar hook-filament junction protein, flagellin synthesis regulatory protein & $468^{*}$ \\
\hline $\operatorname{fgM}$ & 306 & Flagellar hook-filament junction protein, flagellin synthesis regulatory protein & $468^{*}$ \\
\hline$A h A$ & 142 & $\begin{array}{l}\text { Part of the che } f l a \text { operon; three loci } A, B, F \text {; homologous to the corresponding } \\
\text { genes of E. coli and S. typhimurium; flagellar genes }\end{array}$ & $103 *, 360$ \\
\hline
\end{tabular}


Table 1 (cont.)

\begin{tabular}{|c|c|c|c|}
\hline $\begin{array}{l}\text { Gene } \\
\text { symbol }\end{array}$ & $\begin{array}{c}\text { Map } \\
\text { position }\end{array}$ & $\begin{array}{l}\text { Functions, products, phenotypes, other characteristics, former or } \\
\text { alternative symbols }\end{array}$ & Reference \\
\hline$A b B$ & 142 & $\begin{array}{l}\text { Part of the che-fla operon; three loci } A, B, F \text {; homologous to the corresponding } \\
\text { genes of E. coli and S. typhimurium; flagellar genes }\end{array}$ & $102^{*}, 360$ \\
\hline$A b F$ & 142 & $\begin{array}{l}\text { Part of the che-fla operon; three loci } A, B, F \text {; homologous to the corresponding } \\
\text { genes of E. coli and S. typhimurium; flagellar genes }\end{array}$ & $101 *$ \\
\hline$f i D$ & 305 & Flagellar protein; homologous to fiD of E. coli & $109 *$ \\
\hline$f i E$ & 142 & $\begin{array}{l}\text { Part of che-fla operon; } 13 \text { loci } E-K, P-R \text { and } Z \text {; flagellar genes; homologous to the } \\
\text { corresponding genes of E. coli and S. typhimurium }\end{array}$ & $876^{*}$ \\
\hline$f i F$ & 142 & $\begin{array}{l}\text { Part of che-fla operon; } 13 \text { loci } E-K, P-R \text { and } Z \text {; flagellar genes; homologous to the } \\
\text { corresponding genes of E. coli and S. typhimurium }\end{array}$ & $360,876^{*}$ \\
\hline$f i G$ & 142 & $\begin{array}{l}\text { Part of che-fla operon; } 13 \text { loci } E-K, P-R \text { and } Z \text {; flagellar genes; homologous to the } \\
\text { corresponding genes of E. coli and } S \text {. typhimurium }\end{array}$ & $14^{*}, 876$ \\
\hline$f i H$ & 142 & $\begin{array}{l}\text { Part of che-fla operon; } 13 \text { loci } E-K, P-R \text { and } Z \text {; flagellar genes; homologous to the } \\
\text { corresponding genes of E. coli and } S \text {. typhimurium }\end{array}$ & $14^{*}, 876$ \\
\hline fiI & 142 & $\begin{array}{l}\text { Part of che-fla operon; } 13 \text { loci } E-K, P-R \text { and } Z \text {; flagellar genes; homologous to the } \\
\text { corresponding genes of E. coli and S. typhimurium }\end{array}$ & $14^{*}, 876$ \\
\hline fiiJ & 142 & $\begin{array}{l}\text { Part of che-fla operon; } 13 \text { loci } E-K, P-R \text { and } Z \text {; flagellar genes; homologous to the } \\
\text { corresponding genes of E. coli and } S \text {. typhimurium; cheF }\end{array}$ & $14^{*}, 851,876$ \\
\hline$f i K$ & 142 & $\begin{array}{l}\text { Part of } c b e-f l a \text { operon; } 13 \text { loci } E-K, P-R \text { and } Z \text {; flagellar genes; homologous to the } \\
\text { corresponding genes of } E \text {. coli and } S \text {. typhimurium }\end{array}$ & $14^{*}, 876$ \\
\hline$f i L$ & 142 & $\begin{array}{l}\text { Part of che-fla operon; } 13 \text { loci } E-K, P-R \text { and } Z \text {; flagellar genes; homologous to the } \\
\text { corresponding genes of E. coli and S. typhimurium }\end{array}$ & $14^{*}, 876$ \\
\hline$f i M$ & 142 & $\begin{array}{l}\text { Part of che-fla operon; } 13 \text { loci } E-K, P-R \text { and } Z \text {; flagellar genes; homologous to the } \\
\text { corresponding genes of E. coli and } S \text {. typhimurium }\end{array}$ & $14^{*}, 876,877^{*}$ \\
\hline$f i P$ & 142 & $\begin{array}{l}\text { Part of che-fla operon; } 13 \text { loci } E-K, P-R \text { and } Z \text {; flagellar genes; homologous to the } \\
\text { corresponding genes of E. coli and } S \text {. typbimurium; che } C\end{array}$ & $52^{*}, 102,876$ \\
\hline fliQ & 142 & $\begin{array}{l}\text { Part of che-fla operon; } 13 \text { loci } E-K, P-R \text { and } Z \text {; flagellar genes; homologous to the } \\
\text { corresponding genes of } E \text {. coli and } S \text {. typhimurium }\end{array}$ & $52^{*}, 102,876$ \\
\hline$f i \mathrm{R}$ & 142 & $\begin{array}{l}\text { Part of che-fla operon; } 13 \text { loci } E-K, P-R \text { and } Z \text {; flagellar genes; homologous to the } \\
\text { corresponding genes of E. coli and } S \text {. typhimurium }\end{array}$ & $52 *, 102,360,876$ \\
\hline fis & 305 & Flagellar protein; homologous to fiS of E. coli & $109 *$ \\
\hline$f i T$ & 305 & Flagellar protein; homologous to $f i T$ of E. coli & $109 *$ \\
\hline$f i Y$ & 142 & $\begin{array}{l}\text { Part of che-fla operon; } 13 \text { loci } E-K, P-R \text { and } Z \text {; flagellar genes; homologous to the } \\
\text { corresponding genes of E. coli and S. typhimurium; cheD }\end{array}$ & $55^{*}, 876,877^{*}$ \\
\hline$f i Z$ & 142 & $\begin{array}{l}\text { Part of che-fla operon; } 13 \text { loci } E-K, P-R \text { and } Z \text {; flagellar genes; homologous to the } \\
\text { corresponding genes of E. coli and S. typbimurium; formerly che } A\end{array}$ & $52^{*}, 876$ \\
\hline fnr & 324 & Anaerobic regulatory protein & $609 *$ \\
\hline folc & 242 & Folylpolyglutamate synthetase & $434^{*}$ \\
\hline folk & 9 & Dihydropteridine pyrophosphokinase & $539 *$ \\
\hline fru $A$ & 123 & Fructose transport & 217 \\
\hline fruB & 123 & Fructose-1-phosphate kinase & 217 \\
\hline fruC & 51 & Fructokinase & 219 \\
\hline ftr & uC & Fluorotryptophan resistance; maps near aroC & 43 \\
\hline$f t s A$ & 134 & Homologous to E. coli cell division gene $f t s A$; location of spoIIN279 & $44^{*}, 168,220,235$ \\
\hline$f t s H$ & 8 & Cell division protein & $139,539 *$ \\
\hline$f t s L$ & 133 & Cell division gene homologous to $E$. coli & $134 *, 844$ \\
\hline$f t s Z$ & 134 & Homologous to $E$. coli cell division gene $f t s Z ; t s-1$ & $44^{*}, 168,235,269 *$ \\
\hline fum $\mathrm{R}$ & 288 & Regulation of fumarate hydratase & 305 \\
\hline fun & & See $r p s L$ & \\
\hline fur $A$ & & See $\operatorname{pyr} A A$ & \\
\hline fur $B$ & 41 & Fluorouracil resistance & 868 \\
\hline furC & 326 & Resistance to 5-fluorouracil in the presence of uracil & 870 \\
\hline furE & 326 & Resistance to 5-fluorouracil in the presence of uracil & 870 \\
\hline furF & 170 & Resistance to 5-fluorouracil in the presence of uracil & 138 \\
\hline
\end{tabular}


Table 1 (cont.)

\begin{tabular}{|c|c|c|c|}
\hline $\begin{array}{l}\text { Gene } \\
\text { symbol }\end{array}$ & $\begin{array}{c}\text { Map } \\
\text { position }\end{array}$ & $\begin{array}{c}\text { Functions, products, phenotypes, other characteristics, former or } \\
\text { alternative symbols }\end{array}$ & Reference \\
\hline fus & 11 & Elongation factor $\mathrm{G}$ & 846 \\
\hline$g a b P$ & 52 & $\gamma$-Aminobutyrate permease & $65,831^{*}$ \\
\hline galK & 331 & Galactokinase & $225^{*}$ \\
\hline galT & 331 & Galactose-1-phosphate-uridyltransferase & $225^{*}$ \\
\hline gap & & See $g a p B$ & \\
\hline gap $B$ & 256 & Glyceraldehyde-3-phosphate dehydrogenase; gap & $393 *, 790 *$ \\
\hline$g c a A$ & & See $g \operatorname{lm} S$ & \\
\hline$g c a D$ & 7 & $\mathrm{~N}$-Acetylglucosamine-1-phosphate uridyltransferase; tms & $254 \#, 298^{*}, 523 *$ \\
\hline$g d h$ & 34 & Structural gene for glucose dehydrogenase & $392 *$ \\
\hline $\operatorname{ger} A 1$ & & See $\operatorname{ger} A A$ & \\
\hline $\operatorname{ger} A 2$ & & See $\operatorname{ger} A B$ & \\
\hline ger 43 & & See ger $A C$ & \\
\hline $\operatorname{ger} A A$ & 289 & $\begin{array}{l}\text { Germination defective; defective in germination response to alanine and related } \\
\text { amino acids; ger } A 1\end{array}$ & $175^{*}$ \\
\hline $\operatorname{ger} A B$ & 289 & $\begin{array}{l}\text { Germination defective; defective in germination response to alanine and related } \\
\text { amino acids; ger } A 2\end{array}$ & $175^{*}$ \\
\hline $\operatorname{ger} A C$ & 289 & $\begin{array}{l}\text { Germination defective; defective in germination response to alanine and related } \\
\text { amino acids; ger } A 3\end{array}$ & $175^{*}$ \\
\hline $\operatorname{ger} B A$ & 311 & $\begin{array}{l}\text { Germination defective; defective in germination response to the combinations of } \\
\text { glucose, fructose, asparagine and } \mathrm{KCl} \text {; comprises three genes }\end{array}$ & $120,121 *, 478$ \\
\hline $\operatorname{ger} B B$ & 311 & $\begin{array}{l}\text { Germination defective; defective in germination response to the combinations of } \\
\text { glucose, fructose, asparagine and } \mathrm{KCl} \text {; comprises three genes }\end{array}$ & $120,121 *, 478$ \\
\hline $\operatorname{ger} B C$ & 311 & $\begin{array}{l}\text { Germination defective; defective in germination response to the combinations of } \\
\text { glucose, fructose, asparagine and } \mathrm{KCl} \text {; comprises three genes }\end{array}$ & $120,121 *, 478$ \\
\hline $\operatorname{gerC1}$ & & See $\operatorname{ger} C A$ & \\
\hline $\operatorname{gerC} 2$ & & See $\operatorname{ger} C B$ & \\
\hline $\operatorname{gerC} 3$ & & See $\operatorname{gerCC}$ & \\
\hline $\operatorname{ger} C A$ & 204 & $\begin{array}{l}\text { Germination defective; temperature-sensitive germination in alanine; comprises } \\
\text { three genes; ger } C B \text { product containing } S \text {-adenosylmethionine-binding site; ger } C C \text { is } \\
\text { homologue to } \cot E \text {; ger } C 58 \text { mutation is in } \operatorname{ger} C C \text {; gerC1 }\end{array}$ & $478,847^{*}$ \\
\hline $\operatorname{ger} C B$ & 204 & $\begin{array}{l}\text { Germination defective; temperature-sensitive germination in alanine; comprises } \\
\text { three genes; ger } C B \text { product containing } S \text {-adenosylmethionine-binding site; ger } C C \text { is } \\
\text { homologue to } \cot E \text {; ger } C 58 \text { mutation is in ger } C C \text {; ger } C 2\end{array}$ & $478,847^{*}$ \\
\hline $\operatorname{gerCC}$ & 204 & $\begin{array}{l}\text { Germination defective; temperature-sensitive germination in alanine; comprises } \\
\text { three genes; } \operatorname{ger} C B \text { product containing } S \text {-adenosylmethionine-binding site; } \operatorname{ger} C C \text { is } \\
\text { homologue to } \cot E \text {; gerC } 58 \text { mutation is in } \operatorname{ger} C C \text {; } \operatorname{ger} C 3\end{array}$ & $478,847^{*}$ \\
\hline $\operatorname{gerD}$ & 13 & Defective germination in a range of germinants & $478,846,852^{*}$ \\
\hline gerE & 252 & $\begin{array}{l}\text { Germination defective; defective germination in a range of germinants; } \\
\text { transcriptional regulator of spore-coat genes }\end{array}$ & $124 *$ \\
\hline $\operatorname{gerF}$ & 301 & Germination defective; defective germination in a range of germinants & $478,711 *$ \\
\hline $\operatorname{ger} G$ & 294 & $\begin{array}{l}\text { Germination defective; a mutant lacks phosphoglycerate kinase ( } p g k \text { activity); } \\
\text { germinates poorly in alanine; sporulates poorly }\end{array}$ & 478 \\
\hline gerH & 248 & Defective germination in a range of germinants & 578 \\
\hline gerI & 296 & Defective germination in a range of germinants & 578 \\
\hline gerJ & 206 & $\begin{array}{l}\text { Defective germination in a range of germinants; allele gerJ } 51 \text { is in many laboratory } \\
\text { strains; } t 2 m\end{array}$ & 429\#, 804 \\
\hline $\operatorname{ger} K A$ & 32 & Defective germination response to glucose & $328,329 *$ \\
\hline $\operatorname{ger} K B$ & 32 & Defective germination response to glucose & $328,329 *$ \\
\hline $\operatorname{ger} K C$ & 32 & Defective germination response to glucose & $328,329 *$ \\
\hline $\operatorname{ger} M$ & 251 & Defective germination and sporulation & $648 \#, 699 *$ \\
\hline$g g a$ & & See $g g a A$ and $g g a B$ & \\
\hline gga $A$ & 309 & $\begin{array}{l}\text { Membrane-bound enzyme involved in the biosynthesis of galactosamine-containing } \\
\text { minor teichoic acids; gga, pha-3 }\end{array}$ & $169,170,396^{*}$ \\
\hline
\end{tabular}


Table 1 (cont.)

\begin{tabular}{|c|c|c|c|}
\hline $\begin{array}{l}\text { Gene } \\
\text { symbol }\end{array}$ & $\begin{array}{c}\text { Map } \\
\text { position }\end{array}$ & $\begin{array}{c}\text { Functions, products, phenotypes, other characteristics, former or } \\
\text { alternative symbols }\end{array}$ & Reference \\
\hline$g g a B$ & 309 & $\begin{array}{l}\text { Membrane-bound enzyme involved in the biosynthesis of galactosamine-containing } \\
\text { minor teichoic acids; gga, pha-3 }\end{array}$ & $169,170,396^{*}$ \\
\hline $\operatorname{gid} A$ & 360 & Two genes homologous to gid $A$ and $B$ of E. coli & $538^{*}$ \\
\hline gid $B$ & 360 & Two genes homologous to gid $A$ and $B$ of E. coli & $538^{*}$ \\
\hline gld & & See eglS & \\
\hline $\operatorname{glg} A$ & 275 & $\begin{array}{l}\text { Fourth gene in glycogen operon; synthesizes } 1,4-\alpha \text {-glucan chains using ADP } \\
\text { glucose; starch (bacterial glycogen synthase) }\end{array}$ & $357^{*}$ \\
\hline$g \lg B$ & 275 & $\begin{array}{l}\text { First gene of glycogen operon; introduces } 1,6-\alpha \text {-linkages in starch and glycogen; } \\
1,4-\alpha \text {-glucan-branching enzyme }\end{array}$ & $357^{*}$ \\
\hline$g \lg C$ & 275 & $\begin{array}{l}\text { Second gene in glycogen operon; activates glucose-1-phosphate using ATP; } \\
\text { ADPglucose pyrophosphorylase }\end{array}$ & $357^{*}$ \\
\hline$g \lg D$ & 275 & $\begin{array}{l}\text { Third gene in glycogen operon; protein with similarity to ADPglucose } \\
\text { pyrophosphorylase }\end{array}$ & $357^{*}$ \\
\hline $\operatorname{glg} P$ & 275 & $\begin{array}{l}\text { Fifth and last gene of glycogen operon; degrades starch and glycogen by } \\
\text { phosphorylation; glycogen phosphorylase }\end{array}$ & $357^{*}$ \\
\hline$g \operatorname{lm} S$ & 23 & L-Glutamine-D-fructose-6-phosphate aminotransferase; gcaA & 196 \\
\hline$g \ln A$ & 167 & Glutamine synthetase structural gene & $512 *, 734^{*}$ \\
\hline$g \ln \mathrm{R}$ & 167 & Negative regulator of glutamine synthetase & $184 \#, 734^{*}$ \\
\hline$g \ln X$ & 178 & Glutamine biosynthesis & $7^{*}$ \\
\hline$g l p D$ & 70 & Glycerol-3-phosphate dehydrogenase & $309 *, 525$ \\
\hline$g l p F$ & 70 & Shows identity to E. coli gene $g l p F$ which is a glycerol facilitator & $48^{*}, 525$ \\
\hline$g l p K$ & 70 & Glycerol kinase & $48^{*}, 309^{*}, 525$ \\
\hline$g l p P$ & 70 & Pleiotropic glycerol mutant; positively acting regulator protein & $48^{*}, 413,525$ \\
\hline$g l p Q$ & 18 & $\begin{array}{l}\text { Hydrolysis of deacylated phospholipids; glyceróphosphoryl diester } \\
\text { phosphodiesterase }\end{array}$ & $524 *$ \\
\hline$g l p T$ & 18 & Fosfomycin resistance, glycerol phosphate transport defect & 354 \\
\hline glrS & 232 & Glutamate racemase & $62^{*}$ \\
\hline glt $A$ & & See $g l t B$ & \\
\hline$g l t B$ & 177 & Glutamate synthase; glt $A$ & $57 \#, 58^{*}$ \\
\hline$g l t C$ & 177 & Positive regulator of $g l t A B$ & $58^{*}$ \\
\hline gltP & NM & Proton/glutamate symport protein & $757^{*}$ \\
\hline glt $X$ & 10 & Glutamyl-tRNA synthetase & $77^{*}, 205^{*}$ \\
\hline gly $A$ & 321 & Glycine requirement; $g l y C$ & $95,444 *$ \\
\hline$g l y B$ & 76 & Glycine requirement & 268,525 \\
\hline$g l y C$ & & See $g l y A$ & \\
\hline gnaB & & See gua $B$ & \\
\hline gne $A$ & 332 & UDP- $N$-acetylglucosamine 4-epimerase & 170 \\
\hline$g n t K$ & 344 & Gluconate utilization; gluconate kinase & $201 *, 856^{*}$ \\
\hline gntP & 344 & Gluconate utilization; gluconate permease & $201 *, 856^{*}$ \\
\hline$g n t \mathrm{R}$ & 344 & Gluconate utilization; repressor & $202^{*}, 856^{*}$ \\
\hline$g n t Z$ & 344 & Gluconate utilization; 6-phosphogluconate dehydrogenase & $201^{*}, 615,856^{*}$ \\
\hline$g p r$ & 226 & Spore protein; germination protease for small acid-soluble spore proteins & $749 *$ \\
\hline $\operatorname{gps} A$ & 205 & NADH-dependent glycerol-3-phosphate dehydrogenase & $481,717^{*}$ \\
\hline gra & & See amy $R$ & \\
\hline$g r a \mathrm{R}$ & & See $\operatorname{ccp} A$ & \\
\hline $\operatorname{grl} A$ & 171 & Gyrase-like protein B & $630^{*}$ \\
\hline$g r l B$ & 171 & Gyrase-like protein A & $630^{*}$ \\
\hline groEL & 45 & Phage growth; heat-shock protein chaperonin & $\begin{array}{l}104,412^{*}, 541 \\
666^{*}\end{array}$ \\
\hline groES & 45 & Phage growth; heat-shock protein chaperonin & $\begin{array}{l}104,412^{*}, 541 \\
666^{*}\end{array}$ \\
\hline $\operatorname{grp} E$ & 225 & Homologous to grpE of E. coli & $814^{*}$ \\
\hline$g \operatorname{si} A A$ & 115 & Glucose-starvation-inducible genes; two cistrons & $496^{*}, 497^{*}, 566$ \\
\hline
\end{tabular}


Table 1 (cont.)

\begin{tabular}{|c|c|c|c|}
\hline $\begin{array}{l}\text { Gene } \\
\text { symbol }\end{array}$ & $\begin{array}{c}\text { Map } \\
\text { position }\end{array}$ & $\begin{array}{c}\text { Functions, products, phenotypes, other characteristics, former or } \\
\text { alternative symbols }\end{array}$ & Reference \\
\hline gsi $A B$ & 115 & Glucose-starvation-inducible genes; two cistrons & $496^{*}, 497^{*}, 566$ \\
\hline$g s i B$ & 36 & Glucose-starvation-inducible protein B & $497^{*}$ \\
\hline gsiC & & See $\operatorname{kin} A$ & \\
\hline gsp10 & uc & Spore outgrowth; maps near the che cluster & $208^{*}$ \\
\hline$g s p A$ & 333 & $\sigma^{\mathrm{B}}$-dependent general stress protein & $27 *$ \\
\hline$g \operatorname{ta} A$ & & See tagE & \\
\hline$g t a B$ & 308 & Glucosylation of teichoic acid; UDPglucose pyrophosphorylase & $78 \#, 587,710 *, 788$ \\
\hline$g t a C$ & 71 & Glucosylation of teichoic acid; lacks phosphoglucomutase & 587 \\
\hline gtaD & & See tage & \\
\hline$g t a E$ & 71 & Glucosylation of teichoic acid & 587 \\
\hline gua $A$ & 54 & GMP synthetase; previous gua $A$ is now gua $B$ & $65,432 *, 660$ \\
\hline gua & 0 & Inosine monophosphate dehydrogenase; previous guaB is now gua $A ; g n a B$ & $348^{*}, 660$ \\
\hline guaC & NM & Guanosine monophosphate reductase & 160 \\
\hline guaF & NM & Hypoxanthine-guanine phosphoribosyltransferase & 160 \\
\hline guaP & NM & Inosine-guanosine phosphorylase & 160 \\
\hline gut $A$ & 50 & D-Glucitol permease & $219 \#$ \\
\hline$g u t B$ & 50 & D-Glucitol hydrogenase & $219 \#, 520^{*}$ \\
\hline$g u t \mathrm{R}$ & 50 & $\begin{array}{l}\text { Constitutive synthesis of D-glucitol permease and D-glucitol dehydrogenase; } \\
\text { regulatory for glucitol catabolism; transcriptional regulation }\end{array}$ & $219 \#, 848^{*}$ \\
\hline $\operatorname{gyr} A$ & 0 & DNA gyrase; nal $A, \operatorname{caf} B$ & $96,482^{*}$ \\
\hline$g y r B$ & 0 & DNA gyrase; nov $A$ & $267,482 *$ \\
\hline bag & 306 & Flagellin & $388^{*}, 466$ \\
\hline$b b s$ & 204 & DNA-binding protein HBsu; immediately upstream of $m \operatorname{tr} A ; b b s U, d b p A$ & $292^{*}, 461 *$ \\
\hline$b b s U$ & & See $b b s$ & \\
\hline$b d s$ & 5 & Pleiotropic extragenic suppressors of mutations & 689 \\
\hline $\operatorname{bem} A$ & 244 & Glutamyl-tRNA reductase of the C-5 pathway for $\delta$-aminolevulinate synthetase & $\begin{array}{l}263^{*}, 362,572^{*} \\
668,669\end{array}$ \\
\hline bem $B$ & 244 & Porphobilinogen synthase & $49,263^{*}, 722$ \\
\hline bem $C$ & 244 & Hydroxymethylbilane synthase & $49,263^{*}, 572^{*}, 722$ \\
\hline bemD & 244 & Uroporphyrinogen III synthase & $263 *, 463,722$ \\
\hline bemE & 77 & Uroporphyrinogen decarboxylase & $264 *, 462$ \\
\hline bemF & & See bemH & \\
\hline bem $G$ & & See $b e m Y$ & \\
\hline bemH & 77 & Ferrochelatase; $b e m F$ & $264 *, 462$ \\
\hline bemK & & See bemL & \\
\hline bemL & 244 & Glutamate-1-semialdehyde 2,1-aminotransferase; bem K & $263 *$ \\
\hline bem $X$ & 244 & Membrane protein of unknown function required for bemL synthesis & $263 *, 669$ \\
\hline bem $Y$ & 77 & Coproporphyrinogen III oxidase and protporphyrinogen IX oxidase; bemG & $264^{*}$ \\
\hline bis $A$ & 300 & Histidine requirement; probable location of all histidine enzymes except bisH & $711^{*}, 799 \#$ \\
\hline bis $H$ & 202 & $\begin{array}{l}\text { Histidinol-phosphate aminotransferase, tyrosine and phenylalanine } \\
\text { aminotransferase; aroJ }\end{array}$ & $290^{*}, 516$ \\
\hline bolB & 2 & Probable DNA polymerase III, $\delta$ subunit & 541 \\
\hline bom & 284 & $\begin{array}{l}\text { Threonine and methionine requirement; homoserine dehydrogenase; a deletion in } \\
\text { this area over this gene, the gene for homoserine dehydratase and } t h r B ; t d m\end{array}$ & $24,557^{*}, 785,786$ \\
\hline bos & 14 & Suppresses the temperature-sensitive phenotype of elongation factor $G$ mutants & 451 \\
\hline bpr & 76 & Overproduction of proteases; cat $A, s c 0$ & $525,562 *$ \\
\hline $\operatorname{bprT}$ & 8 & Hypoxanthine-guanine phosphoribosyltransferase; $b p t$ & $539 *$ \\
\hline bpt & & See $b p r T$ & \\
\hline $\operatorname{brc} A$ & 225 & Encodes a negative regulator of class I heat-shock genes & $672 *$ \\
\hline$b s d B M$ & 344 & DNA-methyltransferase $B s u \mathrm{~B}$; modification methylase $B s u \mathrm{BI}$ & $321,767,836^{*}$ \\
\hline$b s d B R$ & 344 & $\begin{array}{l}\text { Host-specificity-determinant B of } B . \text { subtilis IAM } 1247 \text {; restriction endonuclease } \\
B s u B \text {; previously } b s r B \text {; type II restriction enzyme BsuBI }\end{array}$ & $321,767,836^{*}$ \\
\hline bsdCM & 59 & DNA-methyltransferase $B s u C$ & 321,767 \\
\hline
\end{tabular}


Table 1 (cont.)

\begin{tabular}{|c|c|c|c|}
\hline $\begin{array}{l}\text { Gene } \\
\text { symbol }\end{array}$ & $\begin{array}{c}\text { Map } \\
\text { position }\end{array}$ & $\begin{array}{l}\text { Functions, products, phenotypes, other characteristics, former or } \\
\text { alternative symbols }\end{array}$ & Reference \\
\hline$b s d C R$ & 59 & $\begin{array}{l}\text { Host-specificity-determinant } C \text { of } B \text {. subtilis IAM } 1247 \text {; restriction endonuclease } \\
\text { BsuC; previously } b s r C\end{array}$ & 321,767 \\
\hline$b s d E M$ & 338 & DNA-methyltransferase $B s u \mathrm{E}$ & $206,321,767$ \\
\hline bsdER & 338 & $\begin{array}{l}\text { Host-specificity-determinant } \mathrm{E} \text { of } B \text {. subtilis IAM } 1231 \text {; restriction endonuclease } \\
B s u \mathrm{E} \text {; previously bsdE }\end{array}$ & 321,767 \\
\hline$b s d F M$ & 59 & DNA-methyltransferase $B s u F$ & $321,767,798^{*}$ \\
\hline$b s d F R$ & 59 & $\begin{array}{l}\text { Host-specificity-determinant } \mathrm{F} \text { of } B . \text { subtilis IAM } 1231 \text {; restriction endonuclease } \\
B s u \mathrm{~F} \text {; isoschizomer of } H p a \mathrm{II} \text {; previously } b s r F\end{array}$ & $321,349 *, 767$ \\
\hline$b s d M M$ & 47 & DNA-methyltransferase BsuM & $321,645,767$ \\
\hline$b s d M R$ & 47 & $\begin{array}{l}\text { Host-specificity-determinant } \mathrm{M} \text { of } B . \text { subtilis Marburg identical to nonB; restriction } \\
\text { endonuclease } B s u \mathrm{M} \text {; isosochizomer of } \mathrm{XboI} \text {; previously } h s r M\end{array}$ & $321,645,767$ \\
\hline$b s d R M$ & 59 & DNA-methyltransferase BsuR & $321,361 *, 766,767$ \\
\hline$b s d \mathrm{RR}$ & 59 & $\begin{array}{l}\text { Host-specificity-determinant R of } B \text {. subtilis; restriction endonuclease } B s u \mathrm{R} \text {; } \\
\text { isoschizomer of HaeIII; previously } h s r \mathrm{R}\end{array}$ & $321,361 *, 766,767$ \\
\hline$b s l U$ & & See $\operatorname{cod} X$ & \\
\hline$b s l V$ & & See $\operatorname{cod} W$ & \\
\hline butG & 337 & Histidine utilization; formiminoglutamate hydrolase & $345,829,854^{*}$ \\
\hline but $H$ & 337 & Histidine utilization; histidase & $532 *, 829,854^{*}$ \\
\hline but I & 337 & Histidine utilization; imidazolone hydrolase & $345,829,854^{*}$ \\
\hline but $M$ & 337 & Putative histidine permease & $532 *, 829,854 *$ \\
\hline butP & 337 & Histidine utilization; positive regulator of the but operon & $532 *, 829,854 *$ \\
\hline$b u t U$ & 337 & Histidine utilization; urocanase & $532 *, 829,854 *$ \\
\hline$i d b$ & & See $i o l G$ & \\
\hline$i e p$ & & See $\operatorname{deg} U$ & \\
\hline ifm & 304 & Hypermotility; suppresses $f a A$ and $f a D$ mutations & 586 \\
\hline iles & 135 & Isoleucine tRNA synthetase & 193 \\
\hline$i l v A$ & 195 & Threonine dehydratase & $22,29 *, 39$ \\
\hline$i l v B$ & 247 & Condensing enzyme & $237 *, 427 \#$ \\
\hline$i l v C$ & 247 & $\alpha$-Hydroxy- $\beta$-ketoacid reductoisomerase & $237 *, 427 \#$ \\
\hline$i l v D$ & 196 & Dihydroxyacid dehydratase & 22,39 \\
\hline$i l v N$ & 247 & Subunit of the AhaS enzyme (ilvB) & $237^{*}, 427 \#$ \\
\hline $\inf A$ & 12 & Initiation factor I & $69 *$ \\
\hline $\inf B$ & 147 & Initiation factor II & $685^{*}$ \\
\hline infC & 256 & Bacillus stearothermophilus infC homologue; initiation factor IF3 & $825^{*}$ \\
\hline iol & & See $i o l G$ & \\
\hline iol $A$ & 341 & Probable methylmalonate-semialdehyde dehydrogenase; $m m s A$ & $853^{*}$ \\
\hline iolB & 341 & Involved in iol operon & $853^{*}$ \\
\hline iolC & 341 & Involved in iol operon; probable kinase & $853 *$ \\
\hline iolD & 341 & Involved in iol operon & $853^{*}$ \\
\hline iolE & 341 & Involved in iol operon & $853^{*}$ \\
\hline iolF & 341 & Probable inositol transport & $853 *$ \\
\hline iolG & 341 & Inositol dehydrogenase; idh, iol & $200,203^{*}, 853^{*}$ \\
\hline $\mathrm{iolH}$ & 341 & Involved in iol operon & $853^{*}$ \\
\hline ioll & 341 & Involved in iol operon & $853 *$ \\
\hline iolj & 341 & Probable fructose-bisphosphate aldolase; $f b a B$ & $853^{*}$ \\
\hline iolR & 341 & Regulation of the iol operon & $853 *$ \\
\hline iols & 341 & Involved in iol operon & $853^{*}$ \\
\hline$i p i$ & 101 & Intracellular proteinase inhibitor $B s u \mathrm{PI}$ & $681^{*}, 686^{*}$ \\
\hline$i s p A$ & 117 & Intracellular serine protease & $369^{*}$ \\
\hline jag & 360 & Jag spoIIIJ-associated gene & $167^{*}, 538^{*}$ \\
\hline kan & 10 & Kanamycin resistance; maps in the ribosomal protein cluster & 231 \\
\hline$k a p B$ & 280 & Kinase-B-associated protein & $764^{*}$ \\
\hline kat & & See kat $A$ & \\
\hline
\end{tabular}


Table 1 (cont.)

\begin{tabular}{|c|c|c|c|}
\hline $\begin{array}{l}\text { Gene } \\
\text { symbol }\end{array}$ & $\begin{array}{c}\text { Map } \\
\text { position }\end{array}$ & $\begin{array}{l}\text { Functions, products, phenotypes, other characteristics, former or } \\
\text { alternative symbols }\end{array}$ & Reference \\
\hline kat-19 & NM & Catalase; distinct from kat $A$ & $60^{*}$ \\
\hline kat $A$ & 69 & Catalase; kat & $60^{*}, 416$ \\
\hline katB & & See katE & \\
\hline kat $E$ & 335 & Catalase; $\sigma^{\mathrm{B}}$-dependent; kat $B$ & $162^{*}$ \\
\hline $\operatorname{kau} A$ & 182 & Branched-chain $\alpha$-keto transport & 229 \\
\hline $\operatorname{kdg} A$ & 198 & Genes involved in pectin catabolism, deoxyphosphogluconate aldolase & $719 *$ \\
\hline$k d g K$ & 198 & Genes involved in pectin catabolism, deoxygluconate kinase & $719^{*}$ \\
\hline$k d g R$ & 198 & Genes involved in pectin catabolism, regulation of transcription of $k d g$ operon & $719 *$ \\
\hline$k d g T$ & 198 & Genes involved in pectin catabolism, deoxygluconate permease & $719 *$ \\
\hline$k d u D$ & 198 & Genes involved in pectin catabolism, deoxygluconate oxidoreductase & $719 *$ \\
\hline$k d u I$ & 198 & Genes involved in pectin catabolism, deoxyuronate isomerase & $719 *$ \\
\hline $\operatorname{kin} A$ & 118 & Sporulation-specific protein kinase; spoIIJ, spoIIF, scoD, gsiC & $28^{*}, 564^{*}$ \\
\hline $\operatorname{kin} B$ & 280 & Sporulation-specific protein kinase & $764 *$ \\
\hline $\operatorname{kin} C$ & 124 & Histidine protein kinase; phosphorylation of Spo0A & $367,399 *, 824$ \\
\hline $\operatorname{kesg} A$ & 4 & High-level kasugamycin resistance & 759 \\
\hline ksgB & 277 & Low-level kasugamycin resistance & 759 \\
\hline $\mathrm{ksgC}$ & 287 & Fumarate hydratase defective; kasugamycin resistance & 305 \\
\hline $\operatorname{lac} A$ & 290 & Structural gene for $\beta$-galactosidase & 166 \\
\hline $\operatorname{lac} R$ & 290 & Regulatory gene for $\beta$-galactosidase & 166 \\
\hline $\operatorname{lcf} A$ & 253 & Homology with a coenzyme synthetase from E. coli & $825 *$ \\
\hline let $E$ & 26 & L-Lactate dehydrogenase & $274 *, 839 *$ \\
\hline $\operatorname{leu} A$ & 247 & $\alpha$-Isopropylmalate synthase & $503 \#, 825 *$ \\
\hline $\operatorname{leu} B$ & 247 & $\beta$-Isopropylmalate dehydrogenase; previous name $\operatorname{le} u C$ & $325^{*}, 825^{*}$ \\
\hline leuC & 247 & Isopropylmalate isomerase; previous name $\operatorname{le} \mathrm{B}$ & $503 \#, 825 *$ \\
\hline $\operatorname{leu} D$ & 247 & Subunit of isopropylmalate isomerase & $427 \#, 825 *$ \\
\hline leus & 269 & Leucyl-tRNA synthetase & $783^{*}$ \\
\hline $\operatorname{lev} D$ & 233 & Enzyme III for fructose (phosphotransferase-system transport system); sacL & $443 *$ \\
\hline levE & 233 & Enzyme III for fructose (phosphotransferase-system transport system); sacL & $443 *$ \\
\hline $\operatorname{lev} F$ & 233 & Enzyme II for fructose (phosphotransferase-system transport system) & $443^{*}$ \\
\hline $\operatorname{lev} G$ & 233 & Enzyme II for fructose (phosphotransferase-system transport system) & $443 *$ \\
\hline $\operatorname{lev} \mathrm{R}$ & 233 & Regulator of levanase & $158^{*}$ \\
\hline $\operatorname{lex} A$ & 170 & SOS regulatory protein; $\operatorname{din} \mathrm{R}$ & $612^{*}, 630^{*}$ \\
\hline $\operatorname{lic} T$ & 335 & Transcription antiterminator; positive regulation of utilization of $\beta$-glucans & $398,855^{*}$ \\
\hline lin & 24 & Lincomycin resistance & 230 \\
\hline lip & & See $\operatorname{lip} A$ & \\
\hline $\operatorname{lip} A$ & 22 & Lipase; lip & 135 \\
\hline lon & & See $\operatorname{lon} A$ & \\
\hline $\operatorname{lon} A$ & 244 & $\begin{array}{l}\text { ATP-dependent protease; induced by various stresses including heat shock; } \\
\text { homologous to lon of E. coli; lon }\end{array}$ & $620^{*}, 849$ \\
\hline $\operatorname{lon} B$ & 244 & Lon-like protein & $620^{*}, 849 *$ \\
\hline$l p m$ & & See $r p o C$ & \\
\hline lpmB & 286 & Lipiarmycin resistance & 713 \\
\hline$l p p X$ & & See $l y t A$ & \\
\hline lss $A$ & 35 & Thermosensitive lysis; linked to $d d l$ by transformation & 76 \\
\hline$l s s B$ & & See dapE & \\
\hline$l s s D$ & & See $\operatorname{dap} G$ & \\
\hline lss $E$ & 353 & Thermosensitive lysis & 76 \\
\hline$l s s F$ & & See $\operatorname{mur} A$ & \\
\hline$l s s G$ & & See $\sec A$ & \\
\hline lss $H$ & 293 & Thermosensitive lysis & 76 \\
\hline lys $A$ & 210 & Lysine requirement, diaminopimelate decarboxylase & $\begin{array}{l}39,338 \#, 717^{*} \\
838^{*}\end{array}$ \\
\hline
\end{tabular}


Table 1 (cont.)

\begin{tabular}{|c|c|c|c|}
\hline $\begin{array}{l}\text { Gene } \\
\text { symbol }\end{array}$ & $\begin{array}{c}\text { Map } \\
\text { position }\end{array}$ & $\begin{array}{c}\text { Functions, products, phenotypes, other characteristics, former or } \\
\text { alternative symbols }\end{array}$ & Reference \\
\hline lys $C$ & 252 & Aspartokinase II; aec $A$ & $\begin{array}{l}110^{*}, 111,423,571, \\
825^{*}\end{array}$ \\
\hline lys $S$ & 10 & Lysyl-tRNA synthetase & 608 \\
\hline lyt $A$ & 308 & Involved in the secretion of $\mathrm{LytC}$ (amidase); $l p p X$ & $394 *$ \\
\hline lyt $B$ & 308 & Modifier of LytC (amidase); $c w b A$ & $394 *$ \\
\hline lyt $C$ & 308 & $N$-Acetylmuramoyl-L-alanine amidase in vegetative growth; major autolysin; $\mathrm{cwlB}$ & $\begin{array}{l}384 *, 385^{*}, 394 \\
435,711^{*}\end{array}$ \\
\hline lyt $D$ & 310 & $N$-Acetylglucosaminidase & $436^{*}, 610 \#$ \\
\hline lyt $\mathrm{R}$ & 308 & Regulator of LytC (amidase) & $394 *$ \\
\hline lytS & 256 & $\begin{array}{l}\text { Staphylococcus aureus lyts homologue; sensor-kinase involved in controlling the } \\
\text { rate of autolysis }\end{array}$ & $825^{*}$ \\
\hline lyt $T$ & 256 & $\begin{array}{l}\text { Staph. aureus lyt } \mathrm{R} \text { homologue; response-regulator involved in controlling the rate } \\
\text { of autolysis }\end{array}$ & $825^{*}$ \\
\hline maf & 242 & Possible septation function & $88^{*}$ \\
\hline mal & 264 & Malate dehydrogenase, decatboxylating & $393 *$ \\
\hline map & 12 & Methionine amino peptidase & $505^{*}$ \\
\hline$m b l$ & 317 & MBL protein, homologous to E. coli mreB morphogene & $1^{*}$ \\
\hline$m c p A$ & 281 & Methyl-accepting chemotaxis protein; transmembrane receptor & $261 *$ \\
\hline$m c p B$ & 281 & Methyl-accepting chemotaxis protein; transmembrane receptor & $261^{*}$ \\
\hline$m d b$ & & See citH & \\
\hline $\operatorname{mec} A$ & 103 & Medium-independent expression of competence & $151,370^{*}$ \\
\hline$m e c B$ & 10 & Medium-independent expression of competence; $c l p C$ & $151,493^{*}$ \\
\hline$m e n B$ & 273 & $\begin{array}{l}\text { Menaquinone deficient; multiple aminoglycoside resistance; dihydroxynaphthoate } \\
\text { synthase }\end{array}$ & $148^{*}, 633^{*}$ \\
\hline$m e n D$ & 273 & $\begin{array}{l}\text { Menaquinone deficient; multiple aminoglycoside resistance; blocked in formation } \\
\text { of o-succinylbenzoic from chorismic acid }\end{array}$ & $633^{*}$ \\
\hline menE & 273 & $\begin{array}{l}\text { Menaquinone deficient; multiple aminoglycoside resistance; } 0 \text {-succinylbenzoyl } \\
\text { coenzyme A synthetase }\end{array}$ & $148^{*}, 633^{*}$ \\
\hline $\operatorname{men} F$ & 273 & $\begin{array}{l}\text { Menaquinone deficient; multiple aminoglycoside resistance; blocked in formation } \\
\text { of } o \text {-succinylbenzoic from chorismic acid }\end{array}$ & $633^{*}, 634$ \\
\hline $\operatorname{met} A$ & 110 & Responds to methionine, cystathionine or homocysteine & 723 \\
\hline met $B$ & 197 & Responds to methionine or homocysteine; homoserine succinyl transferase & 22,39 \\
\hline metC & 115 & Responds to methionine & 149 \\
\hline$m e t D$ & 100 & Responds to methionine & 860 \\
\hline metE & 272 & $S$-Adenosylmethionine synthetase & $393^{*}, 795 \#$ \\
\hline mets & 4 & Methionyl-tRNA synthetase & $539 *$ \\
\hline mfd & 7 & Transcription-repair coupling factor & $539 *$ \\
\hline $\min C$ & 242 & Cell division inhibitor; Minicell production & $401^{*}, 408^{*}, 787^{*}$ \\
\hline $\min D$ & 242 & ATPase-activator of MinC; Minicell production; $\operatorname{divIVB}$ & $\begin{array}{l}401^{*}, 408^{*}, 613 \\
787^{*}\end{array}$ \\
\hline$m m g A$ & 216 & Similat to Alcaligenes eutrophus acetyl-CoA $C$-acetyltransferase & $81^{*}$ \\
\hline$m m g B$ & 216 & $\begin{array}{l}\text { Similar to Clostridium acetobutylicum NAD-dependent } \beta \text {-hydroxybutyryl-CoA } \\
\text { dehydrogenase }\end{array}$ & $81^{*}$ \\
\hline$m m g C$ & 216 & Similar to product encoded by $B$. subtilis short-chain acyl-CoA dehydrogenase gene & $81^{*}$ \\
\hline$m m g D$ & 216 & Citrate synthase III & $81^{*}$ \\
\hline$m m g E$ & 216 & Involved in $m m g$ operon & $81 *$ \\
\hline$m m r$ & 325 & Methylenomycin-A-resistance protein & $602 *$ \\
\hline$m m s A$ & & See iol $A$ & \\
\hline $\operatorname{mot} A$ & 118 & Paralysed flagella; motility protein & 467,875 \\
\hline $\operatorname{mot} B$ & 118 & Paralysed flagella; motility protein & 467,875 \\
\hline mpo & 218 & Membrane protein overproduction, temperature-sensitive sporulation & 450 \\
\hline$m p r$ & 21 & Metalloprotease, extracellular & $695 *$ \\
\hline$m r a Y$ & 133 & Cell wall synthesis; homologous to $m r a Y$ of E. coli & $168^{*}$ \\
\hline
\end{tabular}


Table 1 (cont.)

\begin{tabular}{|c|c|c|c|}
\hline $\begin{array}{l}\text { Gene } \\
\text { symbol }\end{array}$ & $\begin{array}{c}\text { Map } \\
\text { position }\end{array}$ & $\begin{array}{l}\text { Functions, products, phenotypes, other characteristics, former or } \\
\text { alternative symbols }\end{array}$ & Reference \\
\hline$m r e B$ & 242 & Cell shape determination & $408^{*}, 787^{*}$ \\
\hline$m r e B H$ & 124 & MreBH protein & $824 *$ \\
\hline$m r e C$ & 242 & Cell shape determination & $408^{*}, 787^{*}$ \\
\hline$m r e D$ & 242 & Cell shape determination; $\operatorname{rod} B$ & $351,408^{*}, 787^{*}$ \\
\hline$m r g A$ & 294 & Metalloregulation & $108^{*}$ \\
\hline$m r g C$ & 198 & Metalloregulation & $108^{*}$ \\
\hline$m t l A$ & 34 & Lacks mannitol transport & $8^{*}, 365$ \\
\hline$m t / B$ & & See $m t l D$ & \\
\hline$m t l D$ & 34 & Mannitol-1-phosphate dehydrogenase; $m t l B$ & $8^{*}, 107 \#$ \\
\hline$m \operatorname{tr} A$ & 204 & $\begin{array}{l}\text { Resistance to 5-methyl-tryptophan; GTP cyclohydrolase I, involved in folic acid } \\
\text { biosynthesis }\end{array}$ & $33,232 *$ \\
\hline$m \operatorname{tr} B$ & 204 & Resistance to 5-methyl-tryptophan; RNA-binding transcription regulator & $33,232 *$ \\
\hline $\operatorname{mur} A$ & 316 & $\begin{array}{l}\text { Thermosensitive lysis; phosphoenolpyruvate; uridine- } N \text {-acetylglucosamine } \\
\text { enolpyruvoyltransferase; } l s s F\end{array}$ & 76,632 \\
\hline murB & 134 & Cell division gene region with significant similarity to murB of E. coli & $636^{*}$ \\
\hline murD & 133 & Cell wall synthesis; homologous to murD of E. coli & $168^{*}, 293^{*}$ \\
\hline murE & 133 & Cell wall synthesis; homologous to murE of E. coli & $168^{*}, 293^{*}$ \\
\hline murG & 134 & Cell wall synthesis; homologous to murG of E. coli & $168^{*}, 293^{*}, 323^{*}$ \\
\hline murZ & 323 & UDP- $N$-acetylglucosamine 1 -carboxyvinyltransferase & $762^{*}$ \\
\hline$m u t-1$ & & See polc & \\
\hline mutL & 150 & Mismatch-repair recognition & $223^{*}$ \\
\hline mutS & 150 & Mismatch-repair recognition & $223 *$ \\
\hline$n a d B$ & 240 & Required for NAD biosynthesis; L-aspartate oxidase & $746^{*}$ \\
\hline$n a d C$ & 240 & Required for NAD biosynthesis; probable nicotinate-nucleotide pyrophosphorylase & $746^{*}$ \\
\hline nadE & 27 & A sporulation protein; out $B$ & $13 *, 98,515$ \\
\hline nal A & & See $g y r A$ & \\
\hline nap & 42 & Carboxylesterase & $603 *$ \\
\hline $\operatorname{nar} A$ & 320 & Inability to use nitrate as a nitrogen source; nar $A B$ & $226^{*}, 405$ \\
\hline $\operatorname{nar} A A$ & & See narQ & \\
\hline nar $A B$ & & See nar $A$ & \\
\hline narB & & See $n a s B B$ & \\
\hline narG & 324 & Nitrate reductase subunit $\alpha$ & $308^{*}, 609^{*}$ \\
\hline narH & 324 & Nitrate reductase subunit $\beta$ & $308^{*}, 609 *$ \\
\hline narI & 324 & Nitrate reductase subunit $\gamma$ & $308^{*}, 609^{*}$ \\
\hline narJ & 324 & Nitrate reductase subunit $\delta$ & $308^{*}, 609 *$ \\
\hline narK & 324 & Nitrite-extrusion protein & $609 *$ \\
\hline narQ & 320 & Inability to use nitrate as a nitrogen source; nar $A A$ & $226^{*}, 405$ \\
\hline $\operatorname{nas} A$ & 28 & Nitrate transporter & $511,540^{*}, 543$ \\
\hline $\operatorname{nas} B A$ & 28 & Nitrate reductase; electron-transfer subunit & $511,540^{*}, 543$ \\
\hline$n a s B B$ & 28 & Catalytic subunit of nitrate reductase; nas $C$, nar $B$ & $540^{*}, 543,866$ \\
\hline $\operatorname{nas} B C$ & 28 & Nitrate reductase; nas $D$, nir $B$ & $540^{*}, 543$ \\
\hline nasBD & 28 & Assimilatory nitrate reductase; nas $E$, nirD & $540^{*}, 543$ \\
\hline nasBE & 28 & Uroporphyrinogen III; methyltransferase; nasF & $540^{*}, 543$ \\
\hline nas $C$ & & See $\operatorname{nas} B B$ & \\
\hline nas $D$ & & See nasBC & \\
\hline nasE & & See nas $B D$ & \\
\hline nasF & & See nasBE & \\
\hline$n d b$ & & See $a h p C$ & \\
\hline$n d h F$ & 23 & $\mathrm{NADH}$ dehydrogenase subunit 5 & 487 \\
\hline$n d k$ & 204 & Nucleotide diphosphate kinase & $292 *$ \\
\hline nea & uC & Neamine resistance; see ribosomal protein cluster & 230 \\
\hline neo & UC & Neomycin resistance; see ribosomal protein cluster & 267 \\
\hline nic & 240 & Nicotinic acid requirement & $180 \#$ \\
\hline
\end{tabular}


Table 1 (cont.)

\begin{tabular}{|c|c|c|c|}
\hline $\begin{array}{l}\text { Gene } \\
\text { symbol }\end{array}$ & $\begin{array}{c}\text { Map } \\
\text { position }\end{array}$ & $\begin{array}{c}\text { Functions, products, phenotypes, other characteristics, former or } \\
\text { alternative symbols }\end{array}$ & Reference \\
\hline nidS & 232 & 2-Nitropropane dioxygenase & $62^{*}$ \\
\hline nifs & 240 & $\begin{array}{l}\text { Required for NAD biosynthesis; homologous to the nifS gene products of other } \\
\text { bacteria }\end{array}$ & $746^{*}$ \\
\hline nin & & See comJ & \\
\hline $\operatorname{nir} B$ & & See $n a s B C$ & \\
\hline $\operatorname{nir} D$ & & See nas $B D$ & \\
\hline non $A$ & uC & Permissive for bacteriophage SP10 and $\phi \mathrm{NR} 2$; closely linked to $r \mathrm{fm}$ & 645 \\
\hline $\operatorname{nov} A$ & & See $g y r B$ & \\
\hline$n p r B$ & 101 & Neutral protease & $681^{*}, 765^{*}$ \\
\hline$n p r E$ & 126 & Neutral metalloprotease & $824,841^{*}$ \\
\hline$n p r R$ & 126 & Regulatory gene for neutral protease & $758^{*}$ \\
\hline$n r d A$ & & See $n r d E$ & \\
\hline$n r d E$ & 153 & Ribonucleoside-diphosphate reductase; major subunit; $\operatorname{nrd} A$ & $561 \#, 674 *$ \\
\hline$n r d F$ & 153 & Ribonucleoside-diphosphate reductase; minor subunit & $674 *$ \\
\hline $\operatorname{nrg} A$ & 318 & Nitrogen-regulated membrane-associated protein & $830^{*}$ \\
\hline$n r g B$ & 318 & Nitrogen-regulated PII-like protein & $830^{*}$ \\
\hline nth & 200 & Probable endonuclease III & $80^{*}$ \\
\hline$n u c A$ & 31 & Plays a role in the competence signal; DNase subunit; comI & $199 *, 780^{*}, 794 *$ \\
\hline$n u c B$ & 226 & Extracellular DNase produced during sporulation & $9,777,780$ \\
\hline nир C & 338 & Pyrimidine nucleoside transport protein & $663 *$ \\
\hline nus $A$ & 147 & Transcription termination & $685^{*}$ \\
\hline nus $G$ & 11 & Transcription antitermination factor NusG & $339^{*}$ \\
\hline obg & 240 & Essential GTP-binding protein of unknown function & $763 *$ \\
\hline $\operatorname{odh} A$ & 181 & $\begin{array}{l}\text { 2-Oxoglutarate dehydrogenase, E1 subenzyme of the 2-oxoglutarate dehydrogenase } \\
\text { complex; citK }\end{array}$ & $99 \#, 100^{*}, 617$ \\
\hline$o d b B$ & 181 & $\begin{array}{l}\text { Dihydrolipoamide transsuccinylase, E2 subenzyme of the 2-oxoglutarate } \\
\text { dehydrogenase complex; } i t M\end{array}$ & $99 \#, 100^{*}, 617$ \\
\hline ole & uC & Oleandomycin resistance; see ribosomal protein cluster & 230 \\
\hline$o p p A$ & 104 & Oligopeptide permease; comprises five genes also called spooK; spoOKA & $565^{*}, 576,637^{*}$ \\
\hline$o p p B$ & 104 & Oligopeptide permease; comprises five genes also called $s p o O K$; spoOKB & $565^{*}, 576,637^{*}$ \\
\hline$o p p C$ & 104 & Oligopeptide permease; comprises five genes also called spoOK; spoOKC & $565^{*}, 576,637^{*}$ \\
\hline$o p p D$ & 104 & Oligopeptide permease; comprises five genes also called spoOK; spoOKD & $565^{*}, 576,637^{*}$ \\
\hline$o p p F$ & 104 & Oligopeptide permease; comprises five genes also called spo0K; spoOKE & $565^{*}, 576,637^{*}$ \\
\hline ори $A A$ & 26 & $\begin{array}{l}\text { Glycine betaine transport; ATPase; osmotically regulated binding-protein- } \\
\text { dependent transport system }\end{array}$ & $356^{*}$ \\
\hline ори $A B$ & 26 & Glycine betaine transport; transmembrane protein & $356^{*}$ \\
\hline opuAC & 26 & Glycine betaine transport; glycine-betaine-binding protein & $356^{*}$ \\
\hline $\operatorname{ord} A$ & NM & Ornithine: 2 -oxo-acid aminotransferase & 817 \\
\hline out $A$ & 20 & $\begin{array}{l}\text { Blocked in outgrowth after RNA-, protein- and DNA syntheses have started; } \\
\text { formerly gspIV }\end{array}$ & 11 \\
\hline out $B$ & & See $n a d E$ & \\
\hline outC & 28 & $\begin{array}{l}\text { Blocked in outgrowth after RNA- and protein syntheses have started, but before } \\
\text { DNA synthesis; formerly gsp- } 25\end{array}$ & 11 \\
\hline outD & 158 & $\begin{array}{l}\text { Blocked in outgrowth; protein- and DNA syntheses reduced; formerly } \\
\text { gsp-1 }\end{array}$ & 207 \\
\hline out $E$ & 300 & $\begin{array}{l}\text { Blocked in outgrowth; RNA synthesis normal; protein synthesis reduced; DNA } \\
\text { synthesis prevented; formerly gsp-42 }\end{array}$ & 11 \\
\hline outF & 316 & $\begin{array}{l}\text { Blocked in outgrowth; RNA- and protein syntheses reduced; DNA synthesis } \\
\text { prevented; formerly } g s p-4\end{array}$ & 11,12 \\
\hline out $G$ & & See pkesL & \\
\hline out $H$ & & See $p k s L$ & \\
\hline$o x r$ & 19 & Oxolinic acid resistance & 789 \\
\hline
\end{tabular}


Table 1 (cont.)

\begin{tabular}{|c|c|c|c|}
\hline $\begin{array}{l}\text { Gene } \\
\text { symbol }\end{array}$ & $\begin{array}{c}\text { Map } \\
\text { position }\end{array}$ & $\begin{array}{c}\text { Functions, products, phenotypes, other characteristics, former or } \\
\text { alternative symbols }\end{array}$ & Reference \\
\hline pab & 9 & $p$-Aminobenzoic acid requirement; subunit $A$ of $p$-aminobenzoate synthase; $p a b B$ & $347,693^{*}$ \\
\hline$p a b A$ & & See $\operatorname{trp} G$ & \\
\hline$p a b B$ & & See $p a b$ & \\
\hline$p a b C$ & 9 & Enzyme required for $p$-aminobenzoate synthesis & $693 *$ \\
\hline pac & 5 & Resistance to pactamycin & 771 \\
\hline paiA & 283 & Regulation of sporulation and degradative enzyme production & $313^{*}$ \\
\hline paiB & 283 & Regulation of sporulation and degradative enzyme production & $313^{*}$ \\
\hline pal & & See $s l p$ & \\
\hline $\operatorname{pan} B$ & 57 & Ketopantoate hydroxymethyltransferase & 34 \\
\hline panE & 57 & Ketopantoic acid reductase & 34 \\
\hline$p a p Q$ & 72 & $\begin{array}{l}\text { Phosphatase-associated protein; muralytic when cloned in E. coli; Iap } 60 \\
\text { homologue; inactivation leads to alkaline phosphatase over-expression }\end{array}$ & $816^{*}$ \\
\hline pat $A$ & 118 & Putative aminotransferase; uat & $28^{*}, 564^{*}, 764$ \\
\hline pat $B$ & 280 & Putative aminotransferase & $764 *$ \\
\hline$p b p$ & 175 & $\begin{array}{l}\text { Penicillin-binding protein; mutations affecting PBPs } 2 a, 2 b, 3 \text { and } 4 \text {; probably four } \\
\text { loci }\end{array}$ & 82,687 \\
\hline$p b p B$ & 133 & Penicillin-binding protein; closely related to $p b p B$ of E. coli & $134 *, 168 *, 687,844$ \\
\hline$p b p D$ & 280 & Penicillin-binding protein 4 & $593 *$ \\
\hline$p b p E$ & 296 & Penicillin-binding protein 4 & $592 *$ \\
\hline$p b p F$ & 77 & Penicillin-binding protein class A putative; formerly pon $A$ & $264,591 *$ \\
\hline$p b u G$ & 55 & Purine base uptake & 659 \\
\hline$p b u X$ & 198 & Xanthine permease & $664^{*}$ \\
\hline$p c f$ & 110 & Positive control factor; similar to regions 4,1 and 4,2 of sigma factors & $459^{*}$ \\
\hline pck $A$ & 272 & Phosphoenolpyruvate carboxykinase & $393 *$ \\
\hline$p c p$ & 25 & Pyrrolidone carboxyl peptidase; L-pyroglutamyl peptide hydrolase & $31 *$ \\
\hline$p d h A$ & 125 & Pyruvate dehydrogenase; E-1- $\alpha$ (pyruvate decarboxylase); $b f m A$, ace $A$ & $67,277^{*}, 824$ \\
\hline$p d b B$ & 125 & Pyruvate dehydrogenase component E-1- $\beta$; aceB & $277^{*}, 824$ \\
\hline$p d b C$ & 125 & Pyruvate dehydrogenase component $\mathrm{E} 2 ;$ ace $\mathrm{C}$ & $277^{*}, 824$ \\
\hline$p d b D$ & 125 & $\begin{array}{l}\text { Pyruvate dehydrogenase; lipoamide dehydrogenase E- } 3 \text { component of both } \\
\text { pyruvate dehydrogenase and } \alpha \text {-ketoglutarate dehydrogenase complexes; ace } D \text {, cit } L\end{array}$ & $277^{*}, 303,824$ \\
\hline$p d p$ & 338 & Pyrimidine nucleoside phosphorylase & $639,663^{*}$ \\
\hline$p f k$ & 260 & Phosphofructokinase & $219,393 *$ \\
\hline pgk & NM & 3'-Phosphoglycerolkinase & $197,411 *$ \\
\hline pgm & NM & Phosphoglycerate mutase, PGM & $411^{*}$ \\
\hline$p h a-1$ & 47 & Resistance to phage SPO1 & 405 \\
\hline$p h a-2$ & 280 & Resistance to phage SPP1 & 653 \\
\hline$p h a-3$ & & See $g g a A$ and $g g a B$ & \\
\hline pha-4 & 295 & Resistance to phage & 136 \\
\hline phe $A$ & 240 & Phenylalanine requirement; prephenate dehydratase & $763^{*}$ \\
\hline pheB & 240 & Chorismate mutase & $763 *$ \\
\hline phes & 254 & Phenylalanyl-tRNA synthetase $\alpha$ subunit & $72 \#, 73 *$ \\
\hline phe T & 254 & Phenylalanyl-tRNA synthetase $\beta$ subunit & $72 \#, 73 *$ \\
\hline$p h l$ & & See $r p s L$ & \\
\hline pho $A$ & 72 & Alkaline phosphatase $\mathrm{A} ;$ pho $A I V$ & $316^{*}, 317^{*}, 525$ \\
\hline pho AIII & 45 & Alkaline phosphatase III; $p h o B$ & $63^{*}, 316,317^{*}$ \\
\hline pho AIV & & See pho $A$ & \\
\hline phoB & & See $p h o A I I I$ & \\
\hline phoP & 258 & $\begin{array}{l}\text { Regulation of alkaline phosphatase and phosphodiesterase; homologous to } p h o B \text { of } \\
\text { E. coli }\end{array}$ & $676^{*}$ \\
\hline$p h o \mathrm{R}$ & 258 & $\begin{array}{l}\text { Regulation of alkaline phosphatase and phosphodiesterase; homologous to phoR of } \\
\text { E. coli }\end{array}$ & $677^{*}$ \\
\hline phos & 114 & Constitutive alkaline phosphatase & 577 \\
\hline pho $T$ & 248 & Constitutive alkaline phosphatase & 583 \\
\hline
\end{tabular}


Table 1 (cont.)

\begin{tabular}{|c|c|c|c|}
\hline $\begin{array}{l}\text { Gene } \\
\text { symbol }\end{array}$ & $\begin{array}{c}\text { Map } \\
\text { position }\end{array}$ & $\begin{array}{c}\text { Functions, products, phenotypes, other characteristics, former or } \\
\text { alternative symbols }\end{array}$ & Reference \\
\hline$p k s A$ & & See $p k s L$ & \\
\hline plesF & 152 & Polyketide synthases & $15^{*}, 673^{*}$ \\
\hline$p k s G$ & 152 & Polyketide synthases & $15^{*}, 673^{*}$ \\
\hline$p k s H$ & 152 & Polyketide synthases & $15^{*}, 673^{*}$ \\
\hline pksI & 152 & Polyketide synthases & $15^{*}, 673^{*}$ \\
\hline$p k s J$ & 152 & Polyketide synthases & $15^{*}, 673^{*}$ \\
\hline$p k s K$ & 152 & Polyketide synthases & $15^{*}, 673^{*}$ \\
\hline$p k s L$ & 152 & Polyketide synthase; out $G$, out $H, p k s . A, p k s X$ & $15^{*}, 221 \#, 673^{*}$ \\
\hline$p k s M$ & 152 & Polyketide synthases; $p k s Y$ & $15 *, 673^{*}$ \\
\hline$p k s X$ & & See $p k s L$ & \\
\hline$p k s Y$ & & See $p k s M$ & \\
\hline$p m i$ & 310 & Probable mannose-6-phosphate isomerase & $436^{*}$ \\
\hline$p n p$ & 211 & Putative purine nucleoside phosphorylase & $834^{*}$ \\
\hline$p n p A$ & 140 & Polynucleotide phosphorylase & $425^{*}$ \\
\hline pol $A$ & 257 & DNA polymerase I & $393 *, 561 \#$ \\
\hline polc & 147 & $\begin{array}{l}\text { DNA synthesis, mutator, azopyrimidique resistance; homologous to polC (dnaE) } \\
\text { and } d n a Q(m u t D) \text { of } E \text {. coli }(\alpha \text { and } \varepsilon \text { subunits of DNA polymerase III, carrying } \\
\text { respectively polymerase and } 3^{\prime} \rightarrow 5^{\prime} \text { exonuclease activities); dnaF, dnaP, mut-1, } \\
a z p-12\end{array}$ & $258^{*}, 650$ \\
\hline pon $A$ & 200 & $\begin{array}{l}\text { Penicillin-binding proteins } 1 \mathrm{~A} \text { and } 1 \mathrm{~B} \text {; cell wall synthesis; transglycosilase and } \\
\text { transpeptidase }\end{array}$ & $594^{*}, 719^{*}$ \\
\hline$p p i B$ & 210 & Peptide-prolyl-isomerase; $45 \%$ homologous to $p p i B$ of E. coli & $295^{*}, 717^{*}$ \\
\hline$p p s-1$ & & See $p p s . A$ & \\
\hline$p p s-2$ & & See $p p s B$ & \\
\hline$p p s-3$ & & See $p p s C$ & \\
\hline$p p s A$ & 175 & Peptide synthetase; $p p_{s-1}$ & $756^{*}$ \\
\hline$p p s B$ & 175 & Peptide synthetase; $p p s-2$ & $756^{*}$ \\
\hline$p p s C$ & 175 & Peptide synthetase; $p p s-3$ & $756^{*}$ \\
\hline $\operatorname{prfB}$ & 305 & Peptide-chain-release factor 2 & $559 *$ \\
\hline prk. $A$ & 69 & Novel serine protein kinase & $183^{*}, 525$ \\
\hline $\operatorname{pro} A$ & 115 & Proline requirement; $\gamma$-glutamylphosphate reductase & $90,544 *$ \\
\hline proB & 115 & Proline requirement; $\gamma$-glutamyl kinase & $90,544 *$ \\
\hline prs & 7 & Phosphoribosyl diphosphate synthetase & $298,522 \#, 523 *$ \\
\hline prs-11 & 298 & Protein secretion & 371,481 \\
\hline prs-33 & 149 & Protein secretion & 371,481 \\
\hline $\operatorname{prs} A$ & 76 & Lipoprotein involved in protein secretion & $371,372 *, 525$ \\
\hline $\operatorname{prt} \mathrm{R}$ & & See $\operatorname{deg} R$ & \\
\hline pss & $\mathrm{NM}$ & Phosphatidylserine synthase & $547^{*}$ \\
\hline ptg & 129 & Peptidoglycan biosynthesis & 91 \\
\hline ptm & 107 & Pyrithymine resistance & 208 \\
\hline$p t s G$ & 118 & $\begin{array}{l}\text { An ORF with homology to the E. coli ptsG locus (glucose-specific Enzyme II of } \\
\text { phosphotransferase system has been identified to } p t s H) ; c r r, p t s X\end{array}$ & $\begin{array}{l}141^{*}, 233 \#, 234^{*}, \\
750^{*}\end{array}$ \\
\hline$p t s H$ & 118 & Phosphoenolpyruvate: phosphotransferase, $\mathrm{Hpr}$ & $233 \#, 234 *$ \\
\hline pts $I$ & 118 & Phosphoenolpyruvate: phosphotransferase, Enzyme I & $233 \#, 234^{*}$ \\
\hline$p t s X$ & & See $p t s G$ & \\
\hline$p u p A$ & NM & Adenosine phosphorylase & 257 \\
\hline pupG & NM & Inosine-guanosine phosphorylase & $529 \#$ \\
\hline pur $A$ & 355 & Adenylsuccinate synthetase & $432 *, 585 \#, 660 \#$ \\
\hline pur $B$ & 55 & Purine requirement; adenylosuccinate lyase; formerly purE & $65^{*}, 159^{*}$ \\
\hline purC & 55 & $\begin{array}{l}\text { Purine requirement; phosphoribosyl-aminoimidazole-succinocarboxamide } \\
\text { synthetase }\end{array}$ & $65^{*}, 159^{*}$ \\
\hline purD & 55 & $\begin{array}{l}\text { Purine requirement; phosphoribosylglycamide synthetase; previous purD is now } \\
\text { purK }\end{array}$ & $65^{*}, 159^{*}$ \\
\hline
\end{tabular}


Table 1 (cont.)

\begin{tabular}{|c|c|c|c|}
\hline $\begin{array}{l}\text { Gene } \\
\text { symbol }\end{array}$ & $\begin{array}{l}\text { Map } \\
\text { position }\end{array}$ & $\begin{array}{l}\text { Functions, products, phenotypes, other characteristics, former or } \\
\text { alternative symbols }\end{array}$ & Reference \\
\hline purE & 55 & $\begin{array}{l}\text { Purine requirement; phosphoribosylaminoimidazole carboxylase I; previous purE is } \\
\text { now purB }\end{array}$ & $65 *, 159 *$ \\
\hline purF & 55 & Purine requirement; amido-phosphoribosyltransferase previously designated pur $B$ & $65^{*}, 430^{*}$ \\
\hline purH & 55 & $\begin{array}{l}\text { Purine requirement; phosphoribosylaminoimidazole/carboxamide } \\
\text { formyltransferase/IMP (inosinic acid) cyclohydrolase; } p u r H J\end{array}$ & $65^{*}, 159 *$ \\
\hline purHJ & & See purH & \\
\hline purK & 55 & Purine requirement; phosphoribosylaminoimidazole carboxylase II; formerly purD & $65^{*}, 159^{*}$ \\
\hline purL & 55 & Purine requirement; $5^{\prime}$-phosphoribosyl- $N$-formylglycinamide synthetase II & $65^{*}, 159^{*}$ \\
\hline purM & 55 & Phosphoribosylaminoimidazole synthetase; atb & $65^{*}, 159^{*}$ \\
\hline $\operatorname{purN}$ & 55 & Purine requirement; phosphoribosylglycamide formyltransferase & $65^{*}, 159 *$ \\
\hline purQ & 55 & Purine requirement; 5 -phosphoribosyl- $N$-formylglycinamide synthetase II & $65^{*}, 159 *$ \\
\hline purR & 6 & Repressor of the pur operon & $813^{*}$ \\
\hline pur $T$ & 21 & 5'-Phosphoribosyl-1-glycinamide transformylase & $661 *, 662$ \\
\hline pyc $A$ & 127 & Pyruvate carboxylase & 494\# \\
\hline$p y k A$ & 260 & Pyruvate kinase & $393 *$ \\
\hline $\operatorname{pyr} A A$ & 139 & $\begin{array}{l}\text { Glutaminase of carbamyl phosphate synthetase; mutation confers fluoracyl } \\
\text { resistance; fur } A\end{array}$ & $\begin{array}{l}92,149,406 \#, 604^{*} \text {, } \\
772^{*}\end{array}$ \\
\hline $\operatorname{pyr} A B$ & 139 & Carbamyl-phosphate synthetase & $406 \#, 604 *, 772 *$ \\
\hline pyrB & 139 & Aspartate carbamoyltransferase & $406 \#, 604^{*}$ \\
\hline $\operatorname{pyr} C$ & 139 & Dihydroorotase & $406 \#, 604 *$ \\
\hline pyrD & 139 & Dihydroorotate dehydrogenase & $406 \#, 604 *$ \\
\hline pyrE & 139 & Orotate phosphoribosyltransferase; $p y r X$ & $406 \#, 604 *$ \\
\hline pyrF & 139 & Orotidine- $5^{\prime}$-phosphate decarboxylase & $406 \#, 604 *$ \\
\hline pyrG & & See $\operatorname{ctr} A$ & \\
\hline pyrP & 139 & Putative membrane-bound uracil permease & $772 *$ \\
\hline pyr $\mathrm{R}$ & 139 & Negative regulatory protein PyrR & $444 *, 772 *$ \\
\hline$p y r X$ & & See pyrE & \\
\hline $\operatorname{qcr} A$ & 202 & Menaquinone oxidase; Rieske iron-sulfur protein & $719^{*}, 863^{*}$ \\
\hline$q c r B$ & 202 & Cytochrome reductase; cytochrome $b c$ complex $b$ domain & $719 *, 863 *$ \\
\hline $\operatorname{qcr} C$ & 202 & Cytochrome $c$ reductase complex; cytochrome $c$ domain & $719^{*}, 863^{*}$ \\
\hline$q 0 \times A$ & 331 & Quinol oxidase & $225^{*}, 651^{*}$ \\
\hline$q \circ \times B$ & 331 & Quinol oxidase & $225^{*}, 651^{*}$ \\
\hline $\operatorname{qox} C$ & 331 & Quinol oxidase & $225^{*}, 651^{*}$ \\
\hline$q \circ \times D$ & 331 & Quinol oxidase & $225^{*}, 651^{*}$ \\
\hline $\mathrm{rac} E$ & 251 & Glutamate racemase & $825^{*}$ \\
\hline $\operatorname{rac} X$ & 296 & Apparent amino acid racemase & $592 *$ \\
\hline $\operatorname{rap} A$ & 115 & Response regulator aspartate phosphatase; spoOL & $566^{*}$ \\
\hline $\operatorname{rec} A$ & 149 & $\begin{array}{l}\text { Genetic recombination and radiation resistance; homologous to } \operatorname{rec} A \text { of } E \text {. coli; the } \\
\text { former } \operatorname{rec} E \text { mutations corresponds to alleles of } \operatorname{rec} A ; \operatorname{rec} E\end{array}$ & $\begin{array}{l}150,208^{*}, 300 \\
440 \#, 733^{*}, 845\end{array}$ \\
\hline $\operatorname{rec} B$ & 240 & Genetic recombination and radiation resistance & 300 \\
\hline $\operatorname{rec} D$ & & See $\operatorname{rec} \mathrm{R}$ & \\
\hline recE & & See $\operatorname{rec} A$ & \\
\hline $\operatorname{rec} F$ & 0 & Genetic recombination and radiation resistance & $482 *$ \\
\hline $\operatorname{rec} G$ & 199 & Genetic recombination and radiation resistance & $456,561 \#$ \\
\hline $\mathrm{recH}$ & 69 & Genetic recombination and radiation resistance & 457 \\
\hline recI & 74 & Genetic recombination and radiation resistance & 457 \\
\hline recL & UC & Genetic recombination and radiation resistance; linked to $c y s A$ & 150 \\
\hline $\operatorname{rec} M$ & & See $\operatorname{rec} R$ & \\
\hline $\operatorname{rec} N$ & 217 & Genetic recombination, homologous to $E$. coli recN & $775^{*}$ \\
\hline $\operatorname{rec} P$ & 11 & $\begin{array}{l}\text { Reduced recombination and high sensitivity to mitomycin C; prevents } \phi 105 \\
\text { restriction in } B s u \mathrm{R}^{+} \text {hosts; formerly rec-149 }\end{array}$ & 17 \\
\hline $\operatorname{rec} \mathrm{R}$ & 0 & $\begin{array}{l}\text { Genetic recombination and radiation resistance; homologous to } r e c R \text { of E. coli; } \\
\operatorname{rec} D, \operatorname{rec} M\end{array}$ & $18^{*}, 19,456,738$ \\
\hline
\end{tabular}


Table 1 (cont.)

\begin{tabular}{|c|c|c|c|}
\hline $\begin{array}{l}\text { Gene } \\
\text { symbol }\end{array}$ & $\begin{array}{l}\text { Map } \\
\text { position }\end{array}$ & $\begin{array}{c}\text { Functions, products, phenotypes, other characteristics, former or } \\
\text { alternative symbols }\end{array}$ & Reference \\
\hline $\operatorname{rel} A$ & 248 & ATP:GTP 3'-phosphotransferase; resistance to aminotriazole & 242,703 \\
\hline $\mathrm{relC}$ & & See $r p l K$ & \\
\hline relG & 13 & Defect in glucose uptake & 600 \\
\hline $\operatorname{res} A$ & 208 & Regulatory role in respiration, essential gene & $717^{*}, 748$ \\
\hline$r e s B$ & 208 & Regulatory role in respiration, essential gene & $717^{*}, 748$ \\
\hline $\operatorname{res} C$ & 208 & Regulatory role in respiration, essential gene & $717^{*}, 748$ \\
\hline $\operatorname{res} D$ & 208 & Regulatory role in respiration, signal transduction regulator & $717^{*}, 748$ \\
\hline resE & 208 & Regulatory role in respiration, protein kinase & $717^{*}, 748$ \\
\hline$r e v-4$ & 323 & $\begin{array}{l}\text { Suppressor of some pleiotropic effects (but not asporogeny of spoo mutations); } \\
\text { suppresses effect on sporulation of various drug-resistance mutations; } a b r A\end{array}$ & $762^{*}, 770$ \\
\hline$r f m$ & & See $r p o B$ & \\
\hline rho & 323 & Transcription termination factor Rho & 605 \\
\hline $\operatorname{rib} A$ & 209 & Riboflavin requirement, GTP cyclohydrolase & $\begin{array}{l}358,469 *, 470 * \\
471,606 \#\end{array}$ \\
\hline$r i b B$ & 209 & Riboflavin synthase & $\begin{array}{l}358,469 *, 471 \\
606 \#, 667\end{array}$ \\
\hline $\operatorname{ribC}$ & 147 & Provide constitutive expression of the riboflavin operon & 376 \\
\hline $\operatorname{ribD}$ & 209 & Riboflavin requirement & $\begin{array}{l}358,469 *, 470 * \\
471,606 \#\end{array}$ \\
\hline ribG & 209 & Riboflavin requirement, deaminase & $\begin{array}{l}358,469 *, 470 * \\
471,607 \#\end{array}$ \\
\hline ribH & 209 & Riboflavin requirement, lumazine synthase ( $\beta$ subunit) & $\begin{array}{l}358,424^{*}, 469 * \\
470^{*}, 471,607 \#\end{array}$ \\
\hline$r i b T$ & 209 & Riboflavin requirement, reductase & $\begin{array}{l}358,469 *, 470^{*} \\
471,607 \#\end{array}$ \\
\hline $\operatorname{rip} X$ & 211 & Similar to site-specific recombinases/integrases & 671 \\
\hline rna-53 & 312 & Temperature-sensitive, RNA-sensitive & 622 \\
\hline$r n p A$ & 360 & Homologous to $r n p A$ of E. coli & $535^{*}$ \\
\hline$r n p B$ & 199 & The RNA component of RNase P & $455^{*}, 614^{*}$ \\
\hline $\operatorname{roc} A$ & 327 & Arginine utilization & $225^{*}$ \\
\hline $\operatorname{roc} B$ & 327 & Arginine utilization & $225^{*}$ \\
\hline $\operatorname{roc} C$ & 327 & Arginine utilization & $225^{*}$ \\
\hline $\operatorname{roc} D$ & 354 & Arginine utilization; ornithine aminotransferase & $93 *, 211$ \\
\hline rocE & 354 & Arginine utilization; amino acid permease & $93^{*}, 211$ \\
\hline $\operatorname{rocF}$ & 354 & Arginine utilization; arginase & $93 *, 211$ \\
\hline $\operatorname{rac} \mathrm{R}$ & 354 & Positive regulatory protein & $93^{*}$ \\
\hline $\operatorname{rod} B$ & & See $m r e D$ & \\
\hline $\operatorname{rod} C$ & & See $\operatorname{tag} F$ & \\
\hline $\operatorname{rod} D$ & 198 & Cell-wall-defective; previous rodD is now tagE & 583 \\
\hline$r p h$ & 251 & RNase PH; suppression of cold-sensitive mutations in E. coli & $123 *$ \\
\hline$r p l A$ & 11 & Ribosomal protein BL1, chloramphenicol resistance II & $132,339 *$ \\
\hline$r p l B$ & 12 & Ribosomal protein L2 (BL2) & $704,859 *$ \\
\hline rplC & 12 & Ribosomal protein L3 (BL3); probably micrococcin resistance & $129,859 *$ \\
\hline$r p l D$ & 12 & Ribosomal protein L4 & $859^{*}$ \\
\hline rple & 12 & Ribosomal protein L5 (BL6) & $283 *$ \\
\hline$r p l F$ & 12 & Ribosomal protein L6 (BL8) & $129,599 *$ \\
\hline rplI & 356 & Ribosomal protein L9 & $539 *$ \\
\hline rplj & 11 & Ribosomal protein L10 (BL5) & $132,858^{*}$ \\
\hline rplK & 11 & Ribosomal protein L11 (BL11); thiostrepton resistance; relC & $132,339 *$ \\
\hline$r p l L$ & 11 & Ribosomal protein L12 (BL9); chloramphenicol resistance VI & $64 *, 132$ \\
\hline$r p l M$ & 13 & Ribosomal protein L13 & $846^{*}$ \\
\hline$r p l N$ & 12 & Ribosomal protein L14 & $283 *$ \\
\hline rplo & 12 & Ribosomal protein L15; chloramphenicol resistance III & $505^{*}, 551$ \\
\hline
\end{tabular}


Table 1 (cont.)

\begin{tabular}{|c|c|c|c|}
\hline $\begin{array}{l}\text { Gene } \\
\text { symbol }\end{array}$ & $\begin{array}{l}\text { Map } \\
\text { position }\end{array}$ & $\begin{array}{c}\text { Functions, products, phenotypes, other characteristics, former or } \\
\text { alternative symbols }\end{array}$ & Reference \\
\hline$r p l P$ & 12 & Ribosomal protein L16 & $283^{*}$ \\
\hline rplQ & 12 & Ribosomal protein L17 (BL15) & $69^{*}$ \\
\hline$r p l R$ & 12 & Ribosomal protein L18 & $740^{*}$ \\
\hline$r p l T$ & 256 & B. stearothermophilus rplT homologue; L20 & $825^{*}$ \\
\hline rplU & 241 & Ribosomal protein L21 (BL20) & 128 \\
\hline rplV & 12 & Ribosomal protein L22 (BL17); erythromycin resistance & $704,859^{*}$ \\
\hline$r p l W$ & 12 & Ribosomal protein L23 & $859 *$ \\
\hline$r p l X$ & 12 & Ribosomal protein L24 (BL23) & $283^{*}, 682^{*}$ \\
\hline $\operatorname{rpm} A$ & 241 & Ribosomal protein L27 (BL24) & $181 *$ \\
\hline$r p m B$ & 140 & Ribosomal protein L28 & $409 *$ \\
\hline$r p m C$ & 12 & Ribosomal protein L29 & $283^{*}$ \\
\hline$r p m D$ & 12 & Ribosomal protein L30 (BL27) & $505^{*}$ \\
\hline$r p m E$ & 323 & Ribosomal protein L31 & 605 \\
\hline $\operatorname{rpm} G$ & 11 & Ribosomal protein L33 & $339 *$ \\
\hline$r p m H$ & 0 & Ribosomal protein L34 & $482 *$ \\
\hline$r p m I$ & 256 & B. stearothermophilus rpmI homologue; L35 & $825^{*}$ \\
\hline rpmJ & 12 & Ribosomal protein $\mathrm{B}$ & $599 *$ \\
\hline$r p o A$ & 12 & RNA polymerase $\alpha$ subunit & $739 *$ \\
\hline rpoB & 11 & $\beta$ subunit of RNA polymerase; rifampin resistance; $c r s E, r f m$ & $64 *, 598 \#, 742$ \\
\hline rpoc & 11 & $\beta$ subunit of RNA polymerase; streptolydigin resistance; $l p m$, std & $64 *, 598 \#$ \\
\hline$r p o D$ & & See $\operatorname{sig} A$ & \\
\hline rpoE & 323 & $\delta$ subunit of RNA polymerase & $391 *$ \\
\hline$r p o F$ & & See $\operatorname{sig} B$ & \\
\hline $\operatorname{rps} C$ & 12 & Ribosomal protein S3 (BS3) & $704,859 *$ \\
\hline$r p s D$ & 263 & Ribosomal protein S4 (BS4) & $244^{*}$ \\
\hline rpsE & 12 & Ribosomal protein $\mathrm{S} 5$; spectinomycin resistance; spc $A$ & $131,857^{*}$ \\
\hline$r p s F$ & 358 & Ribosomal protein S6 (BS9) & $130,539 *$ \\
\hline$r p s G$ & 11 & Ribosomal protein S7 (BS7) & 132 \\
\hline rps $H$ & 12 & Ribosomal protein S8 (BS8) & $283^{*}$ \\
\hline rpsI & 13 & Ribosomal protein S9 (BS10) & $131,846^{*}$ \\
\hline rps $J$ & 11 & Ribosomal protein $\mathrm{S} 10$ (BS13); tet $A$ & 704 \\
\hline rps $K$ & 12 & Ribosomal protein S11 (BS11) & $739 *$ \\
\hline rps $L$ & 11 & Ribosomal protein $\mathrm{S} 12(\mathrm{BS} 12, \operatorname{str} A)$; streptomycin resistance; fun, phl, str $A$ & $129,230,282,319$ \\
\hline$r p s M$ & 12 & Ribosomal protein $\mathrm{S} 13$ & $739 *$ \\
\hline $\operatorname{rps} N$ & 12 & Ribosomal protein $\mathrm{S} 14$ & $283 *$ \\
\hline$r p s$ & 140 & Ribosomal protein S15 (BS18) & $425^{*}$ \\
\hline$r p s P$ & 147 & Ribosomal protein S16 (BS17) & $130,208,310^{*}$ \\
\hline rps $Q$ & 12 & Ribosomal protein S17 (BS16) & $283^{*}$ \\
\hline$r p s \mathrm{R}$ & 358 & Ribosomal protein $\mathrm{S} 18$ & $539 *$ \\
\hline$r p s S$ & 12 & Ribosomal protein S19 (BS19) & $551,859 *$ \\
\hline$r p s T$ & 12 & Ribosomal protein S20 (BS20) & 551 \\
\hline $\operatorname{rrn} A$ & 0 & rRNA operon & $533^{*}$ \\
\hline$r r n B$ & 275 & rRNA operon & $239 *$ \\
\hline$r r n D$ & 67 & rRNA operon & $387 \#$ \\
\hline$r r n E$ & 45 & rRNA operon & $387 \#, 644^{*}$ \\
\hline$r r n F$ & NM & rRNA operon known to exist but not cloned or mapped & 66 \\
\hline$r r n G$ & 14 & rRNA operon & $66 \#$ \\
\hline$r r n H$ & 14 & rRNA operon & $66 \#$ \\
\hline$r r n I$ & 13 & rRNA operon & $66 \#$ \\
\hline$r r n J$ & 10 & rRNA operon & 818\# \\
\hline $\mathrm{rrnO}$ & 0 & tRNA operon & $533^{*}$ \\
\hline$r r n W$ & 10 & rRNA operon & $818 \#$ \\
\hline
\end{tabular}


Table 1 (cont.)

\begin{tabular}{|c|c|c|c|}
\hline $\begin{array}{l}\text { Gene } \\
\text { symbol }\end{array}$ & $\begin{array}{c}\text { Map } \\
\text { position }\end{array}$ & $\begin{array}{c}\text { Functions, products, phenotypes, other characteristics, former or } \\
\text { alternative symbols }\end{array}$ & Reference \\
\hline$r s b U$ & 38 & $\begin{array}{l}\text { Predicted RsbU product has significant similarity to RsbX negative regulator of } \sigma^{\mathbf{B}} \text {; } \\
\text { product involved in regulation of } s i g B \text { activity }\end{array}$ & $791^{*}, 826^{*}$ \\
\hline$r s b V$ & 38 & Positive regulator of $\sigma^{\mathrm{B}}$-dependent gene expression & $70,826^{*}$ \\
\hline$r s b W$ & 38 & Negative regulator of $\sigma^{\mathrm{B}}$-dependent gene expression & $70,826 *$ \\
\hline$r s b X$ & 38 & Negative effector of $\sigma^{\mathrm{B}}$-dependent gene expression & $70,71,826^{*}$ \\
\hline$r t p$ & 178 & Replication terminator protein & $7^{*}$ \\
\hline $\operatorname{rvt} A$ & & See $s p o 0 A$ & \\
\hline $\operatorname{sac} A$ & 330 & $\beta$-Fructofuranosidase (sucrase) & $190^{*}$ \\
\hline$s a c B$ & 296 & Levansucrase & $726^{*}$ \\
\hline $\operatorname{sac} C$ & 233 & Levanase & $442 *$ \\
\hline sacL & & See $\operatorname{lev} D$ and $\operatorname{lev} E$ & \\
\hline $\operatorname{sac} P$ & 330 & Sucrose transport; Enzyme II of sucrose phosphotransferase system & $189 *$ \\
\hline $\operatorname{sac} Q$ & & See $\operatorname{deg} Q$ & \\
\hline $\operatorname{sac} \mathrm{R}$ & 296 & Constitutive for levansucrase & $725^{*}$ \\
\hline sacs & & See $\operatorname{sac} X$ and $\operatorname{sac} Y$ & \\
\hline $\operatorname{sac} T$ & 330 & Constitutive $\beta$-fructofuranosidase production & $156^{*}, 404$ \\
\hline $\operatorname{sac} \mathrm{U}$ & & See $\operatorname{deg} S$ & \\
\hline $\operatorname{sac} V$ & 40 & Regulatory gene for levansucrase & $441 *$ \\
\hline $\operatorname{sac} X$ & 332 & Levansucrase regulation; sacS & $32 \#, 726^{*}$ \\
\hline $\operatorname{sac} Y$ & 332 & Levansucrase regulation; antiterminator; sac $S$ & $32 \#, 878^{*}$ \\
\hline $\operatorname{sap} A$ & 114 & $\begin{array}{l}\text { Mutations overcome the sporulation-phosphatase-negative phenotype of early- } \\
\text { blocked spo mutants }\end{array}$ & 579 \\
\hline $\operatorname{sap} B$ & 56 & $\begin{array}{l}\text { Mutations overcome sporulation-phosphatase-negative phenotype of early blocked } \\
\text { spo mutations }\end{array}$ & 577 \\
\hline sas & & See $\operatorname{spoII} A A$ & \\
\hline$s b c D$ & 98 & Homologous to exonuclease SbcD of E. coli & 374 \\
\hline$s b p$ & 134 & Small basic protein & $168^{*}, 636^{*}$ \\
\hline $\operatorname{sco} A$ & 109 & $\begin{array}{l}\text { Sporulation control; protease and phosphatase overproduction; delayed spore } \\
\text { formation }\end{array}$ & 465 \\
\hline $\operatorname{sco} C$ & & See $h p r$ & \\
\hline$s c o D$ & & See $\operatorname{kin} A$ & \\
\hline scr & 0 & Small cytoplasmic RNA; homologous to ffs of E. coli & $18^{*}, 736,738^{*}$ \\
\hline$s d h A$ & 252 & $\begin{array}{l}\text { Flavoprotein subunit of succinate dehydrogenase; note that the } s d h \text { loci have been } \\
\text { reorganized; } c i t F\end{array}$ & $574 *$ \\
\hline$s d b B$ & 252 & Iron protein subunit of succinate dehydrogenase & $574^{*}$ \\
\hline$s d b C$ & 252 & Cytochrome $b_{558} ;$ subunit of succinate dehydrogenase complex & $428 *$ \\
\hline $\sec A$ & 305 & $\begin{array}{l}\text { Secretion of proteins; homologous to } \sec A \text { of E. coli; mutation confers resistance to } \\
\text { sodium azide; } l_{s s} G, t_{s-341} \text { div-341, aq } i\end{array}$ & $\begin{array}{l}76,305,364^{*}, 475 \\
643^{*}\end{array}$ \\
\hline $\sec E$ & 11 & Pre-protein translocase SecE subunit & $339 *$ \\
\hline $\sec Y$ & 12 & Secretion of proteins; homologous to $\sec Y$ of E. coli & $505^{*}, 740^{*}$ \\
\hline $\operatorname{sen} S$ & 69 & Enhances expression of genes for several extracellular proteins & $803^{*}$ \\
\hline $\operatorname{ser} A$ & 207 & Requirement for serine; glycerophosphate dehydrogenase & $429,717^{*}$ \\
\hline $\operatorname{ser} C$ & 257 & Requirement for serine; defined by Tn917 insertion & 784 \\
\hline $\operatorname{ser} R$ & 26 & Serine resistance & $839 *$ \\
\hline $\operatorname{ser} S$ & 0 & Seryl-tRNA synthetase & $539 *$ \\
\hline$s f p$ & 31 & Surfactin production; highly homologous to the E. coli ent $D$ gene & $243 *, 510$ \\
\hline $\operatorname{sig} A$ & 223 & Major RNA polymerase sigma factor, $\sigma^{A}$ or $\sigma^{43} ; r p o D, \operatorname{crs} A$ & $597,742,802 *$ \\
\hline $\operatorname{sig} B$ & 38 & RNA polymerase sigma factor, $\sigma^{\mathrm{B}}$ or $\sigma^{37} ; r p o F$ & $\begin{array}{l}50,70,71,155^{*}, \\
826\end{array}$ \\
\hline $\operatorname{sigC}$ & NM & RNA polymerase sigma factor, $\sigma^{\mathrm{C}}$ or $\sigma^{32}$ & 342 \\
\hline $\operatorname{sig} D$ & 142 & RNA polymerase sigma factor, $\sigma^{\mathrm{D}}$ or $\sigma^{28}$; autolytic enzymes, allelic to $f a B$ & $276^{*}, 438,439,586$ \\
\hline sigE & 135 & RNA polymerase sigma factor, $\sigma^{\mathrm{E}}$ or $\sigma^{29} ;$ spoIIGB & $\begin{array}{l}168^{*}, 447^{*}, 569 \\
629,730^{*}, 768^{*}\end{array}$ \\
\hline
\end{tabular}


Table 1 (cont.)

\begin{tabular}{|c|c|c|c|}
\hline $\begin{array}{l}\text { Gene } \\
\text { symbol }\end{array}$ & $\begin{array}{c}\text { Map } \\
\text { position }\end{array}$ & $\begin{array}{c}\text { Functions, products, phenotypes, other characteristics, former or } \\
\text { alternative symbols }\end{array}$ & Reference \\
\hline $\operatorname{sig} F$ & 211 & RNA polymerase sigma factor, $\sigma^{\mathrm{F}} ;$ spoII $A C$ & $\begin{array}{l}163^{*}, 185^{*}, 670 \\
744^{*}, 832,834^{*}\end{array}$ \\
\hline $\operatorname{sig} G$ & 135 & RNA polymerase sigma factor, $\sigma^{\alpha} ; s p o I I I G$ & $\begin{array}{l}168^{*}, 352^{*}, 446^{*} \\
744^{*}\end{array}$ \\
\hline sigH & 11 & RNA polymerase sigma factor, $\sigma^{\mathrm{H}}$ or $\sigma^{\mathbf{3 0}} ; s p o 0 \mathrm{H}$ & $154^{*}$ \\
\hline $\operatorname{sigK}$ & & See spoIIIC & \\
\hline $\operatorname{sig} L$ & 295 & RNA polymerase sigma factor, $\sigma^{54}, \sigma^{\mathrm{L}}$ & $157^{*}$ \\
\hline $\operatorname{sig} Z$ & 232 & RNA polymerase subunit sigma factor & $62^{*}$ \\
\hline $\sin$ & & See $\sin R$ & \\
\hline $\sin I$ & 219 & Sporulation inhibition at high-copy-number & $216^{*}$ \\
\hline $\sin \mathrm{R}$ & 219 & Sporulation inhibition at high-copy-number; $\sin , f a D$ & $216^{*}, 586,678^{*}$ \\
\hline sips & 209 & Signal peptidase I & $717^{*}, 774^{*}$ \\
\hline skin & 227 & $\begin{array}{l}226-230^{\circ} \text {; genetic element of } 48 \mathrm{~kb} \text { (most probably is defective prophage) inserted } \\
\text { between spoIVCB and spoIIIC; inside sigK gene }\end{array}$ & $751 *$ \\
\hline slp & 125 & Small lipoprotein; pal & $278^{*}, 824$ \\
\hline smo & 295 & Smooth/rough colony morphology & 218\# \\
\hline sms & 10 & Homologous to ATP-dependent protease & 541 \\
\hline soj & & See $\operatorname{spo0J} A$ & \\
\hline $\operatorname{spc} A$ & & See $r p s E$ & \\
\hline $\operatorname{spc} B$ & 146 & Spectinomycin resistance & 421 \\
\hline $\operatorname{spcD}$ & 2 & Spectinomycin dependence & 281 \\
\hline$s p d A$ & 288 & Sporulation derepressed; low pyruvate carboxylase activity & 161 \\
\hline spe & NM & Endonuclease-excising spore photoproducts; formerly ssp-1 & 499 \\
\hline spl & 118 & Spore photoproduct lyase & $171^{*}, 172^{*}$ \\
\hline $\operatorname{spm} A$ & 208 & Spore-maturation operon & $595,717^{*}$ \\
\hline$s p m B$ & 208 & Spore-maturation operon & $595,717^{*}$ \\
\hline $\operatorname{spo} 0 \mathrm{~A}$ & 217 & Sporulation; mutants blocked at stage $0 ; r v t A, s p o 0 C$, spo0G & $182^{*}, 304^{*}, 684$ \\
\hline spoOB & 240 & Sporulation; mutants blocked at stage 0 ; part of phosphorelay; spoOD & $181^{*}$ \\
\hline spooc & & See $s p o 0 A$ & \\
\hline spooD & & See $s p o 0 B$ & \\
\hline spoot & 115 & $\begin{array}{l}\text { Stage } 0 \text { sporulation; oligosporogenous mutations giving stage } 0 \text { block; less } \\
\text { pleiotropic than } s p 00 A, s p o 0 B \text { or } s p o 0 F \text { mutations }\end{array}$ & $560^{*}$ \\
\hline spoof & 323 & Stage 0 sporulation; part of phosphorelay & $761^{*}$ \\
\hline $\operatorname{spo} 0 \mathrm{G}$ & & See $s p o 0 A$ & \\
\hline spoOH & & See sigH & \\
\hline $\operatorname{spooj} A$ & 359 & $\begin{array}{l}\text { Allele } 87 \text {; originally placed in this locus was found to be in a distinct locus; named } \\
\text { spoIIIJ; soj,spoCM }\end{array}$ & $\begin{array}{l}74,164 \#, 167^{*}, 327 \\
502^{*}, 538^{*}, 629\end{array}$ \\
\hline spoojB & 359 & Stage 0 sporulation; production of Spo0A-P & $305,327,502 *$ \\
\hline$s p o 0 K A$ & & See $o p p A$ & \\
\hline$s p o 0 \mathrm{~KB}$ & & See $o p p B$ & \\
\hline spoOKC & & See $o p p C$ & \\
\hline spoOKD & & See $o p p D$ & \\
\hline spoOKE & & See $o p p F$ & \\
\hline spooL & & See $\operatorname{rap} A$ & \\
\hline spoIIAA & 211 & Stage II sporulation; encoding an anti-anti-sigma-factor antagonist of spoII $A B$; sas & $\begin{array}{l}163 *, 185^{*}, 670 \\
832,834^{*}, 864\end{array}$ \\
\hline spoII $A B$ & 211 & Stage II sporulation; encoding an anti-sigma-factor for SigF and possibly SigG & $\begin{array}{l}163^{*}, 185^{*}, 670 \\
832,834^{*}\end{array}$ \\
\hline spoII $A C$ & & See $s i g F$ & \\
\hline spoIIB & 242 & Stage II sporulation & $434^{*}, 576$ \\
\hline spollC & & See spoIID & \\
\hline spollD & 316 & Stage II sporulation; spoIIC & $419 *, 576$ \\
\hline spoIIE & 8 & Stage II sporulation; spoIIH is an allele of spoIIE; spoIIH & $250^{*}$ \\
\hline
\end{tabular}


Table 1 (cont.)

\begin{tabular}{|c|c|c|c|}
\hline $\begin{array}{l}\text { Gene } \\
\text { symbol }\end{array}$ & $\begin{array}{l}\text { Map } \\
\text { position }\end{array}$ & $\begin{array}{c}\text { Functions, products, phenotypes, other characteristics, former or } \\
\text { alternative symbols }\end{array}$ & Reference \\
\hline spoIIF & & See $k i n A$ & \\
\hline spoIIGA & 135 & Stage II sporulation spoIIG operon & $\begin{array}{l}168^{*}, 447^{*}, 569 \\
629,730^{*}\end{array}$ \\
\hline spoIIGB & & See $s i g E$ & \\
\hline spoIIH & & See spoIIE & \\
\hline spoIIJ & & See $k$ in $A$ & \\
\hline spoIIM & 212 & Defined by $\operatorname{Tn} 917$ insertion; distinct from spoII $A$ & $649,705^{*}, 706$ \\
\hline spoIIP & 226 & Stage II sporulation & $194 *$ \\
\hline spoIIR & 321 & Stage II sporulation protein $\mathrm{R}$ & $353^{*}$ \\
\hline $\operatorname{spoIII} A A$ & 218 & Stage III sporulation & $164 \#, 248 \#, 324 *$ \\
\hline spoIII $A B$ & 218 & Stage III sporulation & $164 \#, 248 \#, 324 *$ \\
\hline spoIII $A C$ & 218 & Stage III sporulation & $249 *, 477$ \\
\hline spoIII AD & 218 & Stage III sporulation & $249 *, 477$ \\
\hline spoIII $A E$ & 218 & Stage III sporulation & $249 *, 477$ \\
\hline spoIII $A F$ & 218 & Stage III sporulation & $249 *, 477$ \\
\hline spoIII $A G$ & 218 & Stage III sporulation & $249 *, 477$ \\
\hline spoIII $A H$ & 218 & Stage III sporulation & $249 *, 477$ \\
\hline spoIIIC & 230 & $\begin{array}{l}\text { Initially designated as stage III sporulation, but very similar phenotype to spoIVC; } \\
3^{\prime} \text { end of } \operatorname{sig} K \text {; } \operatorname{sig} K\end{array}$ & $165^{*}, 380,731^{*}$ \\
\hline spoIIID & 317 & Stage III sporulation & $379 *, 576,728^{*}$ \\
\hline spoIIIE & 149 & $\begin{array}{l}\text { Stage III sporulation; gene required for post-septational chromosome } \\
\text { partitioning }\end{array}$ & $\begin{array}{l}87^{*}, 191^{*}, 193 \\
587 \#\end{array}$ \\
\hline spoIIIF & & See $\operatorname{spoVB}$ & \\
\hline spoIIIG & & See $\operatorname{sig} G$ & \\
\hline spolliJ & 360 & $\begin{array}{l}\text { Stage III sporulation; vegetatively expressed gene essential for } \sigma^{G} \text { activity at stage } \\
\text { III; previously spo0J87 }\end{array}$ & $167^{*}, 538^{*}$ \\
\hline spoIVA & 205 & Stage IV sporulation, spore-coat assembly protein; spoVP & $\begin{array}{l}147,429 \#, 624^{*} \\
649,729^{*}\end{array}$ \\
\hline spoIVB & 217 & Stage IV sporulation; maps immediately upstream of $s p 00 \mathrm{~A}$ & $576,775^{*}$ \\
\hline spoIVCA & 226 & Stage IV sporulation; spoIVC $A$ encodes a recombinase; cis $A$ & $\begin{array}{l}378^{*}, 656^{*}, 657 \\
731^{*}\end{array}$ \\
\hline spoIVCB & 226 & Stage IV sporulation; spoIVCB encodes the N-terminal half of SigK; cis $B$ & $378^{*}, 656^{*}$ \\
\hline spoIVFA & 241 & Stage IV sporulation; bof $B$ & $126^{*}, 164 \#$ \\
\hline spoIVFB & 241 & Stage IV sporulation; bofB & $126^{*}, 164 \#$ \\
\hline spoIVG & 97 & Stage IV sporulation & 576 \\
\hline spoV $A A$ & 211 & Stage V sporulation & $186^{*}, 717^{*}, 838^{*}$ \\
\hline spoV $A B$ & 211 & Stage $V$ sporulation & $186^{*}, 717^{*}, 838^{*}$ \\
\hline spoV $A C$ & 211 & Stage $\mathrm{V}$ sporulation & $186^{*}, 717^{*}, 838^{*}$ \\
\hline spoV $A D$ & 211 & Stage $\mathrm{V}$ sporulation & $186^{*}, 717^{*}, 838^{*}$ \\
\hline spoVAE & 211 & Stage V sporulation & $186^{*}, 717^{*}, 838^{*}$ \\
\hline spo $V A F$ & 211 & Stage V sporulation & $186^{*}, 717^{*}, 838^{*}$ \\
\hline spoVB & 236 & $\begin{array}{l}\text { Stage } V \text { sporulation; the previous spoIIIF is part of spoVB; membrane protein } \\
\text { involved in cortex; spoIIIF }\end{array}$ & $186^{*}, 717^{*}, 838^{*}$ \\
\hline spoVC & 7 & Stage V sporulation; the two mutations placed in this locus may be in separate loci & $318^{*}$ \\
\hline spoVD & 133 & Stage V sporulation; closely related to $p b p B$ of E. coli & $168^{*}, 576$ \\
\hline spoVE & 134 & Stage V sporulation; homologous to ftsW of E. coli & $\begin{array}{l}85^{*}, 168^{*}, 293 \\
322^{*}, 344^{*}, 476\end{array}$ \\
\hline spoVFA & & See $d p a A$ & \\
\hline spoVFB & & See $d p a B$ & \\
\hline spoVG & 6 & Stage V sporulation; previously called $0.4 \mathrm{~kb}$ gene & $315^{*}, 675 \#$ \\
\hline spoVJ & & See spoVK & \\
\hline spoVK & 153 & Defined by $\operatorname{Tn} 917$ insertion; spoVJ & $173^{*}, 192,208,649$ \\
\hline spoVM & 140 & Defined by $\operatorname{Tn} 917$ insertion & $193,409^{*}, 649$ \\
\hline
\end{tabular}


Table 1 (cont.)

\begin{tabular}{|c|c|c|c|}
\hline $\begin{array}{l}\text { Gene } \\
\text { symbol }\end{array}$ & $\begin{array}{c}\text { Map } \\
\text { position }\end{array}$ & $\begin{array}{l}\text { Functions, products, phenotypes, other characteristics, former or } \\
\text { alternative symbols }\end{array}$ & Reference \\
\hline spoVN & & See ald & \\
\hline spoVP & & See spoIVA & \\
\hline spoVQ & 213 & Defined by Tn 917 insertion; less closely linked to $l y s$ than spoV $A$ & 649 \\
\hline spoVR & 72 & Stage V sporulation & $47^{*}, 525$ \\
\hline spoVs & 150 & Stage $V$ sporulation protein $S$ & $208^{*}, 618^{*}$ \\
\hline spoVIA & 255 & Stage VI sporulation & 336 \\
\hline spoVIB & 248 & Stage VI sporulation & 337 \\
\hline spoVIC & 293 & Stage VI sporulation & 335 \\
\hline spoVID & 244 & Stage VI sporulation & $46^{*}$ \\
\hline spocM & & See spo0JA & \\
\hline spoL & 226 & 'Decadent' sporulation & 36 \\
\hline $\operatorname{spr} A$ & NM & $\begin{array}{l}\text { Derepression of homoserine kinase, homoserine dehydrogenase and of the weak } \\
\text { threonine activity }(t d m) \text {; see bom }\end{array}$ & 786 \\
\hline sprE & & See $a p r E$ & \\
\hline $\operatorname{sps} A$ & 328 & Spore-coat polysaccharide & $225^{*}$ \\
\hline $\operatorname{sps} B$ & 328 & Spore-coat polysaccharide & $225^{*}$ \\
\hline $\operatorname{sps} C$ & 328 & Spore-coat polysaccharide & $225^{*}$ \\
\hline$s p s D$ & 328 & Spore-coat polysaccharide & $225^{*}$ \\
\hline spsE & 328 & Spore-coat polysaccharide & $225^{*}$ \\
\hline$s p s F$ & 328 & Spore-coat polysaccharide & $225^{*}$ \\
\hline $\operatorname{sps} G$ & 328 & Spore-coat polysaccharide & $225^{*}$ \\
\hline spsH & 328 & Spore-coat polysaccharide & $225 *$ \\
\hline$s p s I$ & 328 & Spore-coat polysaccharide & $225^{*}$ \\
\hline$s p s j$ & 328 & Spore-coat polysaccharide & $225^{*}$ \\
\hline$s p s K$ & 328 & Spore-coat polysaccharide & $225^{*}$ \\
\hline $\operatorname{srf} A$ & & See $\operatorname{srf} A A$ & \\
\hline $\operatorname{srf} A 1$ & & See $\operatorname{srf} A A$ & \\
\hline $\operatorname{srf} A 2$ & & See $\operatorname{srf} A B$ & \\
\hline $\operatorname{srf} A 3$ & & See $\operatorname{srf} A C$ & \\
\hline $\operatorname{srf} A 4$ & & See $\operatorname{srf} A D$ & \\
\hline $\operatorname{srf} A A$ & 31 & Surfactin production; $\operatorname{srf} A 1, \operatorname{srf} A, \operatorname{com} L$ & $\begin{array}{l}122 *, 204 *, 507 \# \\
509^{*}, 776,781 \#\end{array}$ \\
\hline $\operatorname{srf} A B$ & 31 & Surfactin production; $\operatorname{srf} A 2$ & $\begin{array}{l}122 *, 204^{*}, 507 \#, \\
509^{*}, 776\end{array}$ \\
\hline $\operatorname{srf} A C$ & 31 & Surfactin production; $\operatorname{srf} A^{3}$ & $\begin{array}{l}122 *, 507 \#, 509 * \\
776\end{array}$ \\
\hline $\operatorname{srf} A D$ & 31 & Surfactin production; $\operatorname{srf} A 4$ & $\begin{array}{l}122^{*}, 507 \#, 509^{*} \\
776\end{array}$ \\
\hline$s \mathrm{rm}$ & 14 & Modifies resistance of $s p c A$ strains & 94 \\
\hline ssa & 217 & $\begin{array}{l}\text { Alcohol-resistant sporulation; maps close to or in } s p o 0 A ; r v t \text { mutations have same } \\
\text { phenotype }\end{array}$ & 59 \\
\hline$s s b$ & 358 & Single-stranded DNA-binding protein & $539 *$ \\
\hline $\operatorname{ssp} A$ & 261 & One member of multigene family encoding small acid-soluble spore proteins & $118^{*}, 393^{*}$ \\
\hline $\operatorname{ssp} B$ & 75 & Small acid-soluble spore protein; similar product to $s p A$ & $21,117,118^{*}, 525$ \\
\hline$s s p C$ & 182 & Small acid-soluble spore protein; similar product to $s s p A$ & $116^{*}, 117$ \\
\hline$s s p D$ & 121 & Similar product to $s p A$ & $117,118^{*}$ \\
\hline$s s p E$ & 62 & Small acid-soluble spore protein; similar product to $s p A$ & $21,251 *$ \\
\hline$s s p F$ & 6 & Similar product to $s p A$; same as ' $0.3 \mathrm{~kb}$ gene' & $420,727^{*}$ \\
\hline std & & See $r p o C$ & \\
\hline $\operatorname{str} A$ & & See $r p s L$ & \\
\hline$s \operatorname{tr} B$ & 124 & Streptomycin resistance & 720 \\
\hline $\operatorname{str} C$ & 218 & Streptomycin-uptake-deficient, possible cytochrome oxidase regulator & 460 \\
\hline suA20 & 147 & Suppressor of $\mathrm{recH}$ mutations with increased ATP-dependent deoxyribonuclease & 208,389 \\
\hline
\end{tabular}


Table 1 (cont.)

\begin{tabular}{|c|c|c|c|}
\hline $\begin{array}{l}\text { Gene } \\
\text { symbol }\end{array}$ & $\begin{array}{c}\text { Map } \\
\text { position }\end{array}$ & $\begin{array}{l}\text { Functions, products, phenotypes, other characteristics, former or } \\
\text { alternative symbols }\end{array}$ & Reference \\
\hline$s u b$ & NM & Structural gene for peptide antibiotic subtilin; also called spaS & $38^{*}, 363^{*}$ \\
\hline sul & 9 & Sulfonilamide resistance; probably dihydropteroate synthase & $458 \#, 693^{*}$ \\
\hline sup-3 & 39 & Suppressor, lysyl-tRNA & $286,415,498$ \\
\hline sup-44 & 39 & Suppressor, leucyl-tRNA & 415,422 \\
\hline $\operatorname{tag}-3$ & & See $\operatorname{tag} F$ & \\
\hline $\operatorname{tag} A$ & 310 & Polyglycerol phosphate assembly and export & $453 *, 454$ \\
\hline $\operatorname{tag} B$ & 310 & Polyglycerol phosphate assembly and export & $453^{*}, 454$ \\
\hline $\operatorname{tag} C$ & 310 & Polyglycerol phosphate assembly and export; probably identical to $\operatorname{din} C ; \operatorname{din} C$ & $\begin{array}{l}113^{*}, 222,453^{*} \\
454,651\end{array}$ \\
\hline $\operatorname{tag} D$ & 310 & Glycerol-3-phosphate cytidylyltransferase & $453^{*}, 454,588$ \\
\hline $\operatorname{tag} E$ & 310 & $\begin{array}{l}\text { UDPglucose-teichoic acid glycosyltransferase; cell-wall-defective; formerly rodD; } \\
\text { gta } A, \text { gtaD }\end{array}$ & $454^{*}$ \\
\hline $\operatorname{tag} F$ & 309 & CDPglycerol:poly(glycerol phosphate) glycerophosphotransferase; rodC, tag-3 & $\begin{array}{l}311,312^{*}, 454 \\
589^{*}\end{array}$ \\
\hline $\operatorname{tag} G$ & 309 & Teichoic acid biosynthesis; essential gene & $395,396^{*}$ \\
\hline $\operatorname{tag} H$ & 309 & Teichoic acid biosynthesis; essential gene & $395,396^{*}$ \\
\hline tal & 240 & Resistance to $\beta$-thienylalanine & 115 \\
\hline$t d h F$ & 360 & Thiophen and furan oxidation & $539 *$ \\
\hline$t d k$ & 323 & Thymidine kinase & 605 \\
\hline$t d m$ & & See hom & \\
\hline ten & 248 & $\begin{array}{l}\text { Constitutive transfection enhancement of phage SP82 DNA; transformation } \\
\text { defective }\end{array}$ & 241 \\
\hline $\operatorname{ten} A$ & 61 & Transcription enhancement of aprE & $555^{*}$ \\
\hline $\operatorname{ten} E$ & 61 & Reduction of aprE transcription & $555^{*}$ \\
\hline $\operatorname{ten} I$ & 61 & Regulatory protein TenI & $555^{*}$ \\
\hline $\operatorname{ter} C$ & 179 & Terminus of replication & $105^{*}$ \\
\hline tet & & See $\operatorname{tet} B$ & \\
\hline tet $A$ & & See $r p s J$ & \\
\hline tet $B$ & 357 & Resistance to tetracycline; tet & $20^{*}, 539^{*}, 646^{*}, 821$ \\
\hline tet $L$ & 357 & Tetracycline resistance leader peptide & $539 *, 646^{*}$ \\
\hline $\operatorname{tet} \mathrm{R}$ & 357 & Tetracycline resistance & $539 *$ \\
\hline thfs & 304 & Tetrahydrofolate synthetase & $403 \#$ \\
\hline thiA & 69 & Thiamine requirement & 355 \\
\hline$t h i B$ & 105 & Thiamine requirement & 301 \\
\hline thiC & 335 & Thiamine requirement & 870 \\
\hline $\operatorname{tbr} A$ & & See $t h r B$ & \\
\hline $\operatorname{thr} B$ & 284 & Threonine requirement; homoserine kinase; previous $\operatorname{tbr} B$ is now $\operatorname{thr} C$; $\operatorname{tbr} A$ & $556^{*}$ \\
\hline $\operatorname{thr} C$ & 284 & Threonine requirement; threonine synthase; formerly $t b r B$ & $556^{*}$ \\
\hline $\operatorname{tbrS}$ & 256 & Major threonyl-tRNA synthetase & $601 *$ \\
\hline$t h r Z$ & 325 & Minor threonyl-tRNA synthetase; maps near $\operatorname{sac} A$ & $601 *, 602 *$ \\
\hline tby $A$ & 168 & Thymidylate synthetase A & $517,752 *$ \\
\hline thy $B$ & 195 & Thymidylate synthetase B & $22,333^{*}$ \\
\hline tig & 244 & Possible trigger factor & $825^{*}$ \\
\hline tkt & 170 & Transketolase & $655,665^{*}$ \\
\hline$t / p A$ & 170 & $\begin{array}{l}\text { Thioredoxin-like protein } A \text {; problem of gene symbol redundance see other } t / p A \text { at } \\
281^{\circ}\end{array}$ & $630^{*}$ \\
\hline $\operatorname{tlp} A$ & 281 & $\begin{array}{l}\text { Transmembrane receptor with strong homology to chemotaxis proteins; problem } \\
\text { of gene symbol redundance see other } t / p A \text { at } 170^{\circ}\end{array}$ & $261^{*}$ \\
\hline $\operatorname{tlp} B$ & 281 & Transmembrane receptor with strong homology to chemotaxis proteins & $261 *$ \\
\hline $\operatorname{tlp} C$ & 31 & Methylation enzyme; methyl-accepting chemotaxis protein & $199 *, 262^{*}$ \\
\hline $\operatorname{tm} A$ & 24 & Tunicamycin resistance; hyperproductivity of extracellular $\alpha$-amylase & 528 \\
\hline $\operatorname{tmr} B$ & 27 & Tunicamycin resistance; ATP-binding membrane protein & $526,552 \#, 839 *$ \\
\hline$t m s$ & & See $g c a D$ & \\
\hline
\end{tabular}


Table 1 (cont.)

\begin{tabular}{|c|c|c|c|}
\hline $\begin{array}{l}\text { Gene } \\
\text { symbol }\end{array}$ & $\begin{array}{l}\text { Map } \\
\text { position }\end{array}$ & $\begin{array}{c}\text { Functions, products, phenotypes, other characteristics, former or } \\
\text { alternative symbols }\end{array}$ & Reference \\
\hline tolB & NM & Tolerance to bacteriophage & 331 \\
\hline $\operatorname{top} B$ & 34 & Topoisomerase III & 644 \\
\hline$t p i$ & NM & Triose-phosphate isomerase & $411^{*}$ \\
\hline $\operatorname{tre} A$ & 62 & Trehalose-6-phosphate hydrolase; phospho- $\alpha(1-1$-glucosidase $) ; \operatorname{tre} C$ & $236^{*}, 275^{*}, 405$ \\
\hline $\operatorname{tre} B$ & & See treP & \\
\hline $\operatorname{tre} C$ & & See $\operatorname{tre} A$ & \\
\hline $\operatorname{treP}$ & 62 & Permease Enzyme II trehalose; treB & $236^{*}, 275^{*}, 405$ \\
\hline $\operatorname{tre} \mathrm{R}$ & 62 & Repressor of the trehalose operon & $275^{*}$ \\
\hline $\operatorname{trn} A$ & 0 & $\begin{array}{l}\text { Genes for Ile and Ala tRNAs located between } 16 \mathrm{~S} \text { and } 23 \mathrm{~S} \text { RNAs in the } r r n A \\
\text { operon }\end{array}$ & $533^{*}$ \\
\hline $\operatorname{trn} B$ & 275 & $\begin{array}{l}\text { Linked set of tRNA genes distal to } r n B \text { that contains tRNAs for Val, Thr, Lys, } \\
\text { Leu, Gly, Leu, Arg, Pro, Ala, Met, Ile, Ser, fMet, Asp, Phe, His, Gly, Ile, Met, } \\
\text { Asn, Ser and Glu; previous } \operatorname{trnB} \text { is now trnI; formerly } \operatorname{trnE}\end{array}$ & $239 *$ \\
\hline $\operatorname{trn} D$ & 67 & $\begin{array}{l}\text { Linked set of tRNA genes thought to be distal to } r r n \text { that contains tRNAs for } \\
\text { Asn, Ser, Glu, Val, Met, Asp, Phe, Thr, Tyr, Trp, His, Gln, Gly, Cys, Leu1 and } \\
\text { Leu2; } \operatorname{trnR}\end{array}$ & $809 *$ \\
\hline $\operatorname{trn} E$ & 45 & tRNA Met and Asp; previous $\operatorname{trn} E$ is now $\operatorname{trn} B$ & $644^{*}$ \\
\hline $\operatorname{trnH}$ & & See $\operatorname{trnI}$ & \\
\hline $\operatorname{trnI}$ & 13 & $\begin{array}{l}\text { Linked set of six tRNA genes including tRNAs for Ala, Pro, Arg, Gly, Thr and } \\
\text { Asn located between } r r n H \text { and } r r n I \text {; formerly } \operatorname{trn} B ; \operatorname{trnH}\end{array}$ & $808^{*}$ \\
\hline $\operatorname{trnJ}$ & 10 & $\begin{array}{l}\text { Linked set of nine tRNA genes, Val, Thr, Lys, Leu1, Gly, Arg, Pro, Ala located } \\
\text { between } r r n J \text { and } r r n W\end{array}$ & $240^{*}$ \\
\hline $\operatorname{trnO}$ & 0 & Same tRNA genes as $\operatorname{trn} A$ but located in $r r n O$ & 792 \\
\hline $\operatorname{trn} \mathrm{R}$ & & See $\operatorname{trn} D$ & \\
\hline $\operatorname{trn} S$ & 39 & tRNA Asn, Ser, Glu, GIn, Lys, Leu1 and Leu2 & $212^{*}$ \\
\hline $\operatorname{trn} Y$ & 355 & Linked set of tRNA genes for Lys, Glu, Asp and Phe & $539^{*}, 837^{*}$ \\
\hline $\operatorname{trp} A$ & 203 & Tryptophan synthase $\alpha$ & $289 *$ \\
\hline $\operatorname{trp} B$ & 203 & Tryptophan synthase $\beta$ & $289^{*}$ \\
\hline $\operatorname{trp} C$ & 203 & Indol-3-glycerol-phosphate synthase & $289 *$ \\
\hline $\operatorname{trp} D$ & 203 & Anthranilate phosphoribosyl-transferase & $37 *, 289$ \\
\hline $\operatorname{trp} E$ & 203 & Anthranilate synthase & $37^{*}, 289$ \\
\hline $\operatorname{trp} F$ & 203 & Phosphoribosylanthranilate isomerase & $289^{*}$ \\
\hline $\operatorname{trp} G$ & 9 & $\begin{array}{l}p \text {-Aminobenzoic acid synthase, component II; glutamine amidotransferase; } p a b A \text {, } \\
\operatorname{trp} X\end{array}$ & $347,693 *$ \\
\hline $\operatorname{trps}$ & 104 & Tryptophanyl-tRNA synthase & $114^{*}, 723$ \\
\hline $\operatorname{trp} X$ & & See $\operatorname{trp} G$ & \\
\hline $\operatorname{tr} x$ & & See $\operatorname{tr} x A$ & \\
\hline $\operatorname{tr} x A$ & 252 & Thioredoxin; trx & $111^{*}$ \\
\hline $\operatorname{tr} x C$ & 264 & Thioredoxin & $393 *$ \\
\hline$t s-1$ & & See $f t s Z$ & \\
\hline$t s-31$ & 131 & Temperature-sensitive division & 475 \\
\hline$t s-341$ & & See $\sec A$ & \\
\hline$t s-39$ & 226 & Temperature-sensitive synthesis of phosphatidylethanolamine & 414 \\
\hline$t s-526$ & 2 & Temperature-sensitive division & 475 \\
\hline tsi & 48 & Temperature-sensitive induction of all known SOS functions & 690 \\
\hline tsr & & See $f b a A$ & \\
\hline tua $A$ & 307 & Biosynthesis of teichuronic acid, operon of eight genes & $397^{*}$ \\
\hline $\operatorname{tuaB}$ & 307 & Biosynthesis of teichuronic acid, operon of eight genes & $397^{*}$ \\
\hline tuaC & 307 & Biosynthesis of teichuronic acid, operon of eight genes & $397 *$ \\
\hline tuaD & 307 & Biosynthesis of teichuronic acid, operon of eight genes & $397^{*}$ \\
\hline tuaE & 307 & Biosynthesis of teichuronic acid, operon of eight genes & $397 *$ \\
\hline tuaF & 307 & Biosynthesis of teichuronic acid, operon of eight genes & $397 *$ \\
\hline$t u a G$ & 307 & Biosynthesis of teichuronic acid, operon of eight genes & $397^{*}$ \\
\hline
\end{tabular}


Table 1 (cont.)

\begin{tabular}{|c|c|c|c|}
\hline $\begin{array}{l}\text { Gene } \\
\text { symbol }\end{array}$ & $\begin{array}{c}\text { Map } \\
\text { position }\end{array}$ & $\begin{array}{c}\text { Functions, products, phenotypes, other characteristics, former or } \\
\text { alternative symbols }\end{array}$ & Reference \\
\hline tuaH & 307 & Biosynthesis of teichuronic acid, operon of eight genes & $397 *$ \\
\hline tuf $A$ & 11 & Elongation factor $\mathrm{Tu}$ & 153 \\
\hline $\operatorname{tyr} A$ & 202 & Tyrosine requirement; prephenate dehydrogenase & $290^{*}$ \\
\hline $\operatorname{tyr} \mathrm{R}$ & & See $t y r Z$ & \\
\hline $\operatorname{tyr} S$ & 263 & Tyrosyl-tRNA synthetase & $244,285^{*}$ \\
\hline $\operatorname{tyr} T$ & & See $t y r Z$ & \\
\hline $\operatorname{tyr} Z$ & 332 & Tyrosyl-tRNA synthetase, minor, expresses when $\operatorname{tyr} S$ is inactivated; $\operatorname{tyr} T, \operatorname{tyr} R$ & $224^{*}$ \\
\hline $\operatorname{trm}$ & & See gerJ & \\
\hline nat & & See $\operatorname{pat} A$ & \\
\hline udk & NM & Uridine kinase; also lacks cytidine kinase; mutant resistant to fluorouridine & 518 \\
\hline$u d p$ & NM & Uridine phosphorylase & $455 \#$ \\
\hline unc & NM & Uncoupler resistance & 377 \\
\hline ung & 330 & Putative uracyl-DNA glycosylase & $225^{*}$ \\
\hline$u p p$ & 321 & Uracil phosphoribosyl transferase & $444^{*}, 518$ \\
\hline urg & NM & N-Glucosidase & 431 \\
\hline uvr & & See $w r B$ & \\
\hline wr $A$ & 303 & Excision of UV-induced pyrimidine dimers in DNA & $113^{*}, 300,711$ \\
\hline$u v r B$ & 303 & $\begin{array}{l}\text { Excision of UV-induced pyrimidine dimers in DNA; cytoplasmic protein; previous } \\
w v r B \text { is now } w v r C ; w r, \operatorname{din} A\end{array}$ & $70^{*}, 113^{*}, 711$ \\
\hline$w v r C$ & 252 & $\begin{array}{l}\text { Excision of UV-induced pyrimidine dimers in DNA; homologous to } u v r C \text { of } E \text {. } \\
\text { coli; formerly } u v r B\end{array}$ & $111^{*}, 499$ \\
\hline vals & 242 & Valyl-tRNA synthetase & $433^{*}$ \\
\hline veg & 4 & Veg protein & $539 *$ \\
\hline$v p r$ & 330 & Minor extracellular serine protease & $698^{*}$ \\
\hline VS & 14 & Virginiamycin (VS component) resistance & 627 \\
\hline wap $A$ & 336 & Wall-associated protein & $188^{*}$ \\
\hline$x e p A$ & 112 & XepA protein; homlogues of $x e p A$ are associated with cell lysis genes & $418^{*}$ \\
\hline$x b i$ & 112 & Heat-inducible PBSX & 89 \\
\hline$x b l A$ & 112 & Protein associated with cell lysis upon induction of PBSX; role of a holin & $418^{*}$ \\
\hline$x b l B$ & 112 & Gene product involved in cell lysis upon induction of PBSX; role of a holin; $x p a B$ & $400 \#, 418^{*}$ \\
\hline$x l t$ & 112 & Induced PBSX lacks tails & 213 \\
\hline$x \operatorname{ly} A$ & 112 & $N$-Acetylmuramoyl-L-alanine amidase & $418^{*}$ \\
\hline$x p a A$ & 277 & Hydrolysis of 5-bromo-4-chloroindoyl phosphate (X-phos) & $400 \#$ \\
\hline$x p a B$ & & See $x b l B$ & \\
\hline$x p a C$ & 2 & Hydrolysis of 5-bromo-4-chloroindolyl phosphate (X-phos) & $400 \#$ \\
\hline$x p t$ & 198 & Xanthine phosphoribosyltransferase & $97,659,664^{*}$ \\
\hline xre & 110 & PBSX repressors & $828^{*}$ \\
\hline$x y l A$ & 168 & Xylose isomerase & $375,820^{*}$ \\
\hline$x y l B$ & 168 & Xylulose kinase & $375,819 \#$ \\
\hline$x y / R$ & 168 & Regulation of xylose regulon & $271 \#, 375$ \\
\hline xyn $A$ & 175 & Extracellular $\beta$-xylanase & $\begin{array}{l}554^{*}, 628,760 \\
827^{*}\end{array}$ \\
\hline$x y n B$ & 168 & Cell-associated $\beta$-xyloxidase & $271 \#, 628,760$ \\
\hline $\operatorname{xyn} C$ & 168 & Probably xyloside permease & $271 \#, 760$ \\
\hline$x y n D$ & 171 & Endo-1,4- $\beta$-xylanase D & $630^{*}$ \\
\hline
\end{tabular}

GenBank/DDB J - Accession Number' replaces the bibliographic reference).

As stated above, the method adopted to automatically build the $B$. subtilis genetic map can be applied to other bacterial species, and can help in the follow-up of genome sequencing and gene function analysis projects. We have organized the genetic map data for Escherichia coli from the ECD database [796] on the same model.
To assist in the preparation of $B$. subtilis genetic map updates, we would appreciate information regarding the position and function of new genes or corrections (bsmap@biotec.jouy.inra.fr).

\section{Acknowledgements}

We are particularly grateful to Alexei Sorokin, Pascale Serror, Claude Bruand and to all the participants of the sequencing 
project who helped us to update the map. V.B. is the recipient of a Ministère de la Recherche et de l'Enseignement Supérieur fellowship. This work was supported in part by a Ministère de la Recherche et de l'Enseignement Supérieur grants (décision 92.H.0912, ACC-SV 1995)

\section{References}

1. Abhayawardhane, Y. K. \& Stewart, G. C. (1995). Bacillus subtilis possesses a second determinant with extensive sequence similarity to the Escherichia coli mreB morphogene. J Bacteriol 177, 765-773

2. Adams, A. \& Oishi, M. (1972). Genetic properties of arsenate sensitive mutants of Bacillus subtilis 168. Mol Gen Genet 118, 295-310.

3. Adams, A. (1973). Transposition of the arsenate resistance locus of Bacillus subtilis. Genetics 74, 197-213.

4. Adams, R. \& Schumann, W. (1993). Cloning and mapping of the Bacillus subtilis locus homologous to Eschericbia coli ent genes. Gene 133, 119-121.

5. Ahmed, M., Borsch, C. M., Taylor, S. S., Vazquez-Laslop, N. \& Neyfakh, A. A. (1994). A protein that activates expression of a multidrug efflux transporter upon binding the transporter substrates. J Biol Chem 269, 28506-28513.

6. Ahmed, M., Lyass, L., Markham, P. N., Taylor, S. S., VazquezLaslop, N. \& Neyfakh, A. A. (1995). Two highly similar multidrug transporters of Bacillus subtilis whose expression is differentially regulated. J Bacteriol 177, 3904-3910.

7. Ahn, K. S. \& Wake, R. G. (1991). Variations and coding features of the sequence spanning the replication terminus of Bacillus subtilis 168 and W23 chromosomes. Gene 98, 107-112.

8. Akagawa, E., Kurita, K., Sugawara, T., Nakamura, K., Kasahara, Y., Ogasawara, N. \& Yamane, K. (1995). Determination of $17484 \mathrm{bp}$ nucleotide sequence around the $39^{\circ}$ region of the Bacillus subtilis chromosome and similarity analysis of the products of putative ORFs. Microbiology 141, 3241-3245.

9. Akrigg, A. \& Mandelstam, J. (1978). Extracellular manganese stimulated deoxyribonuclease as a marker event in sporulation of Bacillus subtilis. Biochem J 172, 63-67.

10. Albano, M., Breitling, R. \& Dubnau, D. A. (1989). Nucleotide sequence and genetic organization of the Bacillus subtilis com $G$ operon. J Bacteriol 171, 5386-5404.

11. Albertini, A. M. \& Galizzi, A. (1975). Mutant of Bacillus subtilis with a temperature-sensitive lesion in ribonucleic acid synthesis during germination. J Bacteriol 124, 14-25.

12. Albertini, A. M. \& Galizzi, A. (1982). Pattern of RNA transcription during Bacillus subtilis spore outgrowth. J Gen Microbiol 128, 247-253.

13. Albertini, A. M., Caramori, T., Henner, D., Ferrari, E. \& Galizzi, A. (1987). Nucleotide sequence of the outB locus of Bacillus subtilis and regulation of its expression. J Bacteriol 169, 1480-1484.

14. Albertini, A. M., Caramori, T., Crabb, W. D., Scoffone, F. \& Galizzi, A. (1991). The fla $A$ locus of Bacillus subtilis is part of a large operon coding for flagellar structures, motility functions and an ATPase-like polypeptide. J Bacteriol 173, 3573-3579.

15. Albertini, A. M., Caramori, T., Scoffone, F., Scotti, C. \& Galizzi, A. (1995). Sequence around the $159^{\circ}$ region of the Bacillus subtilis genome: the $p$ ks $X$ locus spans $33.6 \mathrm{~kb}$. Microbiology 141, 299-309.

16. Alonso, J. C., Stiege, C. A., Tailor, R. H. \& Viret, J. F. (1988). Functional analysis of the $\mathrm{dna}(\mathrm{Ts})$ mutants of Bacillus subtilis: plasmid PUB110 replication as a model system. Mol Gen Genet 214, 482-489.

17. Alonso, J. C., Tailor, R. H. \& Luder, G. (1988). Characterization of recombination-deficient mutants of Bacillus subtilis. J Bacteriol 170, 3001-3007.

18. Alonso, J. C., Shirahige, K. \& Ogasawara, N. (1990). Molecular cloning, genetic characterization and DNA sequence analysis of the recM region of Bacillus subtilis. Nucleic Acids Res 18, 6771-6777.

19. Alonso, J. C., Stiege, C. A., Dobrinski, B. \& Lurz, R. (1993). Purification and properties of the RecR protein from Bacillus subtilis 168. J Biol Chem 268, 1424-1429.

20. Amano, H., Ives, C. L., Bott, K. F. \& Shishido, K. (1991). A limited number of Bacillus subtilis strains carry a tetracyclineresistance determinant at a site close to the origin of replication. Biochim Biophys Acta 1088, 251-258.

21. Amjad, M., Castro, J. M., Sandoval, H., Wu, J.-J., Yang, M., Henner, D. J. \& Piggot, P. J. (1990). An Sfil restriction map of the Bacillus subtilis 168 genome. Gene 101, 15-21.

22. Anagnostopoulos, C. \& Schneider-Champagne, A. M. (1966). Determinisme genetique de l'exigence en thymine chez certains mutants de Bacillus subtilis. C R Acad Sci Ser D 262, 1311-1314.

23. Anagnostopoulos, C., Piggot, P. J. \& Hoch, J. A. (1993). The genetic map of Bacillus subtilis. In Bacillus subtilis and Other Grampositive Bacteria, pp. 425 -461. Edited by A. L. Sonenshein, J. A. Hoch \& R. Losick. Washington, DC: American Society for Microbiology.

24. Anagnostopoulos, C. Unpublished data.

25. Anderson, J. J. \& Ganesan, A. T. (1975). Temperature-sensitive deoxyribonucleic acid replication in a $d n a C$ mutant of Bacillus subtilis. J Bacteriol 121, 173-183.

26. Anderson, L. M., Henkin, T. M., Chambliss, G. H. \& Bott, K. F. (1984). New chloramphenicol resistance locus in Bacillus subtilis. $J$ Bacteriol 158, 386-388.

27. Antelmann, H., Bernhardt, J., Schmid, R. \& Hecker, M. (1995). A gene at $333^{\circ}$ on the Bacillus subtilis chromosome encodes the newly identified $\sigma^{\mathrm{B}}$-dependent general stress protein GspA.J Bacteriol 177, 3540-3545.

28. Antoniewski, C., Savelli, B. \& Stragier, P. (1990). The spoIIJ gene, which regulates early developmental steps in Bacillus subtilis, belongs to a class of environmentally responsive genes. J Bacteriol 172, 86-93.

29. Armpriester, J. M. (1991). Direct submission to EMBL/ GenBank/DDBJ - M58606.

30. Aronson, A. I., Song, H.-Y. \& Bourne, N. (1989). Gene structure and precursor processing of a novel Bacillus subtilis spore coat protein. Mol Microbiol 3, 437-444.

31. Awade, A., Cleuziat, P., Gonzales, T. \& Robert-Baudouy, J. (1992). Characterization of the $p c p$ gene encoding the pyrrolidone carboxyl peptidase of Bacillus subtilis. FEBS Lett 305, 67-73.

32. Aymerich, S. \& Steinmetz, M. (1987). Cloning and preliminary characterization of the sacS locus from Bacillus subtilis which controls the regulation of the exoenzyme levansucrase. $\mathrm{Mol} \mathrm{Gen}$ Genet 208, 114-120.

33. Babitzke, P., Gollnick, P. \& Yanofsky, C. (1992). The $m \operatorname{tr} A B$ operon of Bacillus subtilis encodes GTP cyclohydrolase I (mtr $A$ ), an enzyme involved in folic acid biosynthesis, and $m \operatorname{tr} B$, a regulator of tryptophan biosynthesis. J Bacteriol 174, 20592064.

34. Baigori, M., Grau, R., Morbidoni, H. R. \& de Mendoza, D. 
(1991). Isolation and characterization of Bacillus subtilis mutants blocked in the synthesis of pantothenic acid. J Bacteriol 173, $4240-4242$.

35. Balassa, G., Milhaud, P., Raulet, E., Silva, M. T. \& Sousa, J. C. F. (1979). A Bacillus subtilis mutant requiring dipicolinic acid for the development of heat-resistant spores. J Gen Microbiol 110, 365-379.

36. Balassa, G., Milhaud, P., Sousa, J. C. F. \& Silva, M. T. (1979). Decadent sporulation mutants of Bacillus subtilis. J Gen Microbiol 110, 381-392.

37. Band, L., Shimotsu, H. \& Henner, D. J. (1984). Nucleotide sequence of the Bacillus subtilis trpE and $\operatorname{trpD}$ genes. Gene 27, 55-65.

38. Banerjee, S. \& Hansen, J. N. (1988). Structure and expression of a gene encoding the precursor of subtilin, a small protein antibiotic. J Biol Chem 263, 9508-9514.

39. Barat, M., Anagnostopoulos, C. \& Schneider, A.-M. (1965). Linkage relationships of genes controlling isoleucine, valine and leucine biosynthesis in Bacillus subtilis. J Bacteriol 90, 357-369.

40. Barberio, C. Unpublished data.

41. Baumberg, S. \& Mountain, A. (1984). Bacillus subtilis 168 mutants resistant to arginine hydroxamate in the presence of ornithine or citrulline. J Gen Microbiol 130, 1247-1252.

42. Bazzicalupo, M., Parisi, B., Pirali, G., Polsinelli, M. \& Sala, F. (1975). Genetic and biochemical characterization of a ribosomal mutant of Bacillus subtilis resistant to sporangiomycin. Antimicrob Agents Chemother 8, 651-656.

43. Bazzicalupo, M., Gallori, E. \& Polsinelli, M. (1980). Characterization of 5-fluoroindole and 5-fluorotryptophan resistant mutants in Bacillus subtilis. Microbiologica 3, 15-23.

44. Beall, B., Lowe, M. \& Lutkenhaus, J. (1988). Cloning and characterization of Bacillus subtilis homologs of Escherichia coli cell division genes $f t s Z$ and $f t s . A$. J Bacteriol 170, 4855-4864.

45. Beall, B. \& Lutkenhaus, J. (1989). Nucleotide sequence and insertional inactivation of a Bacillus subtilis gene that affects cell division, sporulation, and temperature sensitivity. $J$ Bacteriol 171, 6821-6834.

46. Beall, B. W., Driks, A., Losick, R. \& Moran, C. P., Jr (1993). Cloning and characterization of a gene required for assembly of the Bacillus subtilis spore coat. J Bacteriol 175, 1705-1716.

47. Beall, B. W. \& Moran, C. P. (1994). Cloning and characterization of spoVR, a gene from Bacillus subtilis involved in spore cortex formation. J Bacteriol 176, 2003-2012.

48. Beijer, L., Nilsson, R. P., Holmberg, C. \& Rutberg, L. (1993). The $g l p P$ and $g l p F$ genes of the glycerol regulon in Bacillus subtilis. J Gen Microbiol 139, 349-359.

49. Berek, I., Miczak, A. \& Ivanovics, G. (1974). Mapping of the $\delta$ aminolaevulinic acid dehydrase and porphobilinogen deaminase loci in Bacillus subtilis. Mol Gen Genet 132, 233-239.

50. Binnie, C., Lampe, M. \& Losick, R. (1986). Gene encoding the $\sigma^{37}$ species of RNA polymerase sigma factor from Bacillus subtilis. Proc Natl Acad Sci US A 83, 5943-5947.

51. Bischof, O. (1995). Direct submission to EMBL/GenBank/ DDBJ - Z47978.

52. Bischoff, D., Weinreich, M. D. \& Ordal, G. W. (1992). Nucleotide sequence of Bacillus subtilis flagellar biosynthetic genes $f i P$ and $f i Q$ and identification of a novel flagellar gene, $f i Z$. $J$ Bacteriol 174, 4017-4025.

53. Bischoff, D. S., Bourret, R. B., Kirsch, M. L. \& Ordal, G. W.
(1993). Putification and characterization of Bacillus subtilis CheY. Biochemistry 32, 9256-9261.

54. Bishoff, D. S. \& Ordal, G. W. (1991). Sequence and characterization of Bacillus subtilis CheB, a homolog of Escherichia coli $\mathrm{CheY}$, and its role in a different mechanism of chemotaxis. $J$ Biol Chem 266, 12301-12305.

55. Bishoff, D. S. \& Ordal, G. W. (1992). Identification and characterization of FliY a novel component of the Bacillus subtilis flagellar switch complex. Mol Microbiol 6, 2715-2723.

56. Bishop, P. E. \& Brown, L. R. (1973). Ethidium bromide-resistant mutant of Bacillus subtilis. J Bacteriol 115, 1077-1083.

57. Bohannon, D. E., Rosenkrantz, M. S. \& Sonenshein, A. L. (1985). Regulation of Bacillus subtilis glutamate synthase genes by the nitrogen source. J Bacteriol 163, 957-964.

58. Bohannon, D. E. \& Sonenshein, A. L. (1989). Positive regulation of glutamate biosynthesis in Bacillus subtilis. J Bacteriol 171, $4718-4727$.

59. Bohin, J.-P. \& Lubochinsky, B. (1982). Alcohol-resistant sporulation mutants of Bacillus subtilis. J Bacteriol 150, 944-955.

60. Bol, D. K. \& Yasbin, R. E. (1991). The isolation, cloning and identification of a vegetative catalase gene from Bacillus subtilis. Gene 109, 31-37.

61. Bolotin, A., Khazak, V., Stoynova, N., Ratmanova, K., Yomantas, Y. \& Kozlov, Y. (1995). Identical amino acid sequence of the aro $A(G)$ gene products of Bacillus subtilis 168 and B. subtilis Marburg strain. Microbiology 141, 2219-2222.

62. Bolotin, A., Sorokin, A. \& Ehrlich, S. D. (1996). Mapping of the $150 \mathrm{~kb}$ spoIIIC-phe $A$ region of the Bacillus subtilis chromosome by using Long Range PCR and three yeast artificial chromosomes. Microbiology 142 (in press).

63. Bookstein, C., Edwards, C. W., Kapp, N. V. \& Hulett, F. M. (1990). The Bacillus subtilis 168 alkaline phosphatase III gene: impact of a pho $A I I I$ mutation on total alkaline phosphatase synthesis. J Bacteriol 172, 3730-3737.

64. Boor, K. J., Duncan, M. L. \& Price, C. W. (1995). Genetic and transcriptional organization of the region encoding the $\beta$ subunit of Bacillus subtilis RNA polymerase. $J$ Biol Chem 270, 20329-20336.

65. Borriss, R., Porwollik, S. \& Schroeter, R. (1996). The $52^{\circ}-55^{\circ}$ segment of the Bacillus subtilis 168 chromosome: a region devoted to purine uptake and metabolism, and containing the genes $\cot A, g a b P$ and gua $A$ and the pur $A$ gene cluster within a $34960 \mathrm{bp}$ nucleotide sequence. Microbiology 142 (in press).

66. Bott, K. F., Stewart, G. C. \& Anderson, A. G. (1984). Genetic mapping of cloned ribosomal RNA genes. In Genetics and Biotechnology of Bacilli, pp. 19-34. Edited by A. T. Ganesan \& J. A. Hoch. Orlando, FL: Academic Press.

67. Boudreaux, D. P., Eisenstadt, E., lijima, T. \& Freese, E. (1981). Biochemical and genetic characterization of an auxotroph of Bacillus subtilis altered in the acyl-CoA: acyl-carrier protein transacylase. Eur J Biochem 115, 175-181.

68. Bower, S., Perkins, J., Rogers Yocum, R., Serror, P., Sorokin, A., Rahaim, P., Howitt, C. L., Prasad, N., Ehrlich, S. D. \& Pero, J. (1995). Cloning and characterization of the Bacillus subtilis $\operatorname{bir} A$ gene encoding a repressor of the biotin operon. $J$ Bacteriol 177, 2572-2575.

69. Boylan, S. A., Suh, J. W., Thomas, S. M. \& Price, C. W. (1989). Gene encoding the $\alpha$ core subunit of Bacillus subtilis RNA polymerase is cotranscribed with the genes for initiation factor 1 and ribosomal proteins B, S13, S11, and L17. J Bacteriol 171, 2553-2562. 
70. Boylan, S. A., Thomas, M. D. \& Price, C. W. (1991). Genetic method to identify regulons controlled by nonessential elements: isolation of a gene dependent on alternate transcription factor $\sigma^{\mathrm{B}}$ of Bacillus subtilis. J Bacteriol 173, 7856-7866.

71. Boylan, S. A., Rutherford, A., Thomas, S. M. \& Price, C. W. (1992). Activation of Bacillus subtilis transcription factor $\sigma^{\mathrm{B}}$ by a regulatory pathway responsive to stationaty phase signals. $J$ Bacteriol 174, 3695-3706.

72. Brakhage, A. A., Putzer, H., Shazand, K., Roschenthaler, R. J. \& Grunberg-Manago, M. (1989). Bacillus subtilis phenylalanyltRNA synthetase genes: cloning and expression in Escherichia coli and B. subtilis. J Bacteriol 171, 1228-1232.

73. Brakhage, A. A., Wozny, M. \& Putzer, H. (1990). Structure and nucleotide sequence of the Bacillus subtilis phenylalanyl-tRNA synthetase genes. Biochimie 72, 725-734.

74. Bramucci, M. G., Keggins, K. M. \& Lovett, P. S. (1977). Bacteriophage PMB12 conversion of the sporulation defect in RNA polymerase mutants of Bacillus subtilis. J Virol 24, 194-200.

75. Bramucci, $\mathbf{M}$. Unpublished data.

76. Brandt, C. \& Karamata, D. (1987). Thermosensitive Bacillus subtilis mutants which lyse at the non-permissive temperature. $J$ Gen Microbiol 133, 1159-1170.

77. Breton, R., Watson, D., Yaguchi, M. \& Lapointe, J. (1990). Glutamyl-tRNA synthetases of Bacillus subtilis $168 \mathrm{~T}$ and of Bacillus stearothermophilus. J Biol Chem 265, 18248-18255.

78. Briehl, M., Pooley, H. M. \& Karamata, D. (1989). Mutants of Bacillus subtilis 168 thermosensitive for growth and wall teichoic acid synthesis. J Gen Microbiol 135, 1325-1334.

79. Bruand, C. \& Ehrlich, D. (1995). The Bacillus subtilis dnaI gene is part of the dnaB operon. Microbiology 141, 1199-1200.

80. Bruand, C., Sorokin, A., Serror, P. \& Ehrlich, S. D. (1995). Nucleotide sequence of the Bacillus subtilis dnaD gene. Microbiology 141, 321-322.

81. Bryan, E. M. (1995). Direct submission to EMBL/GenBank/ DDBJ - U29084.

82. Buchanan, C. E. (1987). Absence of penicillin-binding protein 4 from an apparently normal strain of Bacillus subtilis. J Bacteriol 169, 5301-5303.

83. Buchanan, C. E. \& Gustafson, A. (1991). Mapping of the gene for a major penicillin-binding protein to a genetically conserved region of the Bacillus subtilis chromosome and conservation of the protein among related species of Bacillus. J Bacteriol 173, 1807-1809.

84. Buchanan, C. E. \& Ling, M. L. (1992). Isolation and sequence analysis of $d a c B$ which encodes a sporulation-specific penicillin binding protein in Bacillus subtilis. J Bacteriol 174, 1717-1725.

85. Bugaichuk, U. D. \& Piggot, P. J. (1986). Nucleotide sequence of the Bacillus subtilis developmental gene spoVE. J Gen Microbiol 132, 1883-1890.

86. Bussey, L. B. \& Switzer, R. L. (1993). The $\operatorname{deg} A$ gene product accelerates degradation of Bacillus subtilis phosphoribosylpyrophosphate amidotransferase in Escherichia coli. J Bacteriol 175, 6348-6353

87. Butler, P. D. \& Mandelstam, J. (1987). Nucleotide sequence of the sporulation operon, spoIIIE, of Bacillus subtilis. $J$ Gen Microbiol 133, 2359-2370.

88. Butler, Y. X., Abhaydwardhane, Y. \& Stewart, G. C. (1993). Amplification of the Bacillus subtilis maf gene results in arrested septum formation. J Bacteriol 175, 3139-3145.

89. Buxton, R. S. (1976). Prophage mutation causing heat induci- bility of defective Bacillus subtilis bacteriophage PBSX. $J$ Virol 20, 22-28.

90. Buxton, R. S. (1980). Selection of Bacillus subtilis 168 mutants with deletions of PBSX prophage. J Gen Virol 46, 427-437.

91. Buxton, R. S. \& Ward, J. B. (1980). Heat-sensitive lysis mutants of Bacillus subtilis 168 blocked at three different stages of peptidoglycan synthesis. J Gen Microbiol 120, 283-293.

92. Callister, H. \& Wake, R. G. (1981). Characterization and mapping of temperature-sensitive division initiation mutations of Bacillus subtilis. J Bacteriol 145, 1042-1051.

93. Calogero, S., Gardan, R., Glaser, P., Schweizer, J., Rapoport, G. \& Débarbouillé, M. (1994). RocR, a novel regulatory protein controlling arginine utilization in Bacillus subtilis, belongs to the NtrC/NifA family of transcriptional activators. $J$ Bacteriol 176, 1234-1241.

94. Cannon, J. G. \& Bott, K. F. (1980). Mutation affecting expression of spectinomycin resistance in Bacillus subtilis. I Bacteriol 141, 409-412.

95. Canosi, U., Siccardi, A. G., Falaschi, A. \& Mazza, G. (1976). Effect of deoxyribonucleic acid replication inhibitors on bacterial recombination. J Bacteriol 126, 108-121.

96. Canosi, U., Nolli, M., Ferrari, E., Marinone, R. \& Mazza, G. (1979). Genetic mapping of caffeine resistant and sensitive mutants of B. subtilis. Microbiologica 2, 167-172.

97. Capuano, V., Sorokin, A., Galleron, N., Pujic, P. \& Ehrlich, S. D. (1996). Organization of the Bacillus subtilis 168 chromosome between kdg and the attachment site of the SP $\beta$ prophage - use of Long Accurate PCR and yeast artificial chromosomes for sequencing. Microbiology 142 (in press).

98. Caramori, T., Calogero, S., Albertini, A. M. \& Galizzi, A. (1993). Functional analysis of the outB gene of Bacillus subtilis. $J$ Gen Microbiol 139, 31-37.

99. Carlsson, P. \& Hederstedt, L. (1987). Bacillus subtilis citM, the structural gene for dihydrolipoamide transsuccinylase: cloning and expression in Eschericbia coli. Gene 61, 217-224.

100. Carlsson, P. \& Hederstedt, L. (1989). Genetic charcterization of Bacillus subtilis odh $A$ and odbB, encoding 2-oxoglutarate dehydrogenase and dihydrolipoamide transsuccinylase, respectively. J Bacteriol 171, 3667-3672.

101. Carpenter, P. B., Hanlon, D. W. \& Ordal, G. W. (1992). $f h F$, a Bacillus subtilis flagellar gene that encodes a putative GTPbinding protein. Mol Microbiol 6, 2705-2713.

102. Carpenter, P. B., Zuberi, A. R. \& Ordal, G. W. (1993). Bacillus subtilis flagellar proteins FliP, FliQ, FliR, and FlhB are related to Shigella flexneri virulence factors. Gene 137, 243-245.

103. Carpenter, P. B. \& Ordal, G. W. (1993). Bacillus subtilis FlhA: a flagellar protein related to a new family of signal-transducing receptors. Mol Microbiol 7, 735-743.

104. Carrascosa, J. L., Garcia, J. A. \& Salas, M. (1982). A protein similar to Escherichia coli GroEL is present in Bacillus subtilis. J Mol Biol 148, 731-737.

105. Carrigan, C. M., Haarsma, J. A., Smith, M. T. \& Wake, R. G. (1987). Sequence features of the replication terminus of the Bacillus subtilis chromosome. Nucleic Acids Res 15, 8501-8509.

106. Champney, W. S. \& Jensen, R. A. (1969). D-Tyrosine as a metabolic inhibitor of Bacillus subtilis. J Bacteriol 98, 205-214.

107. Chaudhry, G. R., Halpern, Y. S., Saunders, C., Vasantha, N., Schmidt, B. J. \& Freese, E. (1984). Mapping of the glucose dehydrogenase gene in Bacillus subtilis. J Bacteriol 160, 607-611.

108. Chen, L., James, L. P. \& Helmann, J. D. (1993). Metalloregulation in Bacillus subtilis: isolation and characterization of 
two genes differentially repressed by metal ions. $J$ Bacteriol $175,5428-5437$.

109. Chen, L. \& Helmann, J. D. (1994). The Bacillus subtilis $\sigma^{\mathrm{D}}$ dependent operon encoding the flagellar proteins FliD, FliS, and FliT. J Bacterio/ 176, 3093-3101.

110. Chen, N. Y., Hu, F. M. \& Paulus, H. (1987). Nucleotide sequence of the overlapping genes for the subunits of Bacillus subtilis aspartokinase II and their control regions. J Biol Chem 262, 8787-8798.

111. Chen, N. Y., Zhang, J. J. \& Paulus, H. (1989). Chromosomal location of the Bacillus subtilis aspartokinase II gene and nucleotide sequence of the adjacent genes homologous to worC and trx of Escherichia coli. J Gen Microbiol 135, 2931-2940.

112. Chen, N.-Y., Jiang, S.-q., Klein, D. A. \& Paulus, H. (1993). Organization and nucleotide sequence of the Bacillus subtilis diaminopimelate operon, a cluster of genes encoding the first three enzymes of diaminopimelate synthesis and dipicolinate synthase. J Biol Chem 268, 9448-9465.

113. Cheo, D. L., Bayles, K. W. \& Yasbin, R. E. (1991). Cloning and characterization of DNA damage-inducible promoter regions from Bacillus subtilis. J Bacteriol 173, 1696-1703.

114. Chow, K. C. \& Wong, J. T. (1988). Cloning and nucleotide sequence of the structural gene coding for Bacillus subtilis tryptophanyl-tRNA synthetase. Gene 73, 537-543.

115. Coats, J. H. \& Nester, E.W. (1967). Regulation reversal mutation: characterization of end product-activated mutants of Bacillus subtilis. J Biol Chem 242, 4948-4955.

116. Connors, M. J. \& Setlow, P. (1985). Cloning of a small, acidsoluble spore protein gene from Bacillus subtilis and determination of its complete nucleotide sequence. $J$ Bacteriol 161, 333-339.

117. Connors, M. J., Howard, B., Hoch, J. \& Setlow, P. (1986). Determination of the chromosomal location of four Bacillus subtilis genes which code for a family of small acid-soluble spore proteins. J Bacteriol 166, 412-416.

118. Connors, M. J., Mason, J. M. \& Setlow, P. (1986). Cloning and nucleotide sequencing of genes for three small, acidsoluble proteins from Bacillus subtilis spores. J Bacteriol 166, 417-425.

119. Copeland, J. C. \& Marmur, J. (1968). Identification of conserved genetic functions in Bacillus by use of temperaturesensitive mutants. Bacteriol Rev 32, 302-312.

120. Corfe, B. M., Moir, A., Popham, D. \& Setlow, P. (1994). Analysis of the expression and regulation of the ger $B$ spore germination operon of Bacillus subtilis 168. Microbiology 140, 3079-3083.

121. Corfe, B. M., Sammons, R. L., Smith, D. A. \& Mauël, C. (1994). The gerB region of the Bacillus subtilis 168 chromosome encodes a homologue of the ger $A$ spore germination operon. Microbiology 140, 471-478.

122. Cosmina, P., Rodriguez, F., de Ferra, F., Grandi, G., Perego, M., Venema, G. \& van Sinderen, D. (1993). Sequence and analysis of the genetic locus responsible for surfactin synthesis in Bacillus subtilis. Mol Microbiol 8, 821-831.

123. Craven, M. G., Henner, D. J., Alessi, D., Schauer, A. T., Ost, K. A., Deutscher, M. P. \& Friedman, D. I. (1992). Identification of the $r p h$ (RNase $\mathrm{PH}$ ) gene of Bacillus subtilis: evidence for suppression of cold-sensitive mutations in Escherichia coli. J Bacteriol 174, 4727-4735.

124. Cutting, S. \& Mandelstam, J. (1986). The nucleotide sequence and the transcription during sporulation of the gerE gene of Bacillus subtilis. J Gen Microbiol 132, 3012-3024.
125. Cutting, S., Zheng, L. \& Losick, R. (1991). Gene encoding two alkali-soluble components of the spore coat from Bacillus subtilis. J Bacteriol 173, 2915-2919.

126. Cutting, S., Roels, S. \& Losick, R. (1991). Sporulation operon spoIVF and the characterization of mutations that uncouple mother-cell from forespore gene expression in Bacillus subtilis. J Mol Biol 221, 1237-1256.

127. D'Souza, C., Nakano, M. M. \& Zuber, P. (1994). Identification of coms, a gene of the $\operatorname{srf} A$ operon that regulates the establishment of genetic competence in Bacillus subtilis. Proc Natl Acad Sci US A 91, 9397-9401.

128. Dabbs, E. R. (1983). A pair of Bacillus subtilis ribosomal protein genes mapping outside the principle ribosomal protein cluster. J Bacteriol 156, 966-969.

129. Dabbs, E. R. (1983). Arrangement of loci within the principal cluster of ribosomal protein genes of Bacillus subtilis. Mol Gen Genet 192, 124-130.

130. Dabbs, E. R. (1983). Mapping of the genes for Bacillus subtilis ribosomal proteins S6 and S16: comparison of the chromosomal distribution of ribosomal protein genes in this bacterium with the distribution in Escherichia coli. Mol Gen Genet 192, 386-390.

131. Dabbs, E. R. (1983). Mapping of the genes for Bacillus subtilis ribosomal proteins S9, S11 and BL27 by means of antibiotic resistant mutants. Mol Gen Genet 191, 295-300.

132. Dabbs, E. R. (1984). Order of ribosomal protein genes in the rif cluster of Bacillus subtilis is identical to that of Escherichia coli. J Bacteriol 159, 770-772.

133. Daniel, R. A. \& Errington, J. (1993). Cloning, DNA sequence, functional analysis and transcriptional regulation of the genes encoding dipicolinic acid synthetase required for sporulation in Bacillus subtilis. J Mol Biol 232, 468483.

134. Daniel, R. A., Prescott, A. M. \& Errington, J. (1996). A complex four-gene operon containing essential cell division genes $f t s L$ and $p b p B$ in Bacillus subtilis. $J$ Bacteriol 178, $2343-2350$

135. Dartois, V., Baulard, A., Schanck, K. \& Colson, C. (1992). Cloning, nucleotide sequence and expression in Escherichia coli of a lipase gene from Bacillus subtilis 168. Biochim Biophys Acta 1131, 253-260

136. De Lencastre, $\mathbf{H}$. Unpublished data.

137. De la Fuente, V. (1995). Participation au projet de séquencage du génome de Bacillus subtilis 168: séquencage et analyse d'une région chromosomique de $11 \mathrm{~Kb}$. PhD thesis, Université de Poitiers.

138. Dean, D. R., Hoch, J. A. \& Aronson, A. I. (1977). Alteration of the Bacillus subtilis glutamine snythetase results in overproduction of the enzyme. J Bacteriol 131, 981-987.

139. Deuerling, E., Paeslack, B. \& Schumann, W. (1995). The $f t s H$ gene of Bacillus subtilis is transiently induced aftet osmotic and temperature upshift. J Bacteriol 177, 4105-4112.

140. Deutscher, J. (1994). Direct submission to EMBL/GenBank/ DDB J - X79387.

141. Deutscher, J., Reizer, J., Fischer, C., Galinier, A., Saier, M. H. \& Steinmetz, M. (1994). Loss of protein kinase-catalyzed phosphorylation of HPr, a phosphocarrier protein of the phosphotransferase system, by mutation of the $p t s H$ gene confers catabolite repression resistance to several catabolic genes of Bacillus subtilis. J Bacteriol 176, 3336-3344.

142. Devine, K. M. (1993). Direct submission to EMBL/ GenBank/DDBJ - Z26219.

143. Dhaese, P. Unpublished data. 
144. Dingman, D. W. \& Sonenshein, A. L. (1987). Purification of aconitase from Bacillus subtilis and correlation of its $\mathrm{N}$-terminal amino acid sequence with the sequence of the cit $B$ gene. $J$ Bacteriol 169, 3062-3067.

145. Dod, B., Balassa, G., Raulet, E. \& Jeannoda, V. (1978). Spore control (Sco) mutations in Bacillus subtilis. II. Sporulation and the production of extracellular proteases and $\alpha$-amylases by Sco mutants. Mol Gen Genet 163, 45-56.

146. Donovan, W., Zheng, L., Sandman, K. \& Losick, R. (1987). Genes encoding spore coat polypeptides from Bacillus subtilis. J Mol Biol 196, 1-10.

147. Driks, A., Roels, S., Beall, B., Moran, C. P. \& Losick, R. (1994). Subcellular localization of proteins involved in the assembly of the spore coat of Bacillus subtilis. Genes Dev 8, 234-244.

148. Driscoll, J. R. \& Taber, H. W. (1992). Sequence analysis and regulation of the Bacillus subtilis menBE operon. J Bacteriol 174 , 5063-5071.

149. Dubnau, D., Goldthwaite, C., Smith, I. \& Marmur, J. (1967). Genetic mapping in Bacillus subtilis. J Mol Biol 27, 163-185.

150. Dubnau, D. \& Cirigliano, C. (1974). Genetic characterization of recombination-deficient mutants of Bacillus subtilis. J Bacteriol 117, 488-493.

151. Dubnau, D. \& Roggiani, M. (1990). Growth mediumindependent genetic competence mutants of Bacillus subtilis. J Bacteriol 172, 4048-4055.

152. Dubnau, D. (1991). Genetic competence in Bacillus subtilis. Microbiol Rev 55, 395-424.

153. Dubnau, E., Pifko, S., Sloma, A., Cabane, K. \& Smith, I. (1976). Conditional mutations in the translational apparatus of Bacillus subtilis. Mol Gen Genet 147, 1-12.

154. Dubnau, E., Weir, J., Nair, G., Carter, L., III, Moran, C. P., Jr \& Smith, I. (1988). Bacillus sporulation gene spoOH codes for $\sigma^{30}$ $\left(\sigma^{\mathrm{H}}\right) . J$ Bacteriol 170, 1054-1062

155. Duncan, M. L., Kalman, S. S., Thomas, S. M. \& Price, C. W. (1987). Gene encoding the 37,000-dalton minor sigma factor of Bacillus subtilis RNA polymerase: isolation, nucleotide sequence, chromosomal locus, and cryptic function. J Bacteriol 169, 771-778.

156. Débarbouillé, M., Arnaud, M., Fouet, A., Klier, A. \& Rapoport, G. (1990). The $\operatorname{sac} T$ gene regulating the $\operatorname{sac} P A$ operon in Bacillus subtilis shares strong homology with transcriptional antiterminators. J Bacteriol 172, 3966-3973.

157. Débarbouillé, M., Martin-Verstraete, I., Kunst, F. \& Rapoport, G. (1991). The Bacillus subtilis sigL gene encodes an equivalent of $\sigma^{54}$ from gram-negative bacteria. Proc Natl Acad Sci USA 88, 9092-9096.

158. Débarbouillé, M., Martin-Verstraete, I., Klier, A. \& Rapoport, G. (1991). The transcriptional regulator LevR of Bacillus subtilis has domains homologous to both $\sigma^{54}$ and phosphotransferase system-dependent regulators. Proc Natl Acad Sci US $A$ 88, 2212-2216.

159. Ebbole, D. J. \& Zalkin, H. (1987). Cloning and characterization of a 12-gene cluster from Bacillus subtilis encoding nine enzymes for de novo purine nucleotide synthesis. $J$ Biol $\mathrm{Cbem}$ 262, 8274-8287.

160. Endo, T., Uratani, B. \& Freese, E. (1983). Purine salvage pathways of Bacillus subtilis and effect of guanine on growth of GMP reductase mutants. J Bacteriol 155, 169-179.

161. Endo, T., Ishikawa, H. \& Freese, E. (1983). Properties of a Bacillus subtilis mutant able to sporulate continually during growth in synthetic medium. J Gen Microbiol 129, 17-30.
162. Engelmann, S., Lindner, C. \& Hecker, M. (1995). Cloning, nucleotide sequence, and regulation of kat $E$ encoding a $\sigma^{\mathbf{B}}$ dependent catalase in Bacillus subtilis. J Bacteriol 177, 55985605.

163. Errington, J., Fort, P. \& Mandelstam, J. (1985). Duplicated sporulation genes in bacteria: implications for simple developmental systems. FEBS Lett 188, 184-188.

164. Errington, J. \& Jones, D. (1987). Cloning in Bacillus subtilis by transfection with bacteriophage vector $\phi 105 \mathrm{~J} 27$ : isolation and preliminary characterization of transducing phages for 23 sporulation loci. J Gen Microbiol 133, 493-502.

165. Errington, J., Rong, S., Rosenkrantz, M. S. \& Sonenshein, A. L. (1988). Transcriptional regulation and structure of the Bacillus subtilis sporulation locus spoIIIC. J Bacteriol 170, 1162-1167.

166. Errington, J. \& Vogt, C. H. (1990). Isolation and characterization of mutations in the gene encoding an endogenous Bacillus subtilis $\beta$-galactosidase and its regulator. J Bacteriol 172, $488-490$.

167. Errington, J., Appleby, L., Daniel, R., Goodfellow, H., Partridge, S. R. \& Yudkin, M. D. (1992). Structure and function of the spoIIIJ gene of Bacillus subtilis: a vegetatively expressed gene that is essential for $\sigma^{\mathrm{G}}$ activity at an intermediate stage of sporulation. J Gen Microbiol 138, 26092618.

168. Errington, J. (1993). Sporulation in Bacillus subtilis: regulation of gene expression and control of morphogenesis. Microbiol Rev 57, 1-33.

169. Estrela, A. I., de Lencastre, H. \& Archer, L. J. (1986). Resistance of a Bacillus subtilis mutant to a group of temperate bacteriophages. J Gen Microbiol 132, 411-415.

170. Estrela, A.-I., Pooley, H. M., de Lencastre, H. \& Karamata, D. (1991). Genetic and biochemical characterization in Bacillus subtilis 168 mutants specifically blocked in the synthesis of the teichoic acid poly(3-O- $\beta$-D-glucopyranosyl- $N$-acetylgalactosamine 1-phosphate): gne $A$, a new locus, is associated with UDP-N-acetylglucosamine 4-epimerase activity. J Gen Microbiol 137, 943-950.

171. Fajardo-Cavazos, P., Salazar, C. \& Nicholson, W. L. (1992). Molecular cloning and characterization of $s p l$, the gene encoding spore photoproduct lyase, which is involved in repair of ultraviolet radiation-induced DNA damage in Bacillus subtilis spores. XI International Spores Conference (Spores $X I)$, abstract no. 133.

172. Fajardo-Cavazos, P., Salazar, C. \& Nicholson, W. L. (1993). Molecular cloning and characterization of the Bacillus subtilis spore photoproduct lyase $(s p l)$ gene, which is involved in repair of UV radiation-induced DNA damage during spore germination. J Bacteriol 175, 1735-1744.

173. Fan, N., Cutting, S. \& Losick, R. (1992). Characterization of the Bacillus subtilis sporulation gene spoVK. J Bacteriol 174, 1053-1056.

174. Fani, R., Mastromei, G. \& Polsinelli, M. (1984). Isolation and characterization of Bacillus subtilis mutants altered in competence. J Bacteriol 157, 152-157.

175. Feavers, I. M., Miles, J. S. \& Moir, A. (1985). The nucleotide sequence of a spore germination gene (ger $A)$ of Bacillus subtilis 168. Gene 38, 95-102.

176. Fein, J. E. \& Rogers, H. J. (1976). Autolytic enzyme-deficient mutants of Bacillus subtilis 168. J Bacteriol 127, 1427-1442.

177. Ferrari, E., Henner, D. J. \& Yang, M. Y. (1985). Isolation of an 
alanine racemase gene from Bacillus subtilis and its use for plasmid maintenance in B. subtilis. Bio/Tecbnology 3, 1003-1007.

178. Ferrari, E., Scoffone, F., Ciarrocchi, G. \& Galizzi, A. (1985). Molecular cloning of a Bacillus subtilis gene involved in spore outgrowth. J Gen Microbiol 131, 2831-2838.

179. Ferrari, E. Unpublished data.

180. Ferrari, F. A., Lang, D., Ferrari, E. \& Hoch, J. A. (1982). Molecular cloning of the spoOB sporulation locus in bacteriophage lambda. J Bacteriol 152, 809-814.

181. Ferrari, F. A., Trach, K. \& Hoch, J. A. (1985). Sequence analysis of the $s p o O B$ locus reveals a polycistronic transcription unit. $J$ Bacteriol 161, 556-562.

182. Ferrari, F. A., Trach, K., LeCoq, D., Spence, J., Ferrari, E. \& Hoch, J. A. (1985). Characterization of the spoO $A$ locus and its deduced product. Proc Natl Acad Sci US A 82, 2647-2651.

183. Fischer, C., Geourjon, C., Bourson, C. \& Deutscher, J. (1996). Cloning and characterization of the Bacillus subtilis prk. $A$ gene encoding a novel serine protein kinase. Gene 168, 55-60.

184. Fisher, S. H., Rosenkrantz, M. S. \& Sonenshein, A. L. (1984). Glutamine synthetase gene of Bacillus subtilis. Gene 32, 427-438.

185. Fort, P. \& Piggot, P. J. (1984). Nucleotide sequence of sporulation locus spoII A in Bacillus subtilis. J Gen Microbiol 130, 2147-2153.

186. Fort, P. \& Errington, J. (1985). Nucleotide sequence and complementation analysis of a polycistronic sporulation operon, spoV $A$ in Bacillus subtilis. $J$ Gen Microbiol 131, 1091-1105.

187. Foster, S. J. (1991). Cloning, expression, sequence analysis and biochemical characterization of an autolytic amidase of Bacillus subtilis $168 \operatorname{trpC2}$. J Gen Microbiol 137, 1987-1998.

188. Foster, S. J. (1993). Molecular analysis of three major wallassociated proteins of Bacillus subtilis 168: evidence for processing of the product of a gene encoding a $258 \mathrm{kDa}$ precursor, two-domain ligand-binding protein. Mol Microbiol 8, 299-310.

189. Fouet, A., Klier, A. \& Rapoport, G. (1986). Nucleotide sequence of the sucrase gene of Bacillus subtilis. Gene 45, 221-225.

190. Fouet, A., Arnaud, M., Klier, A. \& Rapoport, G. (1987). Bacillus subtilis sucrose-specific enzyme II of the phosphotransferase system: expression in Escherichia coli and homology to enzymes II from enteric bacteria. Proc Natl Acad Sci USA 84, 8773-8777.

191. Foulger, D. \& Errington, J. (1989). The role of the sporulation gene spoIIIE in the regulation of prespore-specific gene expression in Bacillus subtilis. Mol Microbiol 3, 1247-1255.

192. Foulger, D. \& Errington, J. (1991). Sequential activation of dual promoters by different sigma factors maintains spoVJ expression during successive developmental stages of Bacillus subtilis. Mol Microbiol 5, 1363-1373.

193. Foulger, D. \& Errington, J. Unpublished data.

194. Frandsen, N. \& Stragier, P. (1995). Identification and characterization of the Bacillus subtilis spoIIP locus. $J$ Bacteriol 177, 716-722.

195. Fredrick, K. L. \& Helmann, J. D. (1994). Dual chemotaxis signaling pathways in Bacillus subtilis: a $\sigma^{\mathrm{D}}$-dependent gene encodes a novel protein with both $\mathrm{CheW}$ and CheY homologous domains. J Bacteriol 176, 2727-2735.
196. Freese, E. B., Cole, R. M., Klofat, W. \& Freese, E. (1970). Growth, sporulation, and enzyme defects of glucosamine mutants of Bacillus subtilis. J Bacteriol 101, 1046-1062.

197. Freese, E. Unpublished data.

198. Fuhrer, D. K. \& Ordal, G. W. (1991). Bacillus subtilis cheN, a homolog of che $A$, the central regulator of chemotaxis in Eschericbia coli. J Bacteriol 173, 7443 7448.

199. Fujishima, Y. \& Yamane, K. (1995). A $10 \mathrm{~kb}$ nucleotide sequence at the $5^{\prime}$ flanking region $\left(32^{\circ}\right)$ of $\operatorname{srf} A A$ of the Bacillus subtilis chromosome. Microbiology 141, 277-279.

200. Fujita, Y. \& Fujita, T. (1983). Genetic analysis of a pleiotropic deletion mutation ( $\Delta i g f)$ in Bacillus subtilis. J Bacteriol 154, 864-869.

201. Fujita, Y., Fujita, T., Miwa, Y., Nihashi, J. \& Aratani, Y. (1986). Organization and transcription of the gluconate operon, gnt, of Bacillus subtilis. J Biol Chem 261, 13744-13753.

202. Fujita, Y. \& Fujita, T. (1987). The gluconate operon gnt of Bacillus subtilis encodes its own transcriptional negative regulator. Proc Natl Acad Sci US A 84, 4524 4528.

203. Fujita, Y., Shindo, K., Miwa, Y. \& Yoshida, K. (1991). Bacillus subtilis inositol dehydrogenase-encoding gene (idh): sequence and expression in Escherichia coli. Gene 108, 121-125.

204. Fuma, S., Fujishima, Y., Corbell, N., D'Souza, C., Nakano, N. M., Zuber, P. \& Yamane, K. (1993). Nucleotide sequence of $5^{\prime}$ portion of $\operatorname{srf} A$ that contains the region required for competence establishment in Bacillus subtilis. Nucleic Acids Res 21, 93-97.

205. Gagnon, Y., Breton, R., Putzer, H., Pelchat, M., GrunbergManago, M. \& Lapointe, J. (1994). Clustering and COtranscription of the Bacillus subtilis genes encoding the aminoacyl-tRNA synthetases specific for glutamate and for cysteine and the first enzyme for cysteine biosynthesis. J Biol Cbem 269, 7473-7482

206. Gaido, M. L., Prostko, C. R. \& Strobl, J. S. (1988). Isolation and characterization of BsuE methyltransferase, a CGCGspecific DNA methyltransferase from Bacillus subtilis. J Biol Chem 263, 4832-4836.

207. Galizzi, A., Gorrini, F., Rollier, A. \& Polsinelli, M. (1973). Mutants of Bacillus subtilis temperature sensitive in the outgrowth phase of spore germination. I Bacteriol 113, $1482-1490$

208. Galizzi, A. Unpublished data.

209. Gallori, E., Bazzicalupo, M., Parisi, B., Pedaggi, G. \& Polsinelli, M. (1978). Resistance to (L)-azetidine-2-carboxylic acid in Bacillus subtilis. Biochem Biophys Res Commun 85, 1518-1525.

210. Gallori, E. \& Fani, R. (1983). Characterization of D-cycloserine resistant mutants in Bacillus subtilis. Microbiologica 6, 19-26.

211. Gardan, R., Rapoport, G. \& Débarbouillé, M. (1995). Expression of the rocDEF operon involved in arginine catabolism in Bacillus subtilis. J Mol Biol 249, 843-885.

212. Garrity, D. B. \& Zahler, S. A. (1993). The Bacillus subtilis ochre suppressor sup- 3 is located in an operon of seven tRNA genes. J Bacteriol 175, 6512-6517.

213. Garro, A. J., Leffert, H. \& Marmur, J. (1970). Genetic mapping of a defective bacteriophage on the chromosome of Bacillus subtilis 168. J Virol 6, 340-343

214. Garro, A. J., Sprouse, C. \& Wetmur, J. G. (1976). Association of the recombination-deficient phenotype of Bacillus subtilis 
$\mathrm{rec} C$ strains with the presence of an $\mathrm{SPO} 2$ prophage. $J$ Bacteriol 126, 556-558.

215. Gass, K. B. \& Cozzarelli, N. R. (1973). Further genetic and enzymological characterization of the three Bacillus subtilis deoxyribonucleic acid polymerases. J Biol Chem 248, 76887700 .

216. Gaur, N. K., Cabane, K. \& Smith, I. (1988). Structure and expression of the Bacillus subtilis sin operon. J Bacteriol 170, 1046-1053.

217. Gay, P. \& Delobbe, A. (1977). Fructose transport in Bacillus subtilis. Eur J Biochem 79, 363-373.

218. Gay, P., LeCoq, D., Steinmetz, M., Ferrari, E. \& Hoch, J. A. (1983). Cloning structural gene $s a c B$, which codes for exoenzyme levansucrase of Bacillus subtilis: expression of the gene in Eschericbia coli. J Bacteriol 153, 1424-1431.

219. Gay, P., Chalumeau, H. \& Steinmetz, M. (1983). Chromosomal localization of $g u t, f r u C$, and $p f k$ mutations affecting genes involved in Bacillus subtilis D-glucitol catabolism. $J$ Bacteriol 153, 1133-1137.

220. Gholamhoseinian, A., Shen, Z., Wu, J. J. \& Piggot, P. J. (1992). Regulation of transcription of the cell division gene fts $A$ during sporulation of Bacillus subtilis. $J$ Bacteriol 174 4647-4656.

221. Gianni, M. \& Galizzi, A. (1986). Isolation of genes preferentially expressed during Bacillus subtilis spore outgrowth. $J$ Bacteriol 165, 123-132.

222. Gillespie, K. \& Yasbin, R. E. (1987). Chromosomal locations of three Bacillus subtilis din genes. J Bacteriol 169, 3372-3374.

223. Ginetti, F., Perego, M., Albertini, A. M. \& Galizzi, A. Unpublished data.

224. Glaser, P., Danchin, A., Kunst, F., Débarbouillé, M., Vertes, A. \& Dedonder, R. (1991). A gene encoding a tyrosine tRNA synthetase is located near sacS in Bacillus subtilis. DNA Seq 1 , 251-261

225. Glaser, P., Kunst, F., Arnaud, M., Coudart, M. P., Danchin, A., Gonzales, W., Hullo, M. F., lonescu, M., Lubochinsky, B., Marcelino, L., Moszer, I., Presecan, E., Rapoport, G., Santana, M., Schneider, E., Schweizer, J. \& Vertes, A. (1993). Bacillus subtilis genome project: cloning and sequencing of the $97 \mathrm{~kb}$ region from $325^{\circ}$ to $333^{\circ}$. Mol Microbiol 10, 371-384.

226. Glaser, P., Danchin, A., Kunst, F., Zuber, P. \& Nakano, M. M. (1995). Identification and isolation of a gene required for nitrate assimilation and anaerobic growth of Bacillus subtilis. $J$ Bacteriol 177, 1112-1115.

227. Glaser, P. Unpublished data.

228. Glaser, P., De La Fuente, V. \& Danchin, A. Unpublished data.

229. Goldstein, B. J. \& Zahler, S. A. (1976). Uptake of branchedchain $\alpha$-keto acids in Bacillus subtilis. J Bacteriol 127, 667-670.

230. Goldthwaite, C., Dubnau, D. \& Smith, I. (1970). Genetic mapping of antibiotic resistance markers in Bacillus subtilis. Proc Natl Acad Sci US A 65, 96-103.

231. Goldthwaite, C. \& Smith, I. (1972). Genetic mapping of amino-glycoside and fusidic acid resistant mutations in Bacillus subtilis. Mol Gen Genet 114, 181-189.

232. Gollnick, P., Ishino, S., Kuroda, M. I., Henner, D. J. \& Yanofsky, C. (1990). The mtr locus is a two-gene operon required for transcription attenuation in the trp operon of Bacillus subtilis. Proc Natl Acad Sci US A 87, 8726-8730.

233. Gonzy-Tréboul, G. \& Steinmetz, M. (1987). Phosphoenolpyruvate:sugar phosphotransferase system of Bacillus subtilis: cloning of the region containing the $p t s H$ and $p t s I$ genes and evidence for the crr-like gene. J Bacteriol 169, 2287-2290.

234. Gonzy-Tréboul, G., Zagorec, M., Rain-Guion, M.-C. \& Steinmetz, M. (1989). Phosphoenolpyruvate: sugar phosphotransferase system of Bacillus subtilis: nucleotide sequence of $p t s X$, $p t s \mathrm{H}$ and the $5^{\prime}$-end of $p t s I$ and evidence for a $p t s H I$ operon. Mol Microbiol 3, 103-112.

235. Gonzy-Tréboul, G., Karmazyn-Campelli, C. \& Stragier, P. (1992). Developmental regulation of transcription of the Bacillus subtilis fts $A Z$ operon. $J$ Mol Biol 224, 967-979.

236. Gotsche, S. \& Dahl, M. (1995). Purification and characterization of the phospho- $\alpha-(1,1)$-glucosidase (TreA) of Bacillus subtilis 168. J Bacteriol 177, 2721-2726.

237. Grandoni, J. A., Zahler, S. A. \& Calvo, J. M. (1992). Transcriptional regulation of the ilv-leu operon of Bacillus subtilis. $J$ Bacteriol 174, 3212-3219.

238. Gray, J. V., Golinelli-Pimpaneau, G. \& Knowles, J. R. (1990). Monofunctional chorismate mutase from Bacillus subtilis: purification of the protein, molecular cloning of the gene, and overexpression of the gene product in Escherichia coli. Biochemistry 29, 376-383.

239. Green, C. J., Stewart, G. C., Hollis, M. A., Vold, B. S. \& Bott, K. F. (1985). Nucleotide sequence of the Bacillus subtilis ribosomal RNA operon, $r r n B$. Gene 37, 261-266.

240. Green, C. J. \& Vold, B. S. (1992). A cluster of nine tRNA genes between ribosomal gene operons in Bacillus subtilis. J Bacteriol 174, 3147-3151.

241. Green, D. M. (1968). Gene dislinkage in transfection of SP82G phage DNA. Genetics 60, 673-680.

242. Gropp, M., Eizenman, E., Glaser, G., Samarrai, W. \& Rudner, R. (1994). A rel $A(S)$ suppressor mutant allele of Bacillus subtilis which maps to $\operatorname{rel} A$ and responds only to carbon limitation. Gene 140, 91-96.

243. Grossman, T. H., Tuckman, M., Ellestad, S. \& Osburne, M. S. (1993). Isolation and characterization of Bacillus subtilis genes involved in siderophore biosynthesis : relationship between $B$. subtilis sfpO and Escherichia coli entD genes. $J$ Bacteriol 175, 6203-6211

244. Grundy, F. J. \& Henkin, T. M. (1990). Cloning and analysis of the Bacillus subtilis rps $D$ gene, encoding ribosomal protein $\mathrm{S} 4$. J Bacteriol 172, 6372-6379.

245. Grundy, F. J., Waters, D. A., Allen, S. H. \& Henkins, T. M. (1993). Regulation of the Bacillus subtilis acetate kinase gene by CcpA. J Bacteriol 175, 7348-7355.

246. Grundy, F. J., Waters, D. A., Takova, T. Y. \& Henkin, T. M. (1993). Identification of genes involved in utilization of acetate and acetoin in Bacillus subtilis. Mol Microbiol 10, 259-271.

247. Grundy, F. J., Turinsky, A. J. \& Henkin, T. M. (1994). Catabolite regulation of Bacillus subtilis acetate and acetoin utilization genes by CcpA. J Bacteriol 176, 4527-4533.

248. Guerout-Fleury, A.-M. \& Stragier, P. (1992). Unexpected complexity of the spoIIIA locus. XI International Spores Conference (Spores XI), abstract no. 151.

249. Guerout-Fleury, A. M. (1995). Direct submission to EMBL/ GenBank/DDBJ - U35252.

250. Guzman, P., Westpheling, J. \& Youngman, P. (1988). Characterization of the promoter region of the Bacillus subtilis spoIIE operon. J Bacteriol 170, 1598-1609.

251. Hackett, R. H. \& Setlow, P. (1987). Cloning, nucleotide 
sequencing, and genetic mapping of the gene for small, acidsoluble spore protein $\gamma$ of Bacillus subtilis. J Bacteriol 169, 1985-1992.

252. Hahn, J., Inamine, G., Kozlov, Y. \& Dubnau, D. (1993). Characterization of comE, a late competence operon of Bacillus subtilis required for the binding and uptake of transforming DNA. Mol Microbiol 10, 99-111.

253. Haijema, B. J., Hamoen, L. W., Kooistra, J., Venema, G. \& van Sinderen, D. (1995). Expression of the ATP-dependent deoxyribonuclease of Bacillus subtilis is under competencemediated control. Mol Microbiol 15, 203-211.

254. Haldenwang, W. G., Banner, C. D. B., Ollington, J. F., Losick, R., Hoch, J. A., O'Connor, M. B. \& Sonenshein, A. L. (1980). Mapping a cloned gene under sporulation control by insertion of a drug resistance marker into the Bacillus subtilis chromosome. J Bacteriol 142, 90-98.

255. Halling, S. M. \& Burtis, K. C. (1977). Reconstitution studies show that rifampicin resistance is determined by the largest polypeptide of Bacillus subtilis RNA polymerase. $J$ Biol Chem 252, 9024-9031.

256. Halling, S. M., Burtis, K. C. \& Doi, R. H. (1978). $\beta$ subunit of bacterial RNA polymerase is responsible for streptolydigin resistance in Bacillus subtilis. Nature 272, 837-839.

257. Hammer-Jespersen, K. (1983). Nucleoside catabolism. In Metabolism of Nucleotides, Nucleosides and Nucleobases in Microorganisms, pp. 203-258. Edited by A. Munch-Petersen. New York: Academic Press.

258. Hammond, R. A., Barnes, M. H., Mack, S. L., Mitchener, J. A. \& Brown, N. C. (1991). Bacillus subtilis DNA polymerase III: complete sequence, overexpression, and characterization of the polC gene. Gene 98, 29-36.

259. Hamoen, L. W., Eshuis, H., Jongbloed, J., Venema, G. \& van Sinderen, D. (1995). A small gene, designated comS, located within the coding region of the fourth amino acid-activation domain of $\operatorname{srf} A$, is required for competence development in Bacillus subtilis. Mol Microbiol 15, 55-63.

260. Hanlon, D. W., Marquez-Magana, L. M., Carpenter, P. B., Chamberlin, M. J. \& Ordal, G. W. (1992). Sequence and characterization of Bacillus subtilis CheW. J Biol Chem 267, 12055-12060.

261. Hanlon, D. W. \& Ordal, G. W. (1994). Cloning and characterization of genes encoding methyl-accepting chemotaxis proteins in Bacillus subtilis. J Biol Chem 269, 14038-14046.

262. Hanlon, D., Rosario, M. M. L., Ordal, G. W., Venema, G. \& Van Sinderen, D. (1994). Identification of TlpC, a novel $62 \mathrm{kDa}$ MCP-like protein from Bacillus subtilis. Microbiology 140, 1847-1854.

263. Hansson, M., Rutberg, L., Schroder, I. \& Hederstedt, L. (1991). The Bacillus subtilis bem $A X C D B L$ gene cluster, which encodes enzymes of the biosynthetic pathway from glutamate to uroporphyrinogen III. J Bacteriol 173, 2590-2599.

264. Hansson, M. \& Hederstedt, L. (1992). Cloning and characterization of the Bacillus subtilis bemEHY operon which encodes protoheme IX biosynthesis enzymes. J Bacteriol 174, 8081-8093.

265. Hantke, K. \& Schneider, R. (1993). Iron-hydroxamate uptake systems in Bacillus subtilis: identification of a lipoprotein as part of a binding protein-dependent transport system. Mol Microbiol 8, 111-121.

266. Hara, H. \& Yoshikawa, H. (1973). Asymmetric bidirectional replication of Bacillus subtilis chromosome. Nature 244, 200-203.
267. Harford, N. \& Sueoka, N. (1970). Chromosomal location of antibiotic resistance markers in Bacillus subtilis. J Mol Biol 51, 267-286.

268. Harford, N., Lepesant-Kejzlarova, J., Lepesant, J.-A., Hamers, R. \& Dedonder, R. (1976). Genetic circularity and mapping of the replication origin region of the Bacillus subtilis chromosome. In Microbiology-1976, pp. 28-34. Edited by D. Schlessinger. Washington, DC: American Society for Microbiology.

269. Harry, E. J. \& Wake, R. G. (1989). Cloning and expression of a Bacillus subtilis division initiation gene for which a homolog has not been identified in another organism. $J$ Bacteriol 171, 6835-6839.

270. Harry, E. J., Rowland, S. L., Malo, M. S. \& Wake, R. G. (1994). Expression of divIB of Bacillus subtilis during vegetative growth. J Bacteriol 176, 1172-1179.

271. Hastrup, S. (1988). Analysis of the Bacillus subtilis xylose regulon. In Genetics and Biotechnology of Bacilli, vol. 2. Edited by A. T. Ganesan \& J. A. Hoch. San Diego, CA: Academic Press.

272. Hauser, P. M., Crabb, W. D., Fioria, M. G., Scoffone, F. \& Galizzi, A. (1991). A genetic analysis of the flaA locus of Bacillus subtilis. J Bacteriol 173, 3580-3583.

273. Hearne, C. M. \& Ellar, D. J. (1989). Nucleotide sequence of a Bacillus subtilis gene homologous to the dnaK gene of Escherichia coli. Nucleic Acids Res 17, 8373.

274. Hediger, M. A., Frank, G. \& Zuber, H. (1986). Structure and function of L-lactate dehydrogenases from thermophilic and mesophilic bacteria. IV. The primary structure of the mesophilic lactate dehydrogenase from Bacillus subtilis. Biol Chem Hoppe-Seyler 367, 891-903.

275. Helfert, C., Gotsche, S. \& Dahl, M. K. (1995). Cleavage of trehalose-phosphate in Bacillus subtilis is catalysed by a phospho- $\alpha$-(1-1)-glucosidase encoded by the tre $A$ gene. Mol Microbiol 16, 111-120.

276. Helmann, J. D., Marquez, L. M. \& Chamberlin, M. J. (1988). Cloning, sequencing, and disruption of the Bacillus subtilis $\sigma^{28}$ gene. J Bacteriol 170, 1568-1574.

277. Hemila, H., Palva, A., Paulin, L., Arvidson, S. \& Palva, I. (1990). Secretory $S$ complex of Bacillus subtilis: sequence analysis and identity to pyruvate dehydrogenase. J Bacteriol 172, 5052-5063.

278. Hemila, H. (1991). Sequence of a PAL-related lipoprotein from Bacillus subtilis. FEMS Microbiol Lett 82, 37-42.

279. Hemila, H., Koivula, T. \& Paulin, L. Unpublished data.

280. Hemphill, E. H., Gage, I., Zahler, S. A. \& Korman, R. Z. (1980). Prophage mediated production of bacteriocin-like substance by SP $\beta$ lysogens of Bacillus subtilis. Can J Microbiol 26, $1328-1333$.

281. Henkin, T. M., Campbell, K. M. \& Chambliss, G. H. (1979). Spectinomycin dependence in Bacillus subtilis. J Bacteriol 137, 1452-1455.

282. Henkin, T. M. \& Chambliss, G. H. (1984). Genetic analysis of a streptomycin-resistant oligosporogenous Bacillus subtilis. $J$ Bacteriol 157, 202-210.

283. Henkin, T. M., Moon, S. H., Mattheakis, L. C. \& Nomura, M. (1989). Cloning and analysis of the $s p c$ ribosomal protein operon of Bacillus subtilis: comparison with the spc operon of Escherichia coli. Nucleic Acids Res 17, 7469-7486.

284. Henkin, T. M., Grundy, F. J., Nicholson, W. L. \& Chambliss, G. H. (1991). Catabolite repression of $\alpha$-amylase gene ex- 
pression in Bacillus subtilis involves a trans-acting gene product homologous to the Escherichia coli lacI and galR repressors. Mol Microbiol 5, 575-584.

285. Henkin, T. M., Glass, B. L. \& Grundy, F. J. (1992). Analysis of the Bacillus subtilis tyrS gene: conservation of regulatory sequence in multiple tRNA synthetase genes. J Bacteriol 174, 1299-1306.

286. Henner, D. J. \& Steinberg, W. (1979). Genetic location of the Bacillus subtilis sup-3 suppressor mutation. I Bacteriol 139, 668-670.

287. Henner, D. J. \& Hoch, J. A. (1980). The Bacillus subtilis chromosome. Microbiol Rev 44, 57-82.

288. Henner, D. J. \& Hoch, J. A. (1982). The genetic map of Bacillu. subtilis. In The Molecular Biology of the Bacilli, pp. 1-33. Edited by D. Dubnau. New York: Academic Press.

289. Henner, D. J., Band, L. \& Shimotsu, H. (1984). Nucleotide sequence of the Bacillus subtilis tryptophan operon. Gene 34 169-177.

290. Henner, D. J., Band, L., Flaggs, G. \& Chen, E. (1986). The organization and nucleotide sequence of the Bacillus subtilis bisH, tyr $A$, and aroE genes. Gene 49, 147-152.

291. Henner, D. J., Yang, M. \& Ferrari, E. (1988). Localization of Bacillus subtilis sac $\mathrm{U}(\mathrm{Hy})$ mutations to two linked genes with similarities to the conserved procaryotic family of twocomponent signalling systems. J Bacteriol 170, 5102-5109.

292. Henner, D. J., Gollnick, P. \& Moir, A. (1990). Analysis of an 18 kilobase pair region of the Bacillus subtilis chromosome containing the mtr and gerC operons and the aro-trp-aro supraoperon. In Proceedings of the 6th International Symposium on Genetics of Industrial Microorganisms, vol. 2, pp. 657-665. Edited by H. Heslot, J. Davies, J. Florent, L. Bohichou, G. Durand \& L. Penaasse. Strasbourg: Societie Francaise de Microbiologie.

293. Henriques, A. D., de Lencastre, H. \& Piggot, P. J. (1992). A Bacillus subtilis morphogene cluster that includes spoVE is homologous to the mra region of Escherichia coli. Biochimie 74, 735-748.

294. Henriques, A. O., Beall, B. W., Roland, K. \& Moran, C. P. (1995). Characterization of cotJ, a $\sigma^{\mathrm{E}}$-controlled operon affecting the polypeptide composition of the coat of Bacillus subtilis spores. J Bacteriol 177, 3394-3406.

295. Herrler, M., Bang, H. \& Marahiel, M. A. (1994). Cloning and characterization of $p p i B$, a Bacillus subtilis gene which encodes a cyclosporin A-sensitive peptidyl-prolyl cis-trans isomerase. Mol Microbiol 11, 1073-1083.

296. Hicks, K. A. \& Grossman, A. D. (1995). Characterization of csh203:: Tn917lac, a mutation in Bacillus subtilis that makes the sporulation sigma factor $\sigma^{\mathrm{H}}$ essential for normal vegetative growth. J Bacteriol 177, 3736-3742.

297. Higerd, T. B. (1977). Isolation of acetyl esterase mutants of Bacillus subtilis 168. J Bacteriol 129, 973-977.

298. Hilden, I., Krath, B. N. \& Hove-Jensen, B. (1995). Tricistronic operon expression of the genes gcaD (tms), which encodes $N$ acetylglucosamine 1-phosphate uridyltransferase, prs, which encodes phosphoribosyl diphosphate synthetase, and ctc in vegetative cells of Bacillus subtilis. J Bacteriol 177, 7280-7284.

299. Hilton, M. D., Alaeddinoglu, N. G. \& Demain, A. L. (1988). Bacillus subtilis mutant deficient in the ability to produce the dipeptide antibiotic bacilysin: isolation and mapping of the mutation. J Bacteriol 170, 1018-1020.

300. Hoch, J. A. \& Anagnostopoulos, C. (1970). Chromosomal location and properties of radiation sensitivity mutations in Bacillus subtilis. J Bacteriol 103, 295-301.

301. Hoch, J. A. \& Mathews, J. (1972). Genetic studies in Bacillus subtilis. In Spores $V$, pp. 113-116. Edited by H. O. Halvorson, R. Hanson \& L. L. Campbell. Washington, DC: American Society for Microbiology.

302. Hoch, J. A. \& Nester, E. W. (1973). Gene-enzyme relationships of aromatic acid biosynthesis in Bacillus subtilis. J Bacteriol 116, 59-66.

303. Hoch, J. A. \& Coukoulis, H. J. (1978). Genetics of the $\alpha$ ketoglutarate dehydrogenase complex of Bacillus subtilis. $J$ Bacteriol 133, 265-269.

304. Hoch, J. A., Trach, K., Kawamura, F. \& Saito, H. (1985). Identification of the transcriptional suppressor sof-1 as an alteration in the spo0A protein. $J$ Bacteriol 161, 552-555.

305. Hoch, J. A. Unpublished data.

306. Hofemeister, J., Israeli-Reches, M. \& Dubnau, D. (1983). Integration of plasmid pE194 at multiple sites on the Bacillus subtilis chromosome. Mol Gen Genet 189, 58-68.

307. Hofemeister, J. (1994). Direct submission to EMBL/ GenBank/DDBJ - U13634.

308. Hoffmann, T., Troup, B., Szabo, A., Hungerer, C. \& Jahn, D. (1995). The anaerobic life of Bacillus subtilis: cloning of the genes encoding the respiratory nitrate reductase system. FEMS Microbiol Lett 131, 219-225.

309. Holmberg, C., Beijer, L., Rutberg, B. \& Rutberg, L. (1990). Glycerol catabolism in Bacillus subtilis: nucleotide sequence of the genes encoding glycerol kinase $(g l p K)$ and glycerol-3phosphate dehydrogenase $(g / p D)$. J Gen Microbiol 136, 23672375.

310. Honda, K., Nakamura, K., Nishiguchi, M. \& Yamane, K. (1993). Cloning and characterization of a Bacillus subtilis gene encoding a homolog of the 54-kilodalton subunit of mammalian signal recognition particle and Escberichia coli $\mathrm{Ffh} . J$ Bacteriol 175, 4885-4894.

311. Honeyman, A. L. \& Stewart, G. C. (1989). Identification of the protein encoded by $\operatorname{rod} C$, a cell division gene from Bacillus subtilis. Mol Microbiol 2, 735-741.

312. Honeyman, A. L. \& Stewart, G. C. (1989). The nucleotide sequence of the rodC operon of Bacilius subtilis. Mol Microbiol 3, 1257-1268

313. Honjo, M., Nakayama, A., Fukazawa, K., Kawamura, K., Ando, K., Hori, M. \& Furutani, Y. (1990). A novel Bacillus subtilis gene involved in negative control of sporulation and degradative-enzyme production. J Bacteriol 172, 1783-1790.

314. Hoshino, T., McKenzie, T., Schmidt, S., Tanaka, T. \& Sueoka, N. (1987). Nucleotide sequence of Bacillus subtilis dnaB: a gene essential for DNA replication, initiation and membrane attachment. Proc Natl Acad Sci USA 84, 653-657.

315. Hudspeth, D. S. S. \& Vary, P. S. (1992). spoVG sequence of Bacillus megaterium and Bacillus subtilis. Biocbim Biopbys Acta 1130, 229-231.

316. Hulett, F. M., Kim, E. E., Bookstein, C., Kapp, N. V., Edwards, C.W. \& Wyckoff, H.W. (1991). Bacillus subtilis alkaline phosphatase III and IV : cloning, sequence, and comparison of deduced amino acid sequence with Escherichia coli alkaline phosphatase three-dimensional structure. $\int$ Biol Chem 266 , 1077-1084.

317. Hulett, F. M., Lee, J., Shi, L., Sun, G., Chestnut, R., Sharkova, E., Duggan, M. F. \& Kapp, N. (1994). Sequential action of 
two-component genetic switches regulates the PHO regulon in Bacillus subtilis. J Bacteriol 176, 1348-1358.

318. Igo, M., Lampe, M. \& Losick, R. (1988). Structure and regulation of a Bacillus subtilis gene that is transcribed by the EB form of RNA polymerase holoenzyme. In Genetics and Biotechnology of Bacilli, vol. 2, pp. 151-156. Edited by A. T. Ganesan \& J. A. Hoch. San Diego, CA: Academic Press.

319. lijima, T. \& Ikeda, Y. (1970). Mutability of the phleomycinresistant mutants of Bacillus subtilis. I. Isolation of genetically unstable mutants. J Gen Appl Microbiol 16, 419-427.

320. lijima, T., Diesterhaft, M. D. \& Freese, E. (1977). Sodium effect of growth on aspartate and genetic analysis of a Bacillus subtilis mutant with high aspartase activity. J Bacteriol 129, 1440-1447.

321. Ikawa, S., Shibata, T., Matsumoto, K., lijima, T., Saito, H. \& Ando, T. (1981). Chromosomal loci of genes controlling sitespecific restriction endonucleases of Bacillus subtilis. Mol Gen Genet 183, 1-6.

322. Ikeda, M., Sato, T., Wachi, M., Jung, H. K., Ishino, F., Kobayashi, Y. \& Matsuhashi, M. (1989). Structural similarity among Escherichia coli $\mathrm{FtsW}$ and RodA proteins and Bacillus subtilis SpoVE protein, which function in cell division, cell elongation, and spore formation, respectively. J Bacteriol 171, 6375-6378.

323. Ikeda, M., Wachi, M., Jung, H. K., Ishino, F. \& Matsuhashi, M. (1990). Homology among MurC, MurD, MurE and MurF proteins in Escherichia coli and that between E. coli MurG and a possible MurG protein in Bacillus subtilis. J Gen Appl Microbiol 36, 179-187.

324. Illing, N. \& Errington, J. (1991). The spoIII $A$ operon of Bacillus subtilis defines a new temporal class of mother-cellspecific sporulation genes under the control of the $\mathrm{E}$ form of RNA polymerase. Mol Microbiol 5, 1927-1940.

325. Imai, R., Sekiguchi, T., Nosoh, Y. \& Tsuda, K. (1987). The nucleotide sequence of 3 -isopropylmalate dehydrogenase gene from Bacillus subtilis. Nucleic Acids Res 15, 4988.

326. Ionesco, H., Michel, J., Cami, B. \& Schaeffer, P. (1970). Genetics of sporulation in Bacillus subtilis Marburg. J Appl Bacteriol 33, 13-24.

327. Ireton, K., Gunther, N. W. \& Grossman, A. D. (1994). spo0J is required for normal chromosome segregation as well as the initiation of sporulation in Bacillus subtilis. J Bacteriol 176, $5320-5329$.

328. Irie, R., Okamoto, T. \& Fujita, Y. (1982). A germination mutant of Bacillus subtilis deficient in response to glucose. $J$ Gen Appl Microbiol 28, 345-354.

329. Irie, R., Fujita, Y. \& Okamoto, T. (1993). Cloning and sequencing of the gerK spore germination gene of Bacillus subtilis 168. J Gen Microbiol 139, 453-465.

330. Itaya, M. \& Tanaka, T. (1991). Complete physical map of the Bacillus subtilis 168 chromosome constructed by a genedirected mutagenesis method. J Mol Biol 220, 631-648.

331. Ito, J. (1973). Pleiotropic nature of bacteriophage tolerant mutants obtained in early-blocked asporogenous mutants of Bacillus subtilis 168. Mol Gen Genet 124, 97-106.

332. Itoh, T. (1976). Amino acid replacement in the protein $S 5$ from a spectinomycin resistant mutant of Bacillus subtilis. Mol Gen Genet 144, 39-42.

333. Iwakura, M., Kawata, M., Tsuda, K. \& Tanaka, T. (1988). Nucleotide sequences of the thymidylate synthase $B$ and dihydrofolate reductase genes contained in one Bacillus subtilis operon. Gene 64, 9-20.
334. Jaacks, K. J., Healy, J., Losick, R. \& Grossman, A. D. (1989). Identification and characterization of genes controlled by the sporulation-regulatory gene $s p o 0 \mathrm{H}$ in Bacillus subtilis. J Bacteriol 171, 4121-4129.

335. James, W. \& Mandelstam, J. (1985). spoVIC, a new sporulation locus in Bacillus subtilis affecting spore coats, germination and the rate of sporulation. J Gen Microbiol 131, 2409-2419.

336. Jenkinson, H. F. (1981). Germination and resistance defects in spores of Bacillus subtilis mutant lacking a coat polypeptide. $J$ Gen Microbiol 127, 81-91.

337. Jenkinson, H. F. (1983). Altered arrangement of proteins in the spore coat of a germination mutant of Bacillus subtilis. J Gen Microbiol 129, 1945-1958.

338. Jenkinson, H. F. \& Mandelstam, J. (1983). Cloning of the Bacillus subtilis lys and spoIIIB genes in phage $\phi 105 . J$ Gen Microbial 129, 2229-2240.

339. Jeong, S., Yoshikawa, H. \& Takahashi, H. (1993). Isolation and characterization of the $\sec E$ homologue gene of Bacillus subtilis. Mol Microbiol 10, 133-142.

340. Jin, S. \& Sonenshein, A. L. (1994). Identification of two distinct Bacillus subtilis citrate synthase genes. J Bacteriol 176, 4669-4679.

341. Jin, S., de Jesus-Berrios, M. \& Sonenshein, A. L. (1996). A Bacillus subtilis malate dehydrogenase gene. J Bacteriol 178, 560-563.

342. Johnson, W. C., Moran, C. P., Jr \& Losick, R. (1984). Two RNA polymerase sigma factors from Bacillus subtilis discriminate between overlapping promoters for a developmentally regulated gene. Nature 302, 800-804.

343. Johnstone, B. H. Unpublished data.

344. Joris, B., Dive, G., Henriques, A., Piggot, P. J. \& Ghuysen, J. M. (1990). The life-cycle proteins RodA of Escherichia coli and SpoVE of Bacillus subtilis have very similar primary structures. Mol Microbiol 4, 513-517.

345. Kaminskas, E., Kimhi, Y. \& Magasanik, B. (1970). Urocanase and $N$-formimino-L-glutamate formiminohydrolase of Bacillus subtilis, two enzymes of the histidine degradation pathway. $J$ Biol Chem 245, 3536-3544.

346. Kane, J. F., Goode, R. L. \& Wainscott, J. (1975). Multiple mutations in cys $A 14$ mutants of Bacillus subtilis. J Bacteriol 121, 204-211.

347. Kane, J. F. (1977). Regulation of a common aminotransferase subunit. J Bacteriol 132, 419-425.

348. Kanzaki, N. \& Miyagawa, K. (1990). Nucleotide sequence of the Bacillus subtilis IMP dehydrogenase gene. Nucleic Acids Res 18, 6710.

349. Kapfer, W., Walter, J. \& Trautner, T. A. (1991). Cloning, characterization and evolution of the BsuFI restriction endonuclease gene of Bacillus subtilis and purification of the enzyme. Nucleic Acids Res 19, 6457-6463.

350. Karamata, D. \& Gross, J. D. (1970). Isolation and genetic analysis of temperature-sensitive mutants of Bacillus subtilis defective in DNA synthesis. Mol Gen Genet 108, 277-287.

351. Karamata, D., McConnell, M. \& Rogers, H. J. (1972). Mapping of rod mutants of Bacillus subtilis. J Bacteriol 111, 73-79.

352. Karmazyn-Campelli, C., Bonamy, C., Savelli, B. \& Stragier, P. (1989). Tandem genes encoding sigma-factors for consecutive steps of development in Bacillus subtilis. Genes Dev 3, 150-157.

353. Karow, M. L., Glaser, P. \& Piggot, P. J. (1995). Identification of a gene, spoIIR, that links the activation of $\sigma^{E}$ to the 
transcriptional activity of $\sigma^{\mathrm{F}}$ during sporulation in Bacillus subtilis. Proc Natl Acad Sci US A 92, 2012-2016.

354. Kelly, M. S. \& Pritchard, R. H. (1963). Selection for linked loci in Bacillus subtilis by means of transformation. Heredity 17, 598-603.

355. Kelly, M. S. (1967). Physical and mapping properties of distant linkages between genetic markers in transformation of Bacillus subtilis. Mol Gen Genet 99, 333-349.

356. Kempf, B. \& Bremer, E. (1995). OpuA, an osmotically regulated binding protein-dependent transport system for the osmoprotectant glycine betaine in Bacillus subtilis. J Biol Chem 270, 16701-16713.

357. Kiel, J. A., Boels, J. M., Beldman, G. \& Venema, G. (1994). Glycogen in Bacillus subtilis: molecular characterization of an operon encoding enzymes involved in glycogen biosynthesis and degradation. Mol Microbiol 11, 203-218.

358. Kil, Y. V., Mironov, V. N., Gorishin, I. Yu., Kreneva, R. A. \& Perumov, D. A. (1992). Riboflavin operon of Bacillus subtilis: unusual symmetric arrangement of the regulatory region. Mol Gen Genet 233, 483-486.

359. Kirsch, M. L., Peters, P. D., Hanlon, D. W., Kirby, J. R. \& Ordal, G. W. (1993). Chemotactic methylesterase promotes adaptation to high concentrations of attractant in Bacillus subtilis. J Biol Chem 268, 18610-18616.

360. Kirsch, M. L., Carpenter, P. B. \& Ordal, G. W. (1994). A putative ATP-binding protein from the che/fla locus of Bacillus subtilis. DNA Seq 4, 271-275.

361. Kiss, A., Posfai, G., Keller, C. C., Venetianer, P. \& Roberts, R. J. (1985). Nucleotide sequence of the BsuRI restrictionmodification system. Nucleic Acids Res 13, 6403-6421.

362. Kiss, I., Berek, I. \& Ivánovics, G. (1971). Mapping the $\delta$ aminolaevulinic acid synthetase locus in Bacillus subtilis. J Gen Microbiol 66, 153-159.

363. Klein, C., Kaletta, C., Schnell, N. \& Entian, K. D. (1992). Analysis of genes involved in biosynthesis of the antibiotic subtilin. Appl Environ Microbiol 58, 132-142.

364. Klein, M., Hofmann, B., Klose, M. \& Freudl, R. (1994). Isolation and characterization of a Bacillus subtilis $\sec A$ mutant allele conferring resistance to sodium azide. FEMS Microbiol Lett 124, 393-397.

365. Klier, A. F. \& Rapoport, G. (1988). Genetics and regulation of carbohydrate catabolism in Bacillus. Annu Rev Microbiol 42, 65-95.

366. Kobayashi, H., Kobayashi, K. \& Kobayashi, Y. (1977). Isolation and characterization of fusidic acid-resistant, sporulation-defective mutants of Bacillus subtilis. I Bacteriol 132, $262-269$.

367. Kobayashi, K., Shoji, K., Shimizu, T., Nakano, K., Sato, T. \& Kobayashi, Y. (1995). Analysis of a suppressor mutation $s s b$ (kinC) of surOB20 (spoOA) mutation in Bacillus subtilis reveals that $k$ in $C$ encodes a histidine protein kinase. J Bacteriol 177, 176-182.

368. Koide, A. \& Hoch, J. A. (1994). Identification of a second oligopeptide transport system in Bacillus subtilis and determination of its role in sporulation. Mol Microbiol 13, $417-426$.

369. Koide, Y., Nakamura, A., Uozumi, T. \& Beppu, T. (1986). Cloning and sequencing of the major intracellular serine protease gene of Bacillus subtilis. J Bacteriol 167, 110-116.

370. Kong, L., Siranosian, K. J., Grossman, A. D. \& Dubnau, D. (1993). Sequence and properties of $\operatorname{mec} A$, a negative regulator of genetic competence in Bacillus subtilis. Mol Microbiol 9 365-373.

371. Kontinen, V. P. \& Sarvas, M. (1988). Mutants of Bacillus subtilis defective in protein export. I Gen Microbiol 134, $2333-2344$.

372. Kontinen, V. P., Saris, P. \& Sarvas, M. (1991). A gene (prs $A)$ of Bacillus subtilis involved in a novel, late stage of protein export. Mol Microbiol 5, 1273-1283.

373. Kooistra, J., Vosman, B. \& Venema, G. (1988). Cloning and characterization of a Bacillus subtilis transcription unit involved in ATP-dependent DNase synthesis. J Bacteriol 170, 47914797.

374. Kooistra, J. \& Venema, G. (1991). Cloning, sequencing, and expression of Bacillus subtilis genes involved in ATP-dependent nuclease synthesis. J Bacteriol 173, 3644-3655.

375. Kraus, A., Hueck, C., Gartner, D. \& Hillen, W. (1994). Catabolite repression of the Bacillus subtilis $x y l$ operon involves a cis element functional in the context of an unrelated sequence, and glucose exerts additional $x y / R$-dependent repression. $J$ Bacteriol 176, 1738-1745.

376. Kreneva, R. A. \& Perumov, D. A. (1990). Genetic mapping of regulatory mutations of Bacillus subtilis riboflavin operon. Mol Gen Genet 222, 467-469.

377. Krulwich, T. A., Clejan, S., Falk, L. H. \& Guffanti, A. A. (1987). Incorporation of specific exogenous fatty acids into membrane lipids modulates protonophore resistance in Bacillus subtilis. J Bacteriol 169, 4479-4485.

378. Kunkel, B., Sandman, K., Panzer, S., Youngman, P. \& Losick R. (1988). The promoter for a sporulation gene in the spoIVC locus of Bacillus subtilis and its use in studies of temporal and spatial control of gene expression. J Bacteriol 170, 3513-3522.

379. Kunkel, B., Kroos, L., Poth, H., Youngman, P. \& Losick, R. (1989). Temporal and spatial control of the mother-cell regulatory gene spollID of Bacillus subtilis. Genes Dev 3, 1735-1744.

380. Kunkel, B., Losick, R. \& Stragier, P. (1990). The Bacillus subtilis gene for the developmental transcription factor $\sigma^{\mathrm{K}}$ is generated by excision of a dispensable DNA element containing a sporulation recombinase gene. Genes Dev 4, 525-535.

381. Kunst, F., Débarbouillé, M., Msadek, T., Young, M., Mauël, C., Karamata, D., Klier, A., Rapoport, G. \& Dedonder, R. (1988). Deduced polypeptides encoded by the Bacillus subtilis sac $U$ locus share homology with two-component sensorregulator systems. J Bacteriol 170, 5093-5101.

382. Kunst, F., Vassarotti, A. \& Danchin, A. (1995). Organization of the European Bacillus subtilis genome sequencing project. Microbiology 141, 249-255.

383. Kuroda, A. \& Sekiguchi, J. (1990). Cloning, sequencing and genetic mapping of a Bacillus subtilis cell wall hydrolase gene. J Gen Microbiol 136, 2209-2216.

384. Kuroda, A. \& Sekiguchi, J. (1991). Molecular cloning and sequencing of a major Bacillus subtilis autolysin gene. J Bacteriol 173, 7304-7312.

385. Kuroda, A., Rashid, M. H. \& Sekiguchi, J. (1992). Molecular cloning and sequencing of the upstream region of the major Bacillus subtilis autolysin gene: a modifier protein exhibiting sequence homology to the major autolysing and the spoIID product. J Gen Microbiol 138, 1067-1076.

386. Kuroda, A., Asami, Y. \& Sekiguchi, J. (1993). Molecular cloning of a sporulation-specific cell wall hydrolase. $J$ Bacteriol 175, 6260-6268.

387. LaFauci, G., Widom, R. L., Eisner, R. L., Jarvis, E. D. \& Rudner, 
R. (1986). Mapping of rRNA genes with integrable plasmids in Bacillus subtilis. J Bacteriol 165, 204-214.

388. LaVallie, E. R. \& Stahl, M. L. (1989). Cloning of the flagellin gene from Bacillus subtilis and complementation studies of an in vitro-derived deletion mutation. J Bacteriol 171, 3085-3094.

389. Lakomova, N. M., Tsurikova, T. S. \& Prozorov, A. A. (1980). Possible participation of RNA polymerase III in suppression of $\mathrm{recH}$ mutation of Bacillus subtilis. Genetika 16, 583-587.

390. Lamont, I. L. \& Mandelstam, J. (1984). Identification of a new sporulation locus, spoIIIF, in Bacillus subtilis. J Gen Microbiol 130, 1253-1261.

391. Lampe, M., Binnie, C., Schmidt, R. \& Losick, R. (1988). Cloned gene encoding the $\delta$ subunit of Bacillus subtilis RNA polymerase. Gene 67, 13-19.

392. Lampel, K. A., Uratani, B., Chaudhry, G. R., Ramaley, R. F. \& Rudikoff, S. (1986). Characterization of the developmentally regulated Bacillus subtilis glucose dehydrogenase gene. $J$ Bacteriol 166, 238-243.

393. Lapidus, A., Galleron, N., Sorokin, A. \& Ehrlich, S. D. Unpublished data.

394. Lazarevic, V., Margot, P., Suldo, B. \& Karamata, D. (1992). Sequencing and analysis of the Bacillus subtilis lyt $\mathrm{R} A B C$ divergon: a regulatory unit encompassing the structural genes of the $N$-acetylmuramoyl-L-alanine amidase and its modifier. $J$ Gen Microbiol 138, 1949-1961.

395. Lazarevic, V. \& Karamata, D. (1995). The tagGH operon of Bacillus subtilis 168 encodes a two-component $A B C$ transporter involved in the metabolism of two wall teichoic acids. Mol Microbiol 16, 345-355.

396. Lazarevic, V., Mauell, C., Soldo, B., Freymond, P. P., Margot, P. \& Karamata, D. (1995). Sequence analysis of the $308^{\circ}$ to $311^{\circ}$ segment of the Bacillus subtilis 168 chromosome, a region devoted to cell wall metabolism, containing non-coding grey holes which reveal chromosomal rearrangements. Microbiology 141, 329-335.

397. Lazarevic, V. (1995). Sequence analysis of the $305^{\circ}$ to $311^{\circ}$ segment of the B. subtilis 168 chromosome. 8th International Conference on Bacilli, abstract p. 66. Stanford, CA.

398. Le Coq, D. G., Lindner, C., Kruger, S., Steinmetz, M. \& Stulke, J. (1995). New $\beta$-glucoside ( $b g l)$ genes in Bacillus subtilis: the $b g l P$ gene product has both transport and regulatory functions similar to those of $\mathrm{BglF}$, its Escherichia coli homolog.J Bacteriol 177, 1527-1535.

399. LeDeaux, J. R. \& Grossman, A. D. (1995). Isolation and characterization of $k i n C$, a gene that encodes a sensor kinase homologous to the sporulation sensor kinases KinA and KinB in Bacillus subtilis. J Bacteriol 177, 166-175.

400. Lee, J. K., Edwards, C. W. \& Hulett, F. M. (1991). Identi fication of four unique clones encoding $10 \mathrm{kDa}$ proteins from Bacillus that cause phenotypic complementation of a pho $A$ mutant strain of Escherichia coli. J Gen Microbiol 137, 667-677.

401. Lee, S. \& Price, C. W. (1993). The minCD locus of Bacillus subtilis lacks the minE determinant that provides topological specificity to cell division. Mol Microbiol 7, 601-610.

402. Leibovici, J. \& Anagnostopoulos, C. (1969). Proprietes de la threonine desaminase de la souche sauvage et d'un mutant sensible a la valine de Bacillus subtilis. Bull Soc Chim Biol 51, 691-707.

403. Leighton, $\mathbf{T}$. Unpublished data.

404. Lepesant, J.-A., Kunst, F., Lepesant-Kejzlarova, J. \& Dedonder, R. (1972). Chromosomal location of mutations affecting sucrose metabolism in Bacillus subtilis Marburg. Mol Gen Genet 118, 135-160.

405. Lepesant-Kejzlarova, J., Lepesant, J.-A., Walle, J., Billault, A. \& Dedonder, R. (1975). Revision of the linkage map of Bacillus subtilis 168 : indications for circularity of the chromosome. $J$ Bacteriol 121, 823-834.

406. Lerner, C. G., Stephenson, B. T. \& Switzer, R. L. (1987). Structure of the Bacillus subtilis pyrimidine biosynthetic (pyr) gene cluster. J Bacteriol 169, 2202-2206.

407. Leskelä, S., Kontinen, V. P. \& Sarvas, M. (1996). Molecular analysis of an operon in Bacillus subtilis encoding a novel ABC transporter with a role in exoprotein production, sporulation and competence. Microbiology 142, 71-77.

408. Levin, P. A., Margolis, P. S. \& Sun, D. (1992). Cloning and characterization of the $B$. subtilis homologs of the Escherichia coli cell division genes $\min C$ and $\min D . X I$ International Spores Conference (Spores XI), abstract no. 54.

409. Levin, P. A., Fan, N., Ricca, E., Driks, A., Losick, R. \& Cutting, S. (1993). An unusually small gene required for sporulation by Bacillus subtilis. Mol Microbiol 9, 761-771.

410. Levin, P. A. \& Losick, R. (1994). Characterization of a cell division gene from Bacillus subtilis that is required for vegetative and sporulation septum formation. $J$ Bacteriol 176, 1451-1459.

411. Leyva-Vazquez, M. A. \& Setlow, P. (1994). Cloning and nucleotide sequences of the genes encoding triose phosphate isomerase, phosphoglycerate mutase, and enolase from Bacillus subtilis. J Bacteriol 176, 3903-3910.

412. Li, M. \& Wong, S. L. (1992). Cloning and characterization of the groESL operon from Bacillus subtilis. J Bacteriol 174, 3981-3992.

413. Lindgren, V. \& Rutberg, L. (1974). Glycerol metabolism in Bacillus subtilis: gene-enzyme relationships. J Bacteriol 119, 431-442.

414. Lindgren, V., Holmgren, E. \& Rutberg, L. (1977). Bacillus subtilis mutant with temperature-sensitive net synthesis of phosphatidylethanolamine. J Bacteriol 132, 473-484.

415. Lipsky, R. H., Rosenthal, R. \& Zahler, S. A. (1981). Defective specialized SP $\beta$ transducing bacteriophage of Bacillus subtilis that carry the sup-3 or sup-44 gene. J Bacteriol 148, 1012-1015.

416. Loewen, P. C. \& Switala, J. (1987). Genetic mapping of kat $A$, a locus that affects catalase 1 levels in Bacillus subtilis. J Bacteriol 169, 5848-5851.

417. Londono-Vallejo, J. A. \& Dubnau, D. A. (1993). comF, a Bacillus subtilis late competence locus, encodes a protein similar to ATP-dependent RNA/DNA helicases. Mol Microbiol 9, 119-131.

418. Longchamp, P. F., Mauël, C. \& Karamata, D. (1994). Lytic enzymes associated with defective prophages of Bacillus subtilis: sequencing and characterization of the region comprising the $N$-acetylmuramoyl-L-alanine amidase gene of prophage PBSX. Microbiology 140, 1855-1867.

419. Lopez-Dias, I., Clarke, S. \& Mandelstam, J. (1986). spoIID operon of Bacillus subtilis: cloning and sequence. $J$ Gen Microbiol 132, 341-354.

420. Loshon, C. A., Beary, K. E., Chander, M. \& Setlow, P. (1994). Cloning and sequencing of the sspF (originally $0.3 \mathrm{~kb}$ ) genes from Bacillus cereus and Bacillus megaterium. Gene 150, 203-204.

421. Love, E., D'Ambrosio, J., Brown, N. C. \& Dubnau, D. (1976). Mapping of the gene specifying DNA polymerase III of Bacillus subtilis. Mol Gen Genet 144, 313-321. 
422. Lovett, P. S., Ambulos, N. P., Jr, Mulbry, W., Noguchi, N. \& Rogers, E. J. (1991). UGA can be decoded as tryptophan at low efficiency in Bacillus subtilis. J Bacteriol 173, 1810-1812.

423. Lu, Y., Chen, N.-Y. \& Paulus, H. (1991). Identification of aec $A$ mutations in Bacillus subtilis as nucleotide substitutions in the untranslated leader region of the aspartokinase II operon. $J$ Gen Microbiol 137, 1135-1143.

424. Ludwig, H. C., Lottspeich, F., Henschen, A., Ladenstein, R. \& Bacher, A. (1987). Heavy riboflavin synthase of Bacillus subtilis, primary structure of the $\beta$ subunit. J Biol Chem 262, 1016-1021.

425. Luttinger, A., Hahn, J. \& Dubnau, D. (1996). Polynucleotide phosphorylase is necessary for competence development in Bacillus subtilis. Mol Microbiol 19, 343-356.

426. MacKay, R. M., Lo, A., Willick, G., Zuker, M., Baird, S., Dove, M., Moranelli, F. \& Seligy, V. (1986). Structure of a Bacillus subtilis endo- $\beta$-1,4-glucanase gene. Nucleic Acids Res 14, 9159-9170.

427. Mackey, C. J., Warburg, R. J., Halvorson, H. O. \& Zahler, S. A. (1984). Genetic and physical analysis of the $i l v B C$-leu region in Bacillus subtilis. Gene 32, 49-56.

428. Magnusson, K., Philips, M. K., Guest, J. R. \& Rutberg, L. (1986). Nucleotide sequence of the gene for cytochrome $b_{558}$ of the Bacillus subtilis succinate dehydrogenase complex. $J$ Bacteriol 166, 1067-1071.

429. Mahler, I., Warburg, R., Tipper, D. J. \& Halvorson, H. O. (1984). Cloning of an unstable spoII $A$-tyr $A$ fragment from Bacillus subtilis. J Gen Microbiol 130, 411-421.

430. Makaroff, C. A., Zalkin, H., Switzer, R. L. \& Vollmer, S. J. (1983). Cloning of the Bacillus subtilis glutamine phosphoribosylpyrophosphate amidotransferase gene in Escherichia coli. J Biol Chem 258, 10586-10593.

431. Makino, F. \& Munakata, N. (1977). Isolation and characterization of a Bacillus subtilis mutant with a defective $N$ glycosidase activity for uracil-containing deoxyribonucleic acid. I Bacteriol 131, 438-445.

432. Mäntsälä, P. \& Zalkin, H. (1992). Cloning and sequence of Bacillus subtilis pur $A$ and gua $A$, involved in the conversion of IMP to AMP and GMP. J Bacteriol 174, 1883-1890.

433. Margolis, P. \& Losick, R. (1992). XI International Spores Conference (Spores XI), abstract.

434. Margolis, P. S., Driks, A. \& Losick, R. (1993). Sporulation gene spoIIB from Bacillus subtilis. I Bacteriol 175, 528-540.

435. Margot, P. \& Karamata, D. (1992). Identification of the structural gene for $N$-acetylmuramoyl-L-alanine amidase and its modifier in Bacillus subtilis 168: inactivation of these genes by insertional mutagenesis has no effect on growth or cell separation. Mol Gen Genet 232, 359-366.

436. Margot, P., Mauël, C. \& Karamata, D. (1994). The gene of the $N$-acetylglucosaminidase, a Bacillus subtilis 168 cell wall hydrolase not involved in vegetative cell autolysis. Mol Microbiol 12, 535-545.

437. Marini, P., Li, S. J., Gardiol, D., Cronan, J. E. \& de Mendoza, D. (1995). The genes encoding the biotin carboxyl carrier protein and biotin carboxylase subunits of Bacillus subtilis acetyl coenzyme A carboxylase, the first enzyme of fatty acid synthesis. J Bacteriol 177, 7003-7006.

438. Marquez, L. M., Helmann, J. D., Ferrari, E., Parker, H. M., Ordal, G. W. \& Chamberlin, M. J. (1990). Studies of $\sigma^{\mathrm{D}}-$ dependent functions in Bacillus subtilis. $J$ Bacteriol 172, 3435-3443.

439. Marquez-Magana, L. M. \& Chamberlin, M. J. (1994). Charac- terization of the sigD transcription unit of Bacillus subtilis. $J$ Bacteriol 176, 2427-2434.

440. Marrero, R. \& Yasbin, R. E. (1988). Cloning of the Bacillus subtilis rec $E^{+}$gene and functional expression of $r e c E^{+}$in $B$. subtilis. J Bacteriol 170, 335-344.

441. Martin, I., Débarbouillé, M., Klier, A. \& Rapoport, G. (1987). Identification of a new locus, sac $V$, involved in the regulation of levansucrase synthesis in Bacillus subtilis. FEMS Microbiol Lett 44, 39-43.

442. Martin, I., Débarbouillé, M., Ferrari, E., Klier, A. \& Rapoport, G. (1987). Characterization of the levanase gene of Bacillus subtilis which shows homology to yeast invertase. Mol Gen Genet 208, 177-184.

443. Martin-Verstraete, I., Débarbouillé, M., Klier, A. \& Rapoport, G. (1990). Levanase operon of Bacillus subtilis includes a fructose-specific phosphotransferase system regulating the expression of the operon. $J$ Mol Biol 214, 657-671.

444. Martinussen, J., Glaser, P., Andersen, P. S. \& Saxild, H. H. (1995). Two genes encoding uracil phosphoribosyltransferase are present in Bacillus subtilis. J Bacteriol 177, 271-274.

445. Mastromei, G., Barberio, C., Pistolesi, S. \& Polsinelli, M. (1989). Isolation of Bacillus subtilis transformation-deficient mutants and mapping of competence genes. Genet Res 54, 1-5.

446. Masuda, E. S., Anaguchi, H., Yamada, K. \& Kobayashi, Y. (1988). Two developmental genes encoding sigma factor homologs are arranged in tandem in Bacillus subtilis. Proc Natl Acad Sci US A 85, 7637-7641.

447. Masuda, E. S., Anaguchi, H., Sato, T., Takeuchi, M. \& Kobayashi, Y. (1990). Nucleotide sequence of the sporulation gene spoIIG $A$ from Bacillus subtilis. Nucleic Acids Res 18, 657.

448. Mathiopoulos, C. \& Sonenshein, A. L. (1989). Identification of Bacillus subtilis genes expressed early during sporulation. Mol Microbiol 3, 1071--1081.

449. Mathiopoulos, C., Mueller, J. P., Slack, F. J., Murphy, C. G., Patankar, S., Bukusoglu, G. \& Sonenshein, A. L. (1991). A Bacillus subtilis dipeptide transport system expressed early during sporulation. Mol Microbiol 5, 1903-1913.

450. Matsuzaki, S. \& Kobayashi, Y. (1984). New mutation affecting the synthesis of some membrane proteins and sporulation in Bacillus subtilis. J Bacteriol 159, 228-232.

451. Matsuzaki, S. \& Kobayashi, Y. (1985). Genetic heterogeneity in the cys $A$-fus region of the Bacillus subtilis chromosome: identification of the hos gene. J Bacteriol 163, 1336-1338.

452. Mattioli, R., Bazzicalupo, M., Federici, G., Gallori, E. \& Polsinelli, M. (1979). Characterization of mutants of Bacillus subtilis resistant to $S$-(2-aminoethyl)cysteine. I Gen Microbiol 114, 223-225.

453. Mauël, C., Young, M. \& Karamata, D. (1991). Genes concerned with synthesis of poly(glycerol phosphate), the essential teichoic acid in Bacillus subtilis strain 168, are organized in two divergent transcription units. J Gen Microbiol 137, 929-941.

454. Mauël, C., Young, M., Monsutti-Grecescu, A., Marriott, S. A. \& Karamata, D. (1994). Analysis of Bacillus subtilis tag gene expression using transcriptional fusions. Microbiology 140, $2279-2288$

455. Maznitsa, I. I., Sukhodolets, V. V. \& Ukhabotina, L. S. (1983). Cloning of Bacillus subtilis 168 genes compensating the defect of mutations for thymidine phosphorylase and uridine phosphorylase in Escherichia coli cells. Genetika 19, 881-887.

456. Mazza, G., Forunato, A., Ferrari, E., Canosi, U., Falaschi, A. \& 
Polsinelli, M. (1975). Genetic and enzymic studies on the recombination process in Bacillus subtilis. Mol Gen Genet 136, $9-30$.

457. Mazza, G. \& Galizzi, A. (1978). The genetics of DNA replication, repair and recombination in Bacillus subtilis. Microbiologica 1, 111-135.

458. McDonald, K. O. \& Burke, W. F., Jr (1982). Cloning of the Bacillus subtilis sulfanilamide resistance gene in Bacillus subtilis. J Bacteriol 149, 391-394.

459. McDonnell, G. E., Wood, H., Devine, K. M. \& McConnel, D. J. (1994). Genetic control of bacterial suicide: regulation of the induction of PBSX in Bacillus subtilis. J Bacteriol 176, 5820-5830.

460. McEnroe, A. S. \& Taber, H. (1984). Correlation between cytochrome $a a_{3}$ concentration and streptomycin accumulation in Bacillus subtilis. Antimicrob Agents Chemother 26, 507-512.

461. Micka, B., Groch, N., Heinemann, U. \& Marahiel, M. (1991). Molecular cloning, nucleotide sequence, and characterization of the Bacillus subtilis gene encoding the DNA-binding protein HBsu. J Bacteriol 173, 3191-3198.

462. Miczak, A., Berek, I. \& Ivanovics, G. (1976). Mapping the uroporphyrinogen decarboxylase, coproporphyrinogen oxidase and ferrochelatase loci in Bacillus subtilis. Mol Gen Genet $146,85-87$.

463. Miczak, A., Pragai, B. \& Berek, I. (1979). Maping the uroporphyrinogen III cosynthase locus in Bacillus subtilis. Mol Gen Genet 174, 293-295.

464. Miles, J. S. \& Guest, J. R. (1985). Complete nucleotide sequence of the fumarase gene cit $G$ of Bacillus subtilis 168. Nucleic Acids Res 13, 131-140.

465. Milhaud, P., Balassa, G. \& Zucca, J. (1978). Spore control (Sco) mutations in Bacillus subtilis. I. Selection and genetic mapping of Sco mutations. Mol Gen Genet 163, 35-44.

466. Mirel, D. B. \& Chamberlin, M. J. (1989). The Bacillus subtilis flagellin gene ( $h a g)$ is transcribed by the $\sigma^{28}$ form of RNA polymerase. J Bacteriol 171, 3095-3101.

467. Mirel, D. B., Lustre, V. M. \& Chamberlin, M. J. (1992). An operon of Bacillus subtilis motility genes transcribed by the $\sigma^{\mathrm{D}}$ form of RNA polymerase. J Bacteriol 174, 4197-4204.

468. Mirel, D. B., Lauer, P. \& Chamberlin, M. J. (1994). Identification of flagellar synthesis regulatory and structural genes in a $\sigma^{\mathrm{D}}$-dependent operon of Bacillus subtilis. $J$ Bacteriol 176, 4492-4500.

469. Mironov, V. N., Kraev, A. S., Chernov, B. K., Vlyanov, A. B., Golova, Y. B., Pozmogova, G. E., Simonova, M. L. \& Skryabin, K. G. (1989). Genes of riboflavin biosynthesis of Bacillus subtilis: complete primary structure and model of organization. Dokl Akad Nauk SSSR 305, 482-486.

470. Mironov, V. N., Chikindas, M. L., Kraev, A. S., Stepanov, A. I. \& Skryabin, K. G. (1990). Operon organization of the riboflavin biosynthesis genes of Bacillus subtilis. Dokl Akad Nauk SSSR 312, 237-240.

471. Mironov, V. N., Kraev, A. S., Chikindas, M. L., Chernov, B. K., Stepanov, A. I. \& Skryabin, K. G. (1994). Functional organization of the riboflavin biosynthesis operon from Bacillus subtilis SHgw. Mol Gen Genet 242, 201-208.

472. Mitchell, C., Morris, P. W. \& Vary, J. C. (1992). Identification of proteins phosphorylated by ATP during sporulation of Bacillus subtilis. J Bacteriol 174, 2474-2477.

473. Mitchell, C., Morris, P. W., Lum, L., Spiegelman, G. \& Vary, J. C. (1992). The amino acid sequence of a Bacillus subtilis phosphoprotein that matches an orf $Y-t$ sr coding sequence. Mol Microbiol 6, 1345-1349.

474. Mitsushima, K., Takimoto, A., Sonoyama, T. \& Yagi, S. (1995). Gene cloning, nucleotide sequence, and expression of a cephalosporin-C deacetylase from Bacillus subtilis. Appl Environ Microbiol 61, 2224-2229.

475. Miyakawa, Y. \& Komano, T. (1981). Study on the cell cycle of Bacillus subtilis using temperature-sensitive mutants. I. Isolation and genetic analysis of the mutants defective in septum formation. Mol Gen Genet 181, 207-214.

476. Miyao, A., Theeragool, G., Takeuchi, M. \& Kobayashi, Y. (1993). Bacillus subtilis spoVE gene is transcribed by $\sigma^{\mathrm{E}}$ associated RNA polymerase. J Bacteriol 175, 4081-4086.

477. Mizuno, M., Masuda, S., Takemaru, K., Hosono, S., Sato, T., Takeuchi, M. \& Kobayashi, Y. (1996). Systematic sequencing of the $283 \mathrm{~kb} 210^{\circ}-232^{\circ}$ region of the Bacillus subtilis genome containing the skin element and many sporulation genes. Microbiology 142, (in press).

478. Moir, A., Lafferty, E. \& Smith, D. A. (1979). Genetic analysis of spore germination mutants of Bacillus subtilis 168: the correlation of phenotype with map location. I Gen Microbiol 111, 165-180.

479. Mollgaard, H. \& Neuhard, J. (1978). Deoxycitidylate deaminase from Bacillus subtilis. Purification, characterization and physiological function. $J$ Biol Chem 253, 3536-3542.

480. Mollgaard, H. (1980). Deoxyadenosine/deoxycytidine kinase from Bacillus subtilis. Purification, characterization, and physiological function. J Biol Chem 255, 8216-8220.

481. Morbidoni, H. R., de Mendoza, D. \& Cronan, J. E. (1995). Synthesis of $s n$-glycerol 3-phosphate, a key precursor of membrane lipids, in Bacillus subtilis. J Bacteriol 177, 5899-5905.

482. Moriya, S., Ogasawara, N. \& Yoshikawa, H. (1985). Structure and function of the region of the replication origin of the Bacillus subtilis chromosome. III. Nucleotide sequence of some 10000 base pairs in the origin region. Nucleic Acids Res 13, 2251-2265.

483. Morohoshi, F., Hayashi, K. \& Munakata, N. (1989). Bacillus subtilis gene coding for constitutive $0-6$ methylguanine-DNA alkyltransferase. Nucleic Acids Res 17, 6531-6543.

484. Morohoshi, F., Hayashi, K. \& Munakata, N. (1990). Bacillus subtilis ada operon encodes two DNA alkyltransferases. Nucleic Acids Res 18, 5473-5480.

485. Morohoshi, F., Hayashi, K. \& Munakata, N. (1991). Molecular analysis of Bacillus subtilis ada mutants deficient in the adaptive response to simple alkylating agents. J Bacteriol 173, 78347840.

486. Morohoshi, F., Hayashi, K. \& Munkata, N. (1993). Bacillus subtilis alk. $A$ gene encoding inducible 3-methyladenine DNA glycosylase is adjacent to the ada operon. $J$ Bacteriol 175, 6010-6017.

487. Morohoshi, F. \& Munakata, N. Unpublished data.

488. Moszer, I., Glaser, P. \& Danchin, A. (1995). SubtiList: a relational database for the Bacillus subtilis genome. Microbiology 141, 261-268.

489. Mountain, A. \& Baumberg, S. (1980). Map locations of some mutations conferring resistance to arginine hydroxamate in Bacillus subtilis 168. Mol Gen Genet 178, 691-701.

490. Mountain, A., McChesney, J., Smith, M. C. M. \& Baumberg, S. (1986). Gene sequence encoding early enzymes of arginine synthesis within a cluster in Bacillus subtilis, as revealed by cloning in Escherichia coli. J Bacteriol 165, 1026-1028. 
491. Mountain, A., Smith, M. C. M. \& Baumberg, S. (1990). Nucleotide sequence of the Bacillus subtilis argF gene encoding ornithine carbamoyltransferase. Nucleic Acids Res 18, 4594.

492. Msadek, T., Kunst, F., Klier, A. \& Rapoport, G. (1991). DegS$\mathrm{DegU}$ and ComP-ComA modulator-effector pairs control expression of the Bacillus subtilis pleiotropic regulatory gene degQ. J Bacteriol 173, 2366-2377.

493. Msadek, T., Kunst, F. \& Rapoport, G. (1994). MecB of Bacillus subtilis, a member of the ClpC ATPase family, is a pleiotropic regulator controlling competence gene expression and growth at high temperature. Proc Natl Acad Sci US A 91, 5788-5792.

494. Mueller, J. P. \& Taber, H. W. (1988). Genetic regulation of cytochrome $a a_{3}$ in Bacillus subtilis. In Genetics and Biotechnology of Bacilli, vol. 2, pp. 91-95. Edited by A. T. Ganesan \& J. A. Hoch. San Diego, CA: Academic Press

495. Mueller, J. P. \& Taber, H. W. (1989). Isolation and sequence of $\operatorname{cta} A$, a gene required for cytochrome $a a_{3}$ biosynthesis and sporulation in Bacillus subtilis. J Bacteriol 171, 4967-4978.

496. Mueller, J. P. \& Sonenshein, A. L. (1992). Role of the Bacillus subtilis gsiA gene in regulation of early sporulation gene expression. J Bacteriol 174, 4374-4383.

497. Mueller, J. P., Bukusoglu, G. \& Sonenshein, A. L. (1992). Transcriptional regulation of Bacillus subtilis glucose starvation inducible genes: control of gsi $A$ by the ComP-ComA signal transduction system. J Bacteriol 174, 4361-4373.

498. Mulbry, W. W., Ambulos, N. P., Jr \& Lovett, P. S. (1989). Bacillus subtilis mutant allele sup-3 causes lysine insertion at ochre codons: use of sup- 3 in studies of translational attenuation. $J$ Bacteriol 171, 5322-5324.

499. Munakata, H. \& Ikeda, Y. (1968). Mutant of Bacillus subtilis producing ultraviolet-sensitive spores. Biochem Biopbys Res Commun 33, 469-475.

500. Murphy, N., McConnell, D. J. \& Cantwell, B. A. (1984). The DNA sequence of the gene and genetic control sites for the excreted B. subtilis enzyme $\beta$-glucanase. Nucleic Acids Res 12, 5355-5367.

501. Muto A., (1993). Direct submission to EMBL/GenBank/ DDBJ - D25230.

502. Mysliwiec, T. H., Errington, J., Vaidya, A. B. \& Bramucci, M. G. (1991). The Bacillus subtilis spoOJ gene: evidence for involvement in catabolite repression of sporulation. J Bacteriol 173, 1911-1919.

503. Nagahari, K. \& Sakaguchi, K. (1978). Cloning of Bacillus subtilis leucine A, B and C genes with Eschericbia coli plasmids and expression of the leuC gene in E. coli. Mol Gen Genet 158, 263-270.

504. Nakamura, A., Uozumi, T. \& Beppu, T. (1987). Nucleotide sequence of a cellulase gene of Bacillus subtilis. Eur J Biochem 164, 317-320.

505. Nakamura, K., Nakamura, A., Takamatsu, H., Yoshikawa, H. \& Yamane, K. (1990). Cloning and characterization of a Bacillus subtilis gene homologous to E. coli secY.J Biochem (Tokyo) 107, 603-607.

506. Nakane, A., Ogawa, K., Nakamura, K. \& Yamane, K. (1994). Nucleotide sequence of the shikimate kinase gene (aroI) of Bacillus subtilis. J Ferment Bioeng 77, 312-314.

507. Nakano, M. M., Marahiel, M. A. \& Zuber, P. (1988). Identification of a genetic locus required for biosynthesis of the lipopeptide antibiotic surfactin in Bacillus subtilis. J Bacteriol 170, 5662-5668.

508. Nakano, M. M. \& Zuber, P. (1989). Cloning and characterization of $s r f B$, a regulatory gene involved in surfactin production and competence in Bacillus subtilis. J Bacteriol 171, 5347-5353.

509. Nakano, M. M., Magnuson, R., Myers, A., Curry, J., Grossman, A. D. \& Zuber, P. (1991). $\operatorname{srf} A$ is an operon required for surfactin production, competence development, and efficient sporulation in Bacillus subtilis. J Bacteriol 173, 1770-1778.

510. Nakano, M. M., Corbell, N., Besson, J. \& Zuber, P. (1992). Isolation and characterization of $s f p$ : a gene that functions in the production of the lipopeptide biosurfactant, surfactin, in Bacillus subtilis. Mol Gen Genet 232, 313-321.

511. Nakano, M. M., Yang, F., Hardin, P. \& Zuber, P. (1995). Nitrogen regulation of nas $A$ and the nasB operon, which encode genes required for nitrate assimilation in Bacillus subtilis. J Bacteriol 177, 573-579.

512. Nakano, Y., Tanaka, E., Kato, C., Kimura, K. \& Horikoshi, K. (1989). The complete nucleotide sequence of the glutamine synthetase gene (gln $A$ ) of Bacillus subtilis. FEMS Microbiol Lett 48, 81-86.

513. Nasser, D. \& Nester, E. W. (1967). Aromatic amino acid biosynthesis: gene-enzyme relationships in Bacillus subtilis. $J$ Bacteriol 94, 1706-1714.

514. Navarro, J., Chabot, J., Sherrill, K., Aneja, R., Zahler, S. A. \& Racker, E. (1985). Interaction of duramycin with artificial and natural membranes. Biocbemistry 24, 4645-4650.

515. Nessi, C., Albertini, A. M., Speranza, M. L. \& Galizzi, A. (1995). The outB gene of Bacillus subtilis codes for NAD synthetase. J Biol Chem 270, 6181-6185.

516. Nester, E. W. \& Montoya, A. L. (1976). An enzyme common to histidine and aromatic amino acid biosynthesis in Bacillus subtilis. J Bacteriol 126, 699-705.

517. Neuhard, J. , Price, A. R., Schack, L. \& Thomassen, E. (1978). Two thymidylate synthetases in Bacillus subtilis. Proc Natl Acad Sci US A 75, 1194-1198.

518. Neuhard, J. (1983). Utilization of preformed pyrimidine bases and nucleosides. In Metabolism of Nucleotides, Nucleosides, and Nucleobases in Microorganisms, pp. 95-148. Edited by A. Munch-Petersen. New York: Academic Press.

519. Neyfakh, A. A., Bidnenko, V. E. \& Chen, L. B. (1991). Effluxmediated multidrug resistance in Bacillus subtilis: similarities and dissimilarities with the mammalian system. Proc Natl Acad Sci US A 88, 4781-4785.

520. Ng, K., Ye, R., Wu, X. C. \& Wong, S. L. (1992). Characterization of sorbitol dehydrogenase and its gene from Bacillus subtilis. J Biol Chem 267, 24989-24994.

521. Nicholson, W. L. \& Chambliss, G. H. (1986). Molecular cloning of cis-acting regulatory alleles of the Bacillus subtilis amy $\mathrm{R}$ region by using gene conversion transformation. $J$ Bacteriol 165, 663-670.

522. Nilsson, D. \& Hove-Jensen, B. (1987). Phosphoribosylpyrophosphate synthetase of Bacillus subtilis: cloning, characterization and chromosomal mapping of the prs gene. Gene $\mathbf{5 3}$, 247-255.

523. Nilsson, D., Hove-Jensen, B. \& Arnvig, K. (1989). Primary structure of the tms and prs genes of Bacillus subtilis. Mol Gen Genet 218, 565 -571

524. Nilsson, R. P., Beijer, L. \& Rutberg, B. (1994). The $g l p T$ and glpQ genes of the glycerol regulon in Bacillus subtilis. Microbiology 140, 723-730.

525. Noback, M. A., Terpstra, P., Holsappel, S., Venema, G. \& Bron, S. (1996). A $22 \mathrm{~kb}$ DNA sequence in the $c s p B-g l p P F K D$ region at $75^{\circ}$ of the Bacillus subtilis chromosome. Microbiology 142 (in press) 
526. Noda, Y., Yoda, K., Takatsuki, A. \& Yamasaki, M. (1992). $\mathrm{TmrB}$, protein responsible for tunicamycin resistance of Bacillus subtilis is a novel ATP-binding membrane protein. $J$ Bacteriol 174, 4302-4307.

527. Noguchi, N., Sasatsu, M. \& Kono, M. (1993). Genetic mapping in Bacillus subtilis 168 of the aadK gene which encodes aminoglycoside 6-adenylyltransferase. FEMS Microbiol Lett 114, 47-52.

528. Nomura, S., Yamane, K., Sasaki, T., Yamasaki, M., Tamura, G. \& Maruo, B. (1978). Tunicamycin-resistant mutants and chromosomal locations of mutational sites in Bacillus subtilis. $J$ Bacteriol 136, 818-821.

529. Nygaard, P., Duckert, P. \& Saxild, H. H. (1988). Purine gene organization and regulation in Bacillus subtilis. In Genetics and Biotechnology of Bacilli, vol. 2, pp. 57-61. Edited by A. T. Ganesan \& J. A. Hoch. San Diego, CA: Academic Press.

530. Nygaard, P., Duckert, P. \& Saxild, H. H. (1996). Role of adenine deaminase in purine salvage and nitrogen metabolism and characterization of the ade gene in Bacillus subtilis. $J$ Bacteriol 178, 846-853.

531. O’Reilly, M., Woodson, K., Dowds, B. C. \& Devine, K. M. (1994). The citrulline biosynthetic operon, $\arg C-F$, and a ribose transport operon, $r b$ s, from Bacillus subtilis are negatively regulated by spo0 A. Mol Microbiol 11, 87-98.

532. Oda, M., Sugishita, A. \& Furukawa, K. (1988). Cloning and nucleotide sequences of histidase and regulatory genes in the Bacillus subtilis but operon and positive regulation of the operon. J Bacteriol 170, 3199-3205.

533. Ogasawara, N., Moriya, S. \& Yoshikawa, H. (1983). Structure and organization of rRNA operons in the region of the replication origin of the Bacillus subtilis chromosome. Nucleic Acids Res 11, 6301-6318.

534. Ogasawara, N. (1985). Structure and function of the region of the replication origin of the Bacillus subtilis chromosome. Nucleic Acids Res 13, 2251-2265.

535. Ogasawara, N., Moriya, S., von Meyenburg, K., Hansen, F. G. \& Yoshikawa, H. (1985). Conservation of genes and their organization in the chromosomal replication origin region of Bacillus subtilis and Escherichia coli. EMBO J 4, 3345-3350.

536. Ogasawara, N., Moriya, S., Mazza, P. \& Yoshikawa, H. (1986). A Bacillus subtilis dna $G$ mutant harbours a mutation in a gene homologous to the dnaN gene of Escherichia coli. Gene $45,227-231$.

537. Ogasawara, N., Moriya, S., Mazza, P. G. \& Yoshikawa, H. (1986). Nucleotide sequence and organization of $d n a B$ gene and neighboring genes on the Bacillus subtilis chromosome. Nucleic Acids Res 14, 9989-9999.

538. Ogasawara, N. \& Yoshikawa, H. (1992). Genes and their organization in the replication origin region of the bacterial chromosome. Mol Microbiol 6, 629-634.

539. Ogasawara, N., Nakai, S. \& Yoshikawa, H. (1994). Systematic sequencing of the 180 kilobase region of the Bacillus subtilis chromosome containing the replication origin. DNA Res 1 , $1-14$.

540. Ogasawara, N., Fujita, Y., Kobayashi, Y., Sadaie, Y., Tanaka, T., Takahashi, H., Yamane, K. \& Yoshikawa, H. (1995). Systematic sequencing of the Bacillus subtilis genome: progress report of the Japanese group. Microbiology 141, 257-259.

541. Ogasawara, N. Unpublished data.

542. Ogawa, K., Akagawa, E., Nakamura, K. \& Yamane, K. (1995). Determination of a 21548 bp nucleotide sequence around the $24^{\circ}$ region of the Bacillus subtilis chromosome. Microbiology 141, 269-275.

543. Ogawa, K., Akagawa, E., Yamane, K., Sun, Z. W., LaCelle, M., Zuber, P. \& Nakano, M. M. (1995). The nas B operon and nas $A$ gene are required for nitrate/nitrite assimilation in Bacillus subtilis. J Bacteriol 177, 1409-1413.

544. Ogura, M., Kawata-Mukai, M., Itaya, M., Takio, K. \& Tanaka, T. (1994). Multiple copies of the proB gene enhance $\operatorname{deg} S$ dependent extracellular protease production in Bacillus subtilis. $J$ Bacteriol 176, 5673-5680.

545. Ogura, M. \& Tanaka, T. (1996). Transcription of Bacillus subtilis $\operatorname{deg} \mathrm{R}$ is $\sigma^{\mathrm{D}}$-dependent and suppressed by multicopy proB through $\sigma^{\mathrm{D}}$. J Bacteriol 178, 216-222.

546. Ohmiya, K., Tanaka, T., Noguchi, N., O'Hara, K. \& Kono, M. (1989). Nucleotide sequence of the chromosomal gene coding for the aminoglycoside 6-adenylyltransferase from Bacillus subtilis Marburg 168. Gene 78, 377-378.

547. Okada, M., Matsuzaki, H., Shibuya, I. \& Matsumoto, K. (1994). Cloning, sequencing, and expression in Escherichia coli of the Bacillus subtilis gene for phosphatidylserine synthase. $J$ Bacteriol 176, 7456-7461.

548. Ordal, G. W., Nettleton, D. O. \& Hoch, J. A. (1983). Genetics of Bacillus subtilis chemotaxis: isolation and mapping of mutations and cloning of chemotaxis genes. J Bacteriol 154, 1088-1097.

549. Ordal, G. W., Parker, H. M. \& Kirby, J. R. (1985). Complementation and characterization of chemotaxis mutants of Bacillus subtilis. J Bacteriol 164, 802-810.

550. Osawa, S., Takata, R., Tanaka, K. \& Tamaki, M. (1973). Chloramphenicol resistant mutants of Bacillus subtilis. Mol Gen Genet 127, 163-173.

551. Osawa, S. \& Tuki, A. (1978). Mapping by interspecies transformation experiments of several ribosomal protein genes near the replication origin of Bacillus subtilis chromosome. Mol Gen Genet 164, 113-129.

552. Otozai, K., Takeichi, Y., Nakayama, A., Yamane, K., Tanimoto, T., Yamasaki, M., Tamura, G., Nomura, S., Kawamura, F. \& Saito, $\mathrm{H}$. (1984). Cloning of the $\mathrm{AROI}^{+}$gene regions of Bacillus subtilis chromosomal DNAs by $B$. subtilis temperate phage rho11 and Escherichia coli vector systems, and a comparison of physical maps of the gene regions. J Gen Appl Microbiol 30, 15-25.

553. Pai, C. H. (1975). Genetics of biotin biosynthesis in Bacillus subtilis. J Bacteriol 121, 1-8.

554. Paice, M. G., Bourbonnais, R., Desrochers, M., Jurasek, L. \& Yaguchi, M. (1986). A xylanase gene from Bacillus subtilis: nucleotide sequence and comparison with $B$. pumilus gene. Arch Microbiol 144, 201-206.

555. Pang, A. S.-H., Nathoo, S. \& Wong, S.-L. (1991). Cloning and characterization of a pair of novel genes that regulate production of extracellular enzymes in Bacillus subtilis. $J$ Bacteriol 173, 46-54.

556. Parsot, C. (1986). Evolution of biosynthetic pathways: a common ancestor for threonine synthase, threonine dehydratase and D-serine dehydratase. EMBO J 5, 3013-3019.

557. Parsot, C. \& Cohen, G. N. (1988). Cloning and nucleotide sequence of the Bacillus subtilis hom gene coding for homoserine dehydrogenase. $J$ Biol Cbem 263, 14654-14660.

558. Paveia, M. H. \& Archer, L. J. (1980). Location of genes for arabinose utilization in the Bacillus subtilis chromosome. Broteria Genet (Lisbon) 1, 169-176. 
559. Pel, H. J., Rep, M. \& Grivell, L. A. (1992). Sequence comparison of new prokaryotic and mitochondrial members of the polypeptide chain telease factor structure. Nucleic Acids Res 20, 4423-4428.

560. Perego, M. \& Hoch, J. A. (1987). Isolation and sequence of the spoOE gene: its role in initiation of sporulation in Bacillus subtilis. Mol Microbiol 1, 125-132.

561. Perego, M., Ferrari, E., Bassi, M. T., Galizzi, A. \& Mazza, P. (1987). Molecular cloning of Bacillus subtilis genes involved in DNA metabolism. Mol Gen Genet 209, 8-14.

562. Perego, M. \& Hoch, J. A. (1988). Sequence analysis and regulation of the $h p r$ locus, a regulatory gene for protease production and sporulation in Bacillus subtilis. J Bacteriol 170, 2560-2567.

563. Perego, M., Spiegelman, G. B. \& Hoch, J. A. (1988). Structure of the gene for the transition state regulator, $a b r B$ : regulator synthesis is controlled by the $\operatorname{spo} 0 A$ sporulation gene in Bacillus subtilis. Mol Microbiol 2, 689-699.

564. Perego, M., Cole, S. P., Burbulys, D., Trach, K. \& Hoch, J. A (1989). Characterization of the gene for a protein kinase which phosphorylates the sporulation-regulatory proteins Spo0A and Spo0F of Bacillus subtilis. J Bacteriol 171, 6187-6196.

565. Perego, M., Higgins, C. F., Pearce, S. R., Gallagher, M. P. \& Hoch, J. A. (1991). The oligopeptide transport system of Bacillus subtilis plays a role in the initiation of sporulation. Mol Microbiol 5, 173-185.

566. Perego, M., Hanstein, C., Welsh, K. M., Djavakhishvili, T., Glaser, P. \& Hoch, J. A. (1994). Multiple protein-aspartate phosphatases provide a mechanism for the integration of diverse signals in the control of development in B. subtilis. Cell 79, 1047-1055.

567. Perego, M., Glaser, P., Minutello, A., Strauch, M. A., Leopold, K. \& Fischer, W. (1995). Incorporation of D-alanine into lipoteichoic acid and wall teichoic acid in Bacillus subtilis. Identification of genes and regulation. I Biol Chem 270, 15598-15606.

568. Pestka, S., Weiss, D., Vince, R., Wienen, B., Stoffler, G. \& Smith, I. (1976). Thiostrepton-resistant mutants of Bacillus subtilis: localization of resistance to $50 \mathrm{~S}$ subunit. Mol Gen Genet 144, 235-241.

569. Peters, H. K. \& Haldenwang, W. G. (1994). Isolation of a Bacillus subtilis spoIIG $A$ allele that suppresses processingnegative mutations in the pro- $\sigma^{\mathrm{E}}$ gene $($ sigE). $J$ Bacteriol 176, 7763-7766.

570. Peterson, A. M. \& Rutberg, L. (1969). Linked transformation of bacterial and prophage markers in Bacillus subtilis 168 lysogenic for bacteriophage $\phi 105 . J$ Bacteriol 98, 874-877.

571. Petricek, M., Rutberg, L. \& Hederstedt, L. (1989). The structural gene for aspartokinase II in Bacillus subtilis is closely linked to the sdh operon. FEMS Microbiol Lett 61, 85-88.

572. Petricek, M., Rutberg, L., Schroder, I. \& Hederstedt, L. (1990). Cloning and characterization of the bem $A$ region of the Bacillus subtilis chromosome. J Bacteriol 172, 2250-2258.

573. Phang, C. H. \& Jeyaseelan, K. (1988). Isolation and characterization of citC gene of Bacillus subtilis. In Genetics and Biotecbnology of Bacilli, vol. 2, pp. 97-100. Edited by A. 'T. Ganesan \& J. A. Hoch. San Diego, CA: Academic Press.

574. Phillips, M. K., Hederstedt, L., Hasnain, S., Rutberg, L. \& Guest, J. R. (1987). Nucleotide sequence encoding the flavoprotein and iron-sulfur protein subunits of the Bacillus subtilis PY79 succinate dehydrogenase complex. J Bacteriol 169, 864-873.
575. Piggot, P. J. (1975). Characterization of a cym mutant of Bacillus subtilis. J Gen Microbiol 89, 371-374.

576. Piggot, P. J. \& Coote, J. G. (1976). Genetic aspects of bacterial endospore formation. Bacteriol Rev 40, 908-962.

577. Piggot, P. J. \& Taylor, S. Y. (1977). New types of mutation affecting formation of alkaline phosphatase by Bacillus subtilis. $J$ Gen Microbiol 102, 69-80.

578. Piggot, P. J., Moir, A. \& Smith, D. A. (1981). Advances in the genetics of Bacillus subtilis differentiation. In Sporulation and Germination, pp. 29-39. Edited by H. S. Levinson, A. L. Sonenshein \& D. J. Tipper. Washington, DC: American Society for Microbiology.

579. Piggot, P. J. \& Buxton, R. S. (1982). Bacteriophage PBSXinduced deletion mutants of Bacillus subtilis 168 constitutive for alkaline phosphatase. J Gen Microbiol 128, 663-669.

580. Piggot, P. J. \& Hoch, J. A. (1985). Revised genetic linkage map of Bacillus subtilis. Microbiol Rev 49, 158-179.

581. Piggot, P. J. (1989). Revised genetic map of Bacillus subtilis 168. In Regulation of Prokaryotic Development, pp. 1-41. Edited by I. Smith, R. A. Slepecky \& P. Setlow. Washington, DC: American Society for Microbiology.

582. Piggot, P. J., Amjad, M., Wu, J.-J., Sandoval, H. \& Castro, J. (1990). Genetic and physical maps of Bacillus subtilis 168. In Molecular Biology Methods for Bacillus, pp. 494-532. Edited by C. R. Harwood \& S. M. Cutting. London: Wiley.

583. Piggot, P. J. Unpublished data.

584. Polsinelli, M. (1965). Linkage relationship between genes for amino acid or nitrogenous base biosynthesis and genes controlling resistance to structurally correlated analogues. $J$ Gen Microbiol 13, 99-110.

585. Poluektova, E. U., Lakomova, N. M., Belova, T. S. \& Prozorov, A. A. (1984). Cloning of pur $A 16$ locus in $\mathrm{Rec}^{+}$cells of Bacillus subtilis. Genetika 20, 943-948.

586. Pooley, H. M. \& Karamata, D. (1984). Genetic analysis of autolysin-deficient and flagellaless mutants of Bacillus subtilis. $J$ Bacteriol 160, 1123-1129.

587. Pooley, H. M., Paschoud, D. \& Karamata, D. (1987). The gtaB marker in Bacillus subtilis 168 is associated with a deficiency in UDP-glucose pyrophosphorylase. J Gen Microbiol 133, 34813493.

588. Pooley, H. M., Abellan, F.-X. \& Karamata, D. (1991). A conditional-lethal mutant of Bacillus subtilis 168 with a thermosensitive glycerol-3-phosphate cytidylyltransferase, an enzyme specific for the synthesis of the major wall teichoic acid. J Gen Microbiol 137, 921-928.

589. Pooley, H. M., Abellan, F.-X. \& Karamata, D. (1992). CDPglycerol: poly (glycerophosphate) glycerophosphotransferase, which is involved in the synthesis of the major wall teichoic acid in Bacillus subtilis 168 , is encoded by tagF (rodC).J Bacteriol 174, 646-649.

590. Popham, D. L. \& Stragier, P. (1991). Cloning, characterization, and expression of the spoVB gene of Bacillus subtilis. J Bacteriol 173, 7942-7949.

591. Popham, D. L. \& Setlow, P. (1993). Cloning, nucleotide sequence, and regulation of the Bacillus subtilis $p b p F$ gene, which codes for a putative class A high-molecular-weight penicillin-binding protein. $J$ Bacteriol 175, 4870-4876.

592. Popham, D. L. \& Setlow, P. (1993). Cloning, nucleotide sequence, and regulation of the Bacillus subtilis $p b p E$ operon which codes for penicillin-binding protein 4 and an apparent amino acid racemase. J Bacteriol 175, 2917-2925. 
593. Popham, D. L. \& Setlow, P. (1994). Cloning, nucleotide sequence, mutagenesis, and mapping of the Bacillus subtilis $p b p D$ gene, which codes for penicillin-binding protein $4 . J$ Bacteriol 176, 7197-7205.

594. Popham, D. L. \& Setlow, P. (1995). Cloning, nucleotide sequence, and mutagenesis of the Bacillus subtilis pon $A$ operon, which codes for penicillin-binding protein (PBP) 1 and a PBPrelated factor. $J$ Bacteriol 177, 326-335.

595. Popham, D. L., Illades-Aguiar, B. \& Setlow, P. (1995). The Bacillus subtilis dac $B$ gene, encoding penicillin-binding protein 5 , is part of a three-gene operon required for proper spore cortex synthesis and spore core dehydration. J Bacteriol 177 , 4721-4729.

596. Porter, A. C. G. \& Mandelstam, J. (1982). A mutant of Bacillus subtilis secreting a DNAase inhibitor during sporulation. J Gen Microbiol 128, 1903-1914.

597. Price, C. W., Gitt, M. A. \& Doi, R. H. (1983). Isolation and physical mapping of the gene encoding the major sigma-factor of Bacillus subtilis RNA polymerase. Proc Natl Acad Sci US.A 80, 4074-4078.

598. Price, C., Boylan, S., Duncan, M., Kalman, S., Suh, J. W., Thomas, S. \& Van Hoy, B. (1988). Use of lambda-gt11 and antibody probes to isolate genes encoding RNA polymerase subunits from Bacillus subtilis. In Genetics and Biotechnology of Bacilli, vol. 2, pp. 183-188. Edited by A. T. Ganesan \& J. A. Hoch. San Diego, CA: Academic Press.

599. Price, C. W. Unpublished data.

600. Price, V. L. \& Gallant, J. A. (1983). Bacillus subtilis relG mutant: defect in glucose uptake. J Bacteriol 153, 270-273.

601. Putzer, H., Brakhage, A. A. \& Grunberg-Manago, M. (1990). Independent genes for two threonyl-tRNA synthetases in Bacillus subtilis. J Bacteriol 172, 4593-4602.

602. Putzer, H., Gendron, N. \& Grunberg-Manago, M. (1992). Coordinate expression of the two threonyl-tRNA synthetase genes in Bacillus subtilis: control by transcriptional antitermination involving a conserved regulatory sequence. $E M B O J$ 11, 3117-3127.

603. Quax, W. J. \& Broekhuizen, C. P. (1994). Development of a new Bacillus carboxyl esterase for use in the resolution of chiral drugs. Appl Microbiol Biotechnol 41, 425-431.

604. Quinn, C. L., Stephenson, B. T. \& Switzer, R. L. (1991). Functional organization and nucleotide sequence of the Bacillus subtilis pyrimidine biosynthetic operon. $J$ Biol Chem 266, 9113-9127.

605. Quirck, P. G., Dunkley, E. A., Jr, Lee, P. \& Krulwich, T. A. (1993). Identification of a putative Bacillus subtilis rbo gene. J Bacteriol 175, 647-654.

606. Rabinovich, P. M., Beburov, M. Yu., Linevich, Z. K. \& Stepanov, A. I. (1978). Amplification of Bacillus subtilis riboflavin operon genes in Escherichia coli cells. Genetika 14, 1696-1705.

607. Rabinovich, P. M., Yomantas, Yu. V., Haykinson, M. Y. \& Stepanov, A. I. (1984). Cloning of genetic material in bacilli. In Genetics and Biotechnology of Bacilli, pp. 297-308. Edited by A. T. Ganesan \& J. A. Hoch. San Diego, CA: Academic Press.

608. Racine, F. M. \& Steinberg, W. (1974). Genetic location of two mutations affecting the lysyltransfer ribonucleic acid synthetase of Bacillus subtilis. J Bacteriol 120, 384-389.

609. Ramos, H. C., Boursier, L., Moszer, I., Kunst, F., Danchin, A. \& Glaser, P. (1995). Anaerobic transcription activation in Bacillus subtilis: identification of distinct FNR-dependent and -independent regulatory mechanisms. EMBO J14, 5984-5994.
610. Rashid, M. H., Mori, M. \& Sekiguchi, J. (1995). Glucosaminidase of Bacillus subtilis: cloning, regulation, primary structure and biochemical characterization. Microbiology 141, 2391-2404.

611. Raugei, G., Bazzicalupo, M., Federici, G. \& Gallori, E. (1981). Effect of a new pyrimidine analog on Bacillus subtilis growth. J Bacteriol 145, 1079-1081.

612. Raymond-Denise, A. \& Guillen, N. (1991). Identification of dinR, a DNA damage-inducible regulator gene of Bacillus subtilis. J Bacteriol 173, 7084-7091.

613. Reeve, J. N., Mendelson, N. H., Coyne, S. I., Hallock, L. L. \& Cole, R. M. (1973). Minicells of Bacillus subtilis. J Bacterio/ 114, 860-873.

614. Reich, C., Gardiner, K. J., Olsen, G. J., Pace, B., Marsh, T. L. \& Pace, N. R. (1986). The RNA component of the Bacillus subtilis RNase P. Sequence, activity, and partial secondary structure. $J$ Biol Chem 261, 7888-7893.

615. Reizer, A., Deutscher, J., Saier, M. H., Jr \& Reizer, J. (1991). Analysis of the gluconate (gnt) operon of Bacillus subtilis. Mol Microbiol 5, 1081-1089.

616. Renna, M. C., Najimudin, N., Winik, L. R. \& Zahler, S. A. (1993). Regulation of the Bacillus subtilis als $S$, alsD, and als $\mathrm{R}$ genes involved in post-exponential-phase production of acetoin. J Bacteriol 175, 3863-3875.

617. Resnekov, O., Melin, L., Carlsson, P., Mannerlov, M., von Gabain, A. \& Hederstedt, L. (1992). Organization and regulation of the Bacillus subtilis odh $A B$ operon, which encodes two of the subenzymes of the 2-oxoglutarate dehydrogenase complex. Mol Gen Genet 234, 285-296.

618. Resnekov, O., Driks, A. \& Losick, R. (1995). Identification and characterization of sporulation gene spoVS from Bacillus subtilis. J Bacteriol 177, 5628-5635.

619. Ricca, E., Cutting, S. \& Losick, R. (1992). Characterization of bof $A$, a gene involved in intercompartmental regulation of pro- $\sigma^{\mathrm{K}}$ processing during sporulation in Bacillus subtilis. J Bacteriol 174, 3177-3184.

620. Riethdorf, S., Volker, U., Gerth, U., Winkler, A., Engelmann, S. \& Hecker, M. (1994). Cloning, nucleotide sequence, and expression of the Bacillus subtilis lon gene. J Bacteriol 176, 6518-6527.

621. Rima, B. K. \& Takahashi, I. (1978). Synthesis of thymidine nucleotides in Bacillus subtilis. Can J Biochem 56, 158-160.

622. Riva, S., Villani, G., Mastromei, G. \& Mazza, G. (1976). Bacillus subtilis mutant temperature sensitive in the synthesis of ribonucleic acid. J Bacteriol 127, 679-690.

623. Robison, K. Unpublished data.

624. Roels, S., Driks, A. \& Losick, R. (1992). Characterization of spoIV $A$, a sporulation gene involved in coat morphogenesis in Bacillus subtilis. J Bacteriol 174, 575-585.

625. Roels, S. \& Losick, R. (1995). Adjacent and divergently oriented operons under the control of the sporulation regulatory protein GerE in Bacillus subtilis. J Bacteriol 177, 6263-6275.

626. Rogolsky, M. (1968). Genetic mapping of a locus which regulates the production of pigment associated with spores of Bacillus subtilis. J Bacteriol 95, 2426-2427.

627. Ron, E. Z., de Bethune, M.-P. \& Cocito, C. G. (1980). Mapping of virginiamycin $\mathrm{S}$ resistance in Bacillus subtilis. Mol Gen Genet 180, 639-640.

628. Roncero, M. I. G. (1983). Genes controlling xylan utilization by Bacillus subtilis. J Bacteriol 156, 257-263.

629. Rong, S. \& Sonenshein, A. L. (1992). Mutations in the 
precursor region of a Bacillus subtilis sporulation sigma factor. J Bacteriol 174, 3812-3817.

630. Rose, M. \& Entian, K. D. (1996). New genes in the $170^{\circ}$ region of the Bacillus subtilis genome encode DNA gyrase subunits, a thioredoxin, a xylanase and an amino acid transporter. Microbiology 142 (in press).

631. Roten, C.-A. H., Brandt, C. \& Karamata, D. (1991). Genes involved in meso-diaminopimelate synthesis in Bacillus subtilis: identification of the gene encoding aspartokinase I. $J$ Gen Microbiol 137, 951-962.

632. Roten, C.-A. H., Brandt, C. \& Karamata, D. (1991). Identification of $m u r A$, the structural gene of phosphoenolpyruvate: uridine- $N$-acetyl-glucosamine enolpyruvoyl transferase in Bacillus subtilis. In Abstracts of the 6th International Conference on Bacilli, W-8.

633. Rowland, B., Hill, K., Miller, P., Driscoll, J. R. \& Taber, H. W. (1995). Structural organization of a Bacillus subtilis operon encoded menaquinone biosynthetic enzymes. Gene 167, 105109.

634. Rowland, B. M. \& Taber, H. W. (1996). Duplicate isochorismate synthase genes of Bacillus subtilis: regulation and involvement in the biosyntheses of menaquinone and 2,3dihydroxybenzoate. I Bacteriol 178, 854-861.

635. Rowland, B. M., Grossman, T. H., Osburn, M. S. \& Taber, H. W. Unpublished data.

636. Rowland, S. L., Errington, J. \& Wake, R. G. (1995). The Bacillus subtilis cell-division $135^{\circ}-137^{\circ}$ region contains an essential orf with significant similarity to $\operatorname{mur} B$ and a dispensible sbp gene. Gene 164, 113-116.

637. Rudner, D. Z., Ladeaux, J. R., Breton, K. \& Grossman, A. D. (1991). The spoOK locus of Bacillus subtilis is homologous to the oligopeptide permease locus and is required for sporulation and competence. J Bacteriol 173, 1388-1398.

638. Rudner, R., Chevrestt, A., Buchholz, S. R., Studamire, B., White, A. M. \& Jarvis, E. D. (1993). Two tRNA gene clusters associated with rRNA operons $r r n D$ and $r r n E$ in Bacillus subtilis. J Bacteriol 175, 503-509.

639. Rumyantseva, E. V., Sukhodolets, V. V. \& Smirnov, Yu. V. (1979). Isolation and characterization of mutants for genes of nucleoside catabolism in Bacillus subtilis. Genetika 15, 594-604.

640. Sa-Nogueira, I., Paveia, H. \& de Lencastre, H. (1988). Isolation of constitutive mutants for L-arabinose utilization in Bacillus subtilis. J Bacteriol 170, 2855-2857.

641. Sa-Nogueira, I. \& de Lencastre, H. (1989). Cloning and characterization of $\operatorname{ara} A$, ara $B$, and araD, the structural genes for L-arabinose utilization in Bacillus subtilis. J Bacteriol 171, 4088-4091.

642. Sacco, M., Ricca, E., Losick, R. \& Cutting, S. (1995). An additional GerE-controlled gene encoding an abundant spore coat protein from Bacillus subtilis. J Bacteriol 177, 372-377.

643. Sadaie, Y., Takamatsu, H., Nakamura, K. \& Yamane, K. (1991). Sequencing reveals similarity of the wild-type $\mathrm{div}^{+}$ gene of Bacillus subtilis to the Eschericbia coli sec $A$ gene. Gene 98 , $101-105$.

644. Sadaie, Y. Unpublished data.

645. Saito, H., Shibata, T. \& Ando, T. (1979). Mapping of genes determining nonpermissiveness and host-specific restriction to bacteriophages in Bacillus subtilis Marburg. Mol Gen Genet 170, 117-122.

646. Sakaguchi, R., Amano, H. \& Shishido, K. (1988). Nucleotide sequence homology of the tetracycline-resistance determinant naturally maintained in Bacillus subtilis Marburg 168 chromo- some and the tetracycline-resistance gene of $B$. subtilis plasmid pNS1981. Biocbim Biopbys Acta 950, 441-444.

647. Sakamoto, Y., Nakai, S., Moriya, S., Yoshikawa, H. \& Ogasawara, N. (1995). The Bacillus subtilis dna $C$ gene encodes a protein homologous to the DnaB helicase of Escherichia coli. Microbiology 141, 641-644.

648. Sammons, R. L., Slynn, G. M. \& Smith, D. A. (1987). Genetical and molecular studies on ger $M$, a new developmental locus of Bacillus subtilis. J Gen Microbiol 133, 3299-3312.

649. Sandman, K., Losick, R. \& Youngman, P. (1987). Genetic analysis of Bacillus subtilis spo mutations generated by $\mathrm{Tn} 917-$ mediated insertional mutagenesis. Genetics 117, 603-617.

650. Sanjanwala, B. \& Ganesan, A. T. (1991). Genetic structure and domains of DNA polymerase III of Bacillus subtilis. Mol Gen Genet 226, 467-472.

651. Santana, M., Kunst, F., Hullo, M. F., Rapoport, G., Danchin, A. \& Glaser, P. (1992). Molecular cloning, sequencing and physiological characterization of the qox operon from Bacillus subtilis encoding the $a a_{3-600}$ quinol oxidase. I Biol Cbem 267, 10225-10231.

652. Santana, M., lonescu, M. S., Vertes, A., Longin, R., Kunst, F., Danchin, A. \& Glaser, P. (1994). Bacillus subtilis FOF1 ATPase: DNA sequence of the atp operon and characterization of atp mutants. J Bacteriol 176, 6802-6811.

653. Santos, M. A., de Lencastre, H. \& Archer, L. J. (1983). Bacillus subtilis mutation blocking irreversible binding of bacteriophage SSP1. J Gen Microbiol 129, 3499-3504.

654. Saraste, M., Metso, T., Nakari, T., Jalli, T., Lauraeus, M. \& van der Oost, J. (1991). The Bacillus subtilis cytochrome-c oxidase: variations on a conserved protein theme. Eur J Biochem 195 517-525.

655. Sasajima, K. \& Kumada, T. (1983). Deficiency of flagellation in Bacillus subtilis pleiotropic mutant lacking transketolase. Agric Biol Cbem 47, 1375-1376.

656. Sato, T., Samori, Y. \& Kobayashi, Y. (1990). The cis $A$ cistron of Bacillus subtilis sporulation gene spoIVC encodes a protein homologous to a site-specific recombinase. I Bacteriol 172 , 1092-1098

657. Sato, T., Harada, K., Ohta, Y. \& Kobayashi, Y. (1994) Expression of the Bacillus subtilis spoIVCA gene, which encodes a site-specific recombinase, depends on the spoIIGB product. $J$ Bacteriol 176, 935-937.

658. Saxe, C. L. \& Mendelson, N. H. (1984). Identification of mutations associated with macrofiber formation in Bacillus subtilis. Genetics 107, 551-561.

659. Saxild, H. H. \& Nygaard, P. (1987). Genetic and physiological characterization of Bacillus subtilis mutants resistant to purine analogs. J Bacteriol 169, 2977-2983.

660. Saxild, H. H. \& Nygaard, P. (1988). Gene-enzyme relationships of the purine biosynthetic pathway in Bacillus subtilis. Mol Gen Genet 211, 160-167.

661. Saxild, H. H., Jacobsen, J. H. \& Nygaard, P. (1994). Genetic and physiological characterization of a formate-dependent $5^{\prime}$ phosphoribosyl-1-glycinamide transformylase activity in Bacillus subtilis. Mol Gen Genet 242, 415-420.

662. Saxild, H. H., Jacobsen, J. H. \& Nygaard, P. (1995). Functional analysis of the Bacillus subtilis purT gene encoding formatedependent glycinamide ribonucleotide transformylase. Microbiology 141, 2211-2218.

663. Saxild, H. H., Andersen, L. N. \& Hammer, K. (1996). dra-nupC$p d p$ operon of Bacillus subtilis: nucleotide sequence, induction by deoxyribonucleosides, and transcriptional regulation by 
deoR encoded DeoR repressor protein. I Bacteriol 178, 424-434.

664. Saxild, H. H., Christensen, L., Nygaard, P. \& Schou, S. Unpublished data.

665. Schiott, T. (1995). Direct submission to EMBL/GenBank/ DDBJ - X87845.

666. Schmidt, A., Schiesswohl, M., Völker, U., Hecker, M. \& Schumann, W. (1992). Cloning, sequencing, mapping and transcriptional analysis of the groESL operon from Bacillus subtilis. J Bacteriol 174, 3993-3999.

667. Schott, K., Kellermann, J., Lottspeich, F. \& Bacher, A. (1990). Riboflavin synthases of Bacillus subtilis. Purification and amino acid sequence of the $\alpha$ subunit. J Biol Chem 265, 4204-4209.

668. Schröder, I., Hederstedt, L. G., Kannangara, C. \& Gough, P. (1992). Glutamyl-tRNA reductase activity in Bacillus subtilis is dependent on the hem $A$ gene product. Biochem J 281, 843-850.

669. Schröder, I., Johansson, P., Rutberg, L. \& Hederstedt, L. (1994). The bem $X$ gene of the Bacillus subtilis bem $A X C D B L$ operon encodes a membrane protein, negatively affecting the steady-state cellular concentration of HemA (glutamyl-tRNA reductase). Microbiology 140, 731-740.

670. Schuch, R. \& Piggot, P. J. (1994). The $\operatorname{dacF-spoII} A$ operon of Bacillus subtilis, encoding $\sigma^{\mathrm{F}}$, is autoregulated. J Bacteriol 176, 4104-4110.

671. Schuch, R. (1995). Direct submission to EMBL/GenBank/ DDB J - U32685.

672. Schulz, A. \& Schumann, W. (1996). $b r c A$, the first gene of the Bacillus subtilis dnaK operon, encodes a negative regulator of class I heat shock genes. J Bacteriol 178, 1088-1093.

673. Scotti, C., Piatti, M., Cuzzoni, A., Perani, P., Tognoni, A., Grandi, G., Galizzi, A. \& Albertini, A. M. (1993). A Bacillus subtilis large ORF coding for a polypeptide highly similar to polyketide synthases. Gene 130, 65-71.

674. Scotti, C., Valbuzzi, A., Perego, M., Galizzi, A. \& Albertini, A. M. (1996). The Bacillus subtilis genes for ribonucleotide reductase are similar to the genes for the second class 1 $\mathrm{NrdE} / \mathrm{NrdF}$ enzymes of Enterobacteriaceae. Microbiology 142 (in press).

675. Segall, J. \& Losick, R. (1977). Cloned Bacillus subtilis DNA containing a gene that is activated early during sporulation. Cell 11, 751-761.

676. Seki, T., Yoshikawa, H., Takahashi, H. \& Saito, H. (1987). Cloning and nucleotide sequence of $p h o P$, the regulatory gene for alkaline phosphatase and phosphodiesterase in Bacillus subtilis. J Bacteriol 169, 2913-2916.

677. Seki, T., Yoshikawa, H., Takahashi, H. \& Saito, H. (1988). Nucleotide sequence of the Bacillus subtilis pboR gene. $J$ Bacteriol 170, 5935-5938.

678. Sekiguchi, J., Ohsu, H., Kuroda, A., Moriyama, H. \& Akamatsu, T. (1990). Nucleotide sequences of the Bacillus subtilis faD locus and a $B$. licheniformis homologue affecting the autolysin level and flagellation. $J$ Gen Microbiol 136, 1223 1230

679. Sekiguchi, J., Akeo, K., Yamamoto, H., Khasanov, F. K., Alonso, J. C. \& Kuroda, A. (1995). Nucleotide sequence and regulation of a new putative cell wall hydrolase gene, $c w / D$, which affects germination in Bacillus subtilis. J Bacteriol 177, $5582-5589$

680. Seror, S. J., Casaregola, S., Vannier, F., Zouari, N., Dahl, M. \& Boye, E. (1994). A mutant cysteinyl-tRNA synthetase affecting timing of chromosomal replication initiation in B. subtilis and conferring resistance to a protein kinase $\mathrm{C}$ inhibitor. $E M B O J$ 13, 2472-2480.

681. Seror, S. J. Unpublished data.

682. Sharp, P. M., Nolan, N. C., Cholmain, N. N. \& Devine, K. M. (1992). DNA sequence variability at the $r p / X$ locus of Bacillus subtilis. J Gen Microbiol 138, 39-45.

683. Sharrock, R. A. \& Leighton, T. (1981). Intergenic suppressors of temperature-sensitive sporulation in Bacillus subtilis. Mol Gen Genet 183, 532-537.

684. Sharrock, R. A., Rubenstein, S., Chan, M. \& Leighton, T. (1984). Intergenic suppresssion of spo0 phenotype by the Bacillus subtilis mutation rvt $A$. Mol Gen Genet 194, 260-264.

685. Shazand, K., Tucker, J., Chiang, R., Stansmore, K., SperlingPetersen, H. U., Grunberg-Manago, M., Rabinowitz, J. C. \& Leighton, T. (1990). Isolation and molecular genetic characterization of the Bacillus subtilis gene (infB) encoding protein synthesis initiation factor 2. J Bacteriol 172, 2675-2687.

686. Shiga, Y., Yamagata, H. \& Udaka, S. (1993). Characterization of the gene encoding intracellular proteinase inhibitor of Bacillus subtilis and its role for regulation of major intracellular proteinase. J Bacteriol 175, 7130-7137.

687. Shohayeb, M. \& Chopra, I. (1987). Mutations affecting penicillin-binding proteins $2 \mathrm{a}, 2 \mathrm{~b}$ and 3 in Bacillus subtilis alter cell shape and peptidoglycan metabolism. J Gen Microbiol 133, 1733-1742.

688. Siccardi, A. G., Lanza, E., Nielsen, E., Galizzi, A. \& Mazza, G. (1975). Genetic and physiological studies on the site of action of distamycin A. Antimicrob Agents Chemother 8, 370-376.

689. Siccardi, A. G., Ottolenghi, S., Fortunato, A. \& Mazza, G. (1976). Pleiotropic, extragenic suppression of dna mutations in Bacillus subtilis. J Bacteriol 128, 174-181.

690. Siegel, E. C. \& Marmur, J. (1969). Temperature-sensitive induction of bacteriophage in Bacillus subtilis 168. J Virol 4 610-618.

691. Siranosian, K. J., Ireton, K. \& Grossman, A. D. (1993). Alanine dehydrogenase (ald) is required for normal sporulation in Bacillus subtilis. J Bacteriol 175, 6789-6796.

692. Slack, F. J., Serror, P., Joyce, E. \& Sonenshein, A. L. (1995). A gene required for nutritional repression of the Bacillus subtilis dipeptide permease operon. Mol Microbiol 15, 689-702.

693. Slock, J., Stahly, D. P., Han, C.-Y., Six, E. W. \& Crawford, I. P. (1990). An apparent Bacillus subtilis folic acid biosynthetic operon containing $p a b$, an amphibolic $\operatorname{tr} p G$ gene, a third gene required for synthesis of para-aminobenzoic acid, and the dihydropteroate synthase gene. J Bacteriol 172, 7211-7226.

694. Sloma, A., Ally, A., Ally, D. \& Pero, J. (1988). Gene encoding a minor extracellular protease in Bacillus subtilis. J Bacteriol 170, $5557-5563$

695. Sloma, A., Rudolph, C. F., Rufo, G. A., Jr, Sullivan, B. J., Theriault, K. A., Ally, D. \& Pero, J. (1990). Gene encoding a novel extracellular metalloprotease in Bacillus subtilis. $J$ Bacteriol 172, 1024-1029.

696. Sloma, A., Rufo, G. A., Jr, Rudolph, C. F., Sullivan, B. J., Theriault, K. A. \& Pero, J. (1990). Bacillopeptidase F of Bacillus subtilis: purification of the protein and cloning of the gene. J Bacteriol 172, 1470-1477.

697. Sloma, A., Rufo, G. A., Jr, Rudolph, C. F., Sullivan, B. J., Theriault, K. A. \& Pero, J. (1990). Errata: Bacillopeptidase F of Bacillus subtilis: purification of the protein and cloning of the gene. J Bacteriol 172, 5520-5521.

698. Sloma, A., Rufo, G. A., Jr, Theriault, K. A., Dwyer, M., 
Wilson, S. W. \& Pero, J. (1991). Cloning and characterization of the gene for an additional extracellular serine protease of Bacillus subtilis. J Bacteriol 173, 6889-6895.

699. Slynn, G. M., Sammons, R. L., Smith, D. A., Moir, A. \& Corfe, B. M. (1994). Molecular genetical and phenotypical analysis of the ger $M$ spore germination gene of Bacillus subtilis 168 . FEMS Microbiol Lett 121, 315-320.

700. Smith, I. \& Smith, H. (1973). Location of the SPO2 attachment site and the bryamycin resistance marker on the Bacillus subtilis chromosome. J Bacteriol 114, 1138-1142.

701. Smith, I., Weiss, D. \& Pestka, S. (1976). A micrococcinresistant mutant of Bacillus subtilis: localization of resistance to the 50 S subunit. Mol Gen Genet 144, 231-233.

702. Smith, I. \& Paress, P. (1978). Genetic and biochemical characterization of kirromycin resistance mutations in Bacillus subtilis. J Bacteriol 135, 1101-1117.

703. Smith, I., Paress, P., Cabane, K. \& Dubnau, E. (1980). Genetics and physiology of the rel system of Bacillus subtilis. Mol Gen Genet 178, 271-279.

704. Smith, I. (1982). The translational apparatus of Bacillus subtilis. In Molecular Biology of the Bacilli, pp. 111-145. Edited by D. A Dubnau. New York: Academic Press.

705. Smith, K., Bayer, M. E. \& Youngman, P. (1993). Physical and functional characterization of the Bacillus subtilis spoIIM gene. J Bacteriol 175, 3607-3617.

706. Smith, K. \& Youngman, P. (1993). Evidence that the spoIIM gene of Bacillus subtilis is transcribed by RNA polymerase associated with $\sigma^{\mathrm{E}}$. J Bacteriol 175, 3618-3627.

707. Smith, M. C. M., Mountain, A. \& Baumberg, S. (1986). Cloning in Eschericbia coli of a Bacillus subtilis arginine repressor gene through its ability to confer structural stability on a fragment carrying genes of arginine biosynthesis. Mol Gen Genet 205, 176-182.

708. Smith, M. C. M., Czaplewsi, L., North, A. K., Baumberg, S. \& Stockley, P. G. (1989). Sequences required for regulation of arginine biosynthesis promoters are conserved between Bacillus subtilis and Escherichia coli. Mol Microbiol 3, 23-28.

709. Smith, M. C. M., Mountain, A. \& Baumberg, S. (1990). Nucleotide sequence of the Bacillus subtilis arg $C$ gene encoding $\mathrm{N}$-acetylglutamate- $\gamma$-semialdehyde dehydtogenase. Nucleic Acids Res 18, 4595.

710. Soldo, B., Lazarevic, V., Margot, P. \& Karamata, D. (1993). Sequencing and analysis of the divergon comprising gtaB, the structural gene of UDP-glucose pyrophosphorylase of Bacillus subtilis 168. J Gen Microbiol 139, 3185-3195.

711. Soldo, B., Lazarevic, V., Mauël, C. \& Karamata, D. (1996). Sequence of the $305^{\circ}$ to $307^{\circ}$ region of the Bacillus subtilis chromosome. Microbiology 142 (in press).

712. Sonenshein, A. L., Alexander, H. B., Rothstein, D. M. \& Fisher, S. H. (1977). Lipiarmycin-resistant ribonucleic acid polymerase mutants of Bacillus subtilis. J Bacteriol 132, 73-79.

713. Sonenshein, A. L. \& Alexander, H. B. (1979). Initiation of transcription in vitro is inhibited by lipiarmycin. $J$ Mol Biol 127, 55-72.

714. Sonenshein, A. L., Hoch, J. A. \& Losick, R. (editors) (1993). Bacillus subtilis and Other Gram-positive Bacteria: Biochemistry, Pbysiology, and Molecular Genetics. Washington, DC: American Society for Microbiology.

715. Sonenshein, A. L. Unpublished data.

716. Song, B. H. \& Neuhard, J. (1989). Chromosomal location, cloning and nucleotide sequence of the Bacillus subtilis cdd gene encoding cytidine/deoxycytidine deaminase. Mol Gen Genet 216, 462-468.

717. Sorokin, A., Zumstein, E., Azevedo, V., Ehrlich, S. D. \& Serror, P. (1993). The organization of the Bacillus subtilis 168 chromosome region between the spoV $A$ and $\operatorname{ser} A$ genetic loci, based on sequence data. Mol Microbiol 10, 385-395.

718. Sorokin, A., Serror, P., Pujic, P., Azevedo, V. \& Ehrlich, S. D. (1995). The Bacillus subtilis chromosome region encoding homologues of the Escherichia coli $m s s A$ and $r p s A$ gene products. Microbiology 141, 311-319.

719. Sorokin, A., Azevedo, V., Zumstein, E., Galleron, N., Ehrlich, S. D. \& Serror, P. (1996). Sequence analysis of the Bacillus subtilis chromosome region between the $\operatorname{ser} A$ and $k d g$ loci cloned in a yeast artificial chromosome. Microbiology 142, 2005-2016.

720. Staal, S. P. \& Hoch, J. A. (1972). Conditional dihydrostreptomycin resistance in Bacillus subtilis. J Bacteriol 110, 202-207.

721. Stahl, M. L. \& Ferrari, E. (1984). Replacement of the Bacillus subtilis subtilisin structural gene with an in-vitro-derived deletion mutation. J Bacteriol 158, 411-418.

722. Stamford, N. P., Crouzet, J., Cameron, B., Alanine, A. I., Pitt A. R., Yeliseev, A. A. \& Battersby, A. R. (1996). Biosynthesis of vitamin $\mathrm{B} 12$ : the preparative multi-enzyme synthesis of precorrin-3A and 20-methylsirohydrochlorin (a 2,7,20-trimethylisobacteriochlorin). Biochem J 313, 335-342.

723. Steinberg, W. \& Anagnostopoulos, C. (1971). Biochemical and genetic characterization of a temperature-sensitive tryptophanyl-transfer ribonucleic acid synthetase mutant of Bacillus subtilis. J Bacteriol 105, 6-19.

724. Steinmetz, M., Kunst, F. \& Dedonder, R. (1976). Mapping of mutations affecting synthesis of exocellular enzymes in Bacillus. Identity of $s a c U$, amyB and pap mutations. Mol Gen Genet 148, 281-285.

725. Steinmetz, M., LeCoq, D., Aymerich, S., Gonzy-Tréboul, G. \& Gay, P. (1985). The DNA sequence of the gene for the secreted Bacillus subtilis enzyme levansucrase and its genetic control sites. Mol Gen Genet 200, 220-228.

726. Steinmetz, M., Aymerich, S., Gonzy-Tréboul, G. \& LeCoq, D. (1988). Levansucrase induction by sucrose in Bacillus subtilis involves an antiterminator. Homology with the Eschericbia coli bgl operon. In Genetics and Biotechnology of Bacilli, vol. 2, pp. 11-15. Edited by A. T. Ganesan \& J. A. Hoch. San Diego, CA : Academic Press.

727. Stephens, M. A., Lang, N., Sandman, K. \& Losick, R. (1984) A promoter whose utilization is temporally regulated during sporulation in Bacillus subtilis. J Mol Biol 176, 333-348.

728. Stevens, C. M. \& Errington, J. (1990). Differential gene expression during sporulation in Bacillus subtilis: structure and regulation of the spoIIID gene. Mol Microbiol 4, 543-551.

729. Stevens, C. M., Daniel, R., Illing, N. \& Errington, J. (1992). Characterization of a sporulation gene, spoI $V A$, involved in spore coat morphogenesis in Bacillus subtilis. J Bacteriol 174 586-594.

730. Stragier, P., Bouvier, J., Bonamy, C. \& Szulmajster, J. (1984). A developmental gene product of Bacillus subtilis homologous to the sigma factor of Escherichia coli. Nature 312, 376-378.

731. Stragier, P., Kunkel, B., Kroos, L. \& Losick, R. (1989). Chromosomal rearrangement generating a composite gene for a developmental transcription factor. Science 243, 507-512.

732. Stragier, P. Unpublished data.

733. Stranathan, M. C., Bayles, K. W. \& Yasbin, R. E. (1990). The 
nucleotide sequence of the recE $E^{+}$gene of Bacillus subtilis. Nucleic Acids Res 18, 4249.

734. Strauch, M. A., Aronson, A. I., Brown, S. W., Schreier, H. J. \& Sonenshein, A. L. (1988). Sequence of the Bacillus subtilis glutamine synthetase gene region. Gene 71, 257-265.

735. Struck, J. C. R., Vogel, D. W., Ulbrich, N. \& Erdmann, V. A. (1988). A dnaZX-like open reading frame downstream from the Bacillus subtilis scRNA gene. Nucleic Acids Res 16, 2720.

736. Struck, J. C. R., Hartmann, R. K., Toschka, H. Y. \& Erdmann, V. A. (1989). Transcription and processing of Bacillus subtilis small cytoplasmic RNA. Mol Gen Genet 215, 478-482.

737. Struck, J. C. R., Lempicki, R. A., Toschka, H. Y., Erdmann, V. A. \& Fournier, M. J. (1990). Escherichia coli 4.5S RNA gene function can be complemented by heterologous bacterial RNA genes. J Bacteriol 172, 1284-1288.

738. Struck, J. C. R., Alonso, J. C., Toschka, H. Y. \& Erdmann, V. A. (1990). The Bacillus subtilis small cytoplasmic RNA gene and 'dnaX' map near the chromosomal replication origin. Mol Gen Genet 222, 470-472.

739. Suh, J. W., Boylan, S. A. \& Price, C. W. (1986). Gene for the $\alpha$ subunit of Bacillus subtilis RNA polymerase maps in the ribosomal protein gene cluster. J Bacteriol 168, 65-71.

740. Suh, J. W., Boylan, S. A., Thomas, S. M., Dolan, K. M., Oliver, D. B. \& Price, C. W. (1990). Isolation of a $\sec Y$ homologue from Bacillus subtilis: evidence for a common protein export pathway in eubacteria. Mol Microbiol 4, 305-314.

741. Sukhodolets, V. V., Flyakh, Ya. V. \& Rumyantseva, E. V. (1983). Mapping of mutations in genes for nucleoside catabolism on the Bacillus subtilis chromosome. Genetika 19, 221-226.

742. Sun, D. \& Takahashi, I. (1982). Genetic mapping of cataboliteresistant mutants of Bacillus subtilis. Can J Microbiol 28, $1242-1251$.

743. Sun, D. \& Takahashi, I. (1984). A catabolite-resistance mutation is localized in the rpo operon of Bacillus subtilis. Can J Microbiol 30, 423-429.

744. Sun, D., Stragier, P. \& Setlow, P. (1989). Identification of a new sigma-factor involved in compartmentalized gene expression during sporulation of Bacillus subtilis. Genes Dev 3, $141-149$

745. Sun, D. \& Setlow, P. (1991). Cloning, nucleotide sequence, and expression of the Bacillus subtilis ans operon, which codes for L-asparaginase and L-aspartase. J Bacteriol 173, 3831-3845.

746. Sun, D. \& Setlow, P. L. (1993). Cloning, nucleotide sequence, and regulation of the Bacillus subtilis nadB gene and a nifS-like gene, both of which are essential for NAD biosynthesis. $J$ Bacteriol 175, 1423-1432.

747. Sun, D. \& Setlow, P. L. (1993). Cloning and nucleotide sequence of the Bacillus subtilis ans $\mathrm{R}$ gene which encodes a repressor of the ans operon coding for $\mathrm{L}$-asparaginase and $\mathrm{L}$ aspartase. J Bacteriol 175, 2501-2506.

748. Sun, G., Chesnut, R., Sharkova, E., Birkey, S., Duggan, M. F., Sorokin, A., Pujic, P., Ehrlich, S. D. \& Hulett, F. M. (1996). Regulation of aerobic and anaerobic respiration in Bacillus subtilis. J Bacteriol 178, 1374-1385.

749. Sussman, M. D. \& Setlow, P. (1991). Cloning, nucleotide sequence, and regulation of the Bacillus subtilis gpr gene, which codes for the protease that initiates degradation of small, acidsoluble proteins during spore germination. J Bacteriol 173, 291-300.

750. Sutrina, S. L., Reddy, P., Saier, M. H., Jr \& Reizer, J. (1990). The glucose permease of Bacillus subtilis is a single polypeptide chain that functions to energize the sucrose permease. $J$ Biol Chem 265, 18581-18589.

751. Takemaru, K., Mizuno, M., Sato, T., Takeuchi, M. \& Kobayashi, Y. (1995). Complete nucleotide sequence of a skin element excised by DNA rearrangement during sporulation in Bacillus subtilis. Microbiology 141, 323-327.

752. Tam, N. H. \& Borriss, R. (1995). The thy $A$ gene from Bacillus subtilis exhibits similarity with the phage $\phi 3 \mathrm{~T}$ thymidylate synthase gene. Microbiology 141, 291-297.

753. Tanaka, K., Tamaki, M., Osawa, S., Kimura, A. \& Takata, R. (1973). Erythromycin resistant mutants of Bacillus subtilis. Mol Gen Genet 127, 157-161.

754. Tanaka, T. \& Kawata, M. (1988). Cloning and characterization of Bacillus subtilis iep, which has positive and negative effects on production of extracellular proteases. $J$ Bacteriol 170, 3593-3600.

755. Todd, J. A., Roberts, A. N., Johnstone, K., Piggot, P. J., Winter, G. \& Ellar, D. J. (1986). Reduced heat resistance of mutant spores after cloning and mutagenesis of the Bacillus subtilis gene encoding penicillin-binding protein 5. J Bacteriol 167, 257-262.

756. Tognoni, A., Franchi, E., Magistrelli, C., Colombo, E., Cosmina, P. \& Grandi, G. (1995). A putative new peptide synthase operon in Bacillus subtilis: partial characterization. Microbiology 141, 645-648.

757. Tolner, B., Ubbink-Kok, T., Poolman, B. \& Konings, W. N. (1995). Characterization of the proton/glutamate symport protein of Bacillus subtilis and its functional expression in Escherichia coli. J Bacteriol 177, 2863-2869.

758. Toma, S., Del Bue, M., Pirola, A. \& Grandi, G. (1986). $n p r R I$ and $n p r R 2$ regulatory regions for neutral protease expression in Bacillus subtilis. J Bacteriol 167, 740-743.

759. Tominaga, A. \& Kobayashi, Y. (1978). Kasugamycin-resistant mutations of Bacillus subtilis. J Bacteriol 135, 1149-1150.

760. Tomme, P., Gilkes, N. R., Miller, R. C., Warren, A. J. \& Kilburn, D. G. (1994). An internal cellulose-binding domain mediates adsorption of an engineered bifunctional xylanase/ cellulase. Protein Eng 7, 117-123.

761. Trach, K., Chapman, J. W., Piggot, P. J. \& Hoch, J. A. (1985). Deduced product of the stage 0 sporulation gene spooF shares homology with the Spo0A, OmpR and SfrA proteins. Proc Natl Acad Sci USA 82, 7260-7264.

762. Trach, K., Chapman, J. W., Piggot, P. J., LeCoq, D. \& Hoch, J. A. (1988). Complete sequence and transcriptional analysis of the spoOF region of the Bacillus subtilis chromosome. J Bacteriol 170, 4194-4208.

763. Trach, K. \& Hoch, J. A. (1989). The Bacillus subtilis spo0B stage 0 sporulation operon encodes an essential GTP-binding protein. J Bacteriol 171, 1362-1371.

764. Trach, K. A. \& Hoch, J. A. (1993). Multisensory activation of the phosphorelay initiating sporulation in Bacillus subtilis: identification and sequence of the protein kinase of the alternate pathway. Mol Microbiol 8, 69-79.

765. Tran, L., Wu, X.-C. \& Wong, S.-L. (1991). Cloning and expression of a novel protease gene encoding an extracellular neutral protease from Bacillus subtilis. J Bacteriol 173, 63646372.

766. Trautner, T. A., Pawlek, B., Bron, S. \& Anagnostopoulos, C. (1974). Restriction and modification in Bacillus subtilis: biological aspects. Mol Gen Genet 131, 181-191.

767. Trautner, T. A. \& Noyer-Weidner, M. (1993). Restriction/ modification and methylation systems in Bacillus subtilis, 
related species and their phages. In Bacillus subtilis and Other Gram-positive Bacteria, pp. 539-552. Edited by A. L. Sonenshein, J. A. Hoch \& R. Losick, Washington, DC: American Society for Microbiology.

768. Trempy, J. E., Bonamy, C., Szulmajster, J. \& Haldenwang, W. G. (1985). Bacillus subtilis sigma factor $\sigma^{29}$ is the product of the sporulation-essential gene spoIIG. Proc Natl Acad Sci US A 82, 4189-4192.

769. Trowsdale, J. \& Smith, D. A. (1975). Isolation, characterization, and mapping of Bacillus subtilis 168 germination mutants. J Bacteriol 123, 85-95.

770. Trowsdale, J., Chen, S. M. H. \& Hoch, J. A. (1978). Genetic analysis of phenotype revertants of spo0 $\mathrm{A}$ mutants in Bacillus subtilis: a new cluster of ribosomal genes. In Spores VII, pp. 131-135. Edited by G. Chambliss \& J. C. Vary. Washington, DC: American Society for Microbiology.

771. Trowsdale, J., Chen, S. M. H. \& Hoch, J. A. (1979). Genetic analysis of a class of polymyxin resistant partial revertants of stage 0 sporulation mutants of Bacillus subtilis: map of the chromosome region near the origin of replication. Mol Gen Genet 173, 61-70

772. Turner, R. J., Lu, Y. \& Switzer, R. L. (1994). Regulation of the Bacillus subtilis pyrimidine biosynthetic (pyr) gene cluster by an autogenous transcriptional attenuation mechanism. J Bacteriol 176, 3708-3722.

773. Van Alstyne, D. \& Simon, M. I. (1971). Division mutants of Bacillus subtilis: isolation and PBS1 transduction of divisionspecific markers. J Bacteriol 108, 1366-1379.

774. Van Dijl, J. M., de Jong, A., Vehmaanpera, J., Venema, G. \& Bron, S. (1992). Signal peptidase I of Bacillus subtilis: patterns of conserved amino acids in prokaryotic and eukaryotic type I signal peptidases. EMBO J 11, 2819-2828.

775. Van Hoy, B. E. \& Hoch, J. A. (1990). Characterization of the spoIVB and recN loci of Bacillus subtilis. I Bacteriol 172, 1306-1311.

776. Van Sinderen, D., Galli, G., Cosmina, P., de Ferra, F., Withoff, S., Venema, G. \& Grandi, G. (1993). Characterization of the $\operatorname{srf} A$ locus of Bacillus subtilis: only the valine-activating domain of $\operatorname{srf} A$ is involved in the establishment of genetic competence. Mol Microbiol 8, 833-841.

777. Van Sinderen, D., ten Berge, A., Hayema, B. J., Hamoen, L. \& Venema, G. (1994). Molecular cloning and sequence of com $K$, a gene required for genetic competence in Bacillus subtilis. Mol Microbiol 11, 695-703.

778. Van Sinderen, D. \& Venema, G. (1994). comK acts as an autoregulatory control switch in the signal transduction route to competence in Bacillus subtilis. J Bacteriol 176, 5762-5770.

779. Van Sinderen, D., Luttinger, A., Kong, L., Dubnau, D., Venema, G. \& Hamoen, L. (1995). comK encodes the competence transcription factor, the key regulatory protein for competence development in Bacillus subtilis. Mol Microbiol $15,455-462$.

780. Van Sinderen, D., Kiewiet, R. \& Venema, G. (1995). Differential expression of two closely related deoxyribonuclease genes, nuc $A$ and nucB, in Bacillus subtilis. Mol Microbiol 15, 213-223.

781. Van Sinderen, D., Withoff, S., Boels, H. \& Venema, G. (1990). Isolation and characterization of com $L$, a transcription unit involved in competence development of Bacillus subtilis. Mol Gen Genet 224, 396-404.

782. Van der Oost, C., von Wachenfeld, C., Hederstedt, L. \& Saraste, M. (1991). Bacillus subtilis cytochrome oxidase mu- tants: biochemical analysis and genetic evidence for two $a a_{3}$ type oxidases. Mol Microbiol 5, 2063-2072.

783. Vander Horn, P. B. \& Zahler, S. A. (1992). Cloning and nucleotide sequence of the leucyl-tRNA synthetase gene of Bacillus subtilis. J Bacteriol 174, 3928-3935.

784. Vandeyar, M. A. \& Zahler, S. A. (1986). Chromosomal insertions of Tn917 in Bacillus subtilis. J Bacteriol 167, 530-534.

785. Vapnek, D. \& Greer, S. (1971). Minor threonine dehydratase encoded within the threonine synthetic region of Bacillus subtilis. J Bacteriol 106, 983-993.

786. Vapnek, D. \& Greer, S. (1971). Suppression by derepression in threonine dehydratase-deficient mutants of Bacillus subtilis. $J$ Bacteriol 106, 615-625.

787. Varley, A. \& Stewart, G. C. (1992). The DivIV region of the Bacillus subtilis chromosome encodes homologs of Escherichia coli septum placement (MinCD) and cell shape determinants. $J$ Bacteriol 174, 6729-6742.

788. Varon, D., Boylan, S. A., Okamoto, K. \& Price, C. W. (1993). Bacillus subtilis gta $B$ encodes UDP-glucose pyrophosphorylase and is controlled by stationary-phase transcription factor $\sigma^{\mathbf{B}} . J$ Bacteriol 175, 3964-3971.

789. Vazquez-Ramos, J. M. \& Mandelstam, J. (1981). Oxolinic acid-resistant mutants of Bacillus subtilis. J Gen Microbiol 127, $1-9$.

790. Viaene, A. \& Dhaese, P. (1989). Sequence of the glyceraldehyde-3-phosphate dehydrogenase gene from Bacillus subtilis. Nucleic Acids Res 17, 1251.

791. Volker, U., Dufour, A. \& Haldenwang, W. G. (1995). The Bacillus subtilis $r s b U$ gene product is necessary for RsbXdependent regulation of $\sigma^{\mathrm{B}} . J$ Bacteriol 177, 114-122.

792. Vold, B. S. (1985). Structure and organization of genes for transfer RNA in Bacillus subtilis. Microbiol Rev 49, 71-80.

793. Von Wachenfeldt, C. \& Hederstedt, L. (1990). Bacillus subtilis 13-kilodalton cytochrome $c-550$ encoded by $c c c A$ consists of a membrane-anchor and a heme domain. $J$ Biol Chem 265, 13939-13948.

794. Vosman, B., Kuiken, G., Kooistra, J. \& Venema, G. (1988), Transformation in Bacillus subtilis: involvement of the 17 kilodalton DNA-entry nuclease and the competence-specific 18-kilodalton protein. J Bacteriol 170, 3703-3710.

795. Wabiko, H., Ochi, K., Nguyen, D. M., Allen, E. R. \& Freese, E. (1988). Genetic mapping and physiological consequences of metE mutations of Bacillus subtilis. J Bacteriol 170, 2705-2710.

796. Wahl, R., Rice, P., Rice, C. M. \& Kroeger, M. (1994). ECD a totally integrated database of Eschericbia coli. Nucleic Acids Res 22, 3450-3455.

797. Wainscott, V. J. \& Kane, J. F. (1976). Dihydrofolate reductase in Bacillus subtilis. In Microbiology - 1976, pp. 208-213. Edited by D. Schlessinger. Washington, DC: American Society for Microbiology.

798. Walter, J., Noyer-Weidner, M. \& Trautner, T. A. (1990). The amino acid sequence of the CCGG-recognizing DNA methyltransferase M.BsuF1 : implications for the analysis of sequence recognition by cytosine DNA methyltransferases. EMBO J $\mathbf{9}$, 1007-1013.

799. Walton, D. A., Moir, A., Morse, R., Roberts, I. \& Smith, D. A. (1984). The isolation of a $\lambda$ phage carrying DNA from the histidine and isoleucine-valine regions of the Bacillus subtilis chromosome. J Gen Microbiol 130, 1577-1586.

800. Wang, G. F., Kuriki, T., Roy, K. L. \& Kaneda, T. (1993). The primary structure of branched-chain $\alpha$-oxo-acid-dehydrogen- 
ase from Bacillus subtilis and its similarity to other $\alpha$-oxo-acid dehydrogenasese. Eur J Biochem 213, 1091-1099.

801. Wang, L.-F., Price, C. W. \& Doi, R. H. (1985). Bacillus subtilis dnaE encodes a protein homologous to DNA primase of Escherichia coli. J Biol Chem 260, 3368-3372.

802. Wang, L.-F. \& Doi, R. H. (1986). Nucleotide sequence and organization of Bacillus subtilis RNA polymerase major sigma $\left(\sigma^{43}\right)$. Nucleic Acids Res 14, 4293-4307.

803. Wang, L.F. \& Doi, R. H. (1990). Complex character of senS, a novel gene regulating expression of extracellular-protein genes of Bacillus subtilis. J Bacteriol 172, 1939-1947.

804. Warburg, R. J. \& Moir, A. (1981). Properties of a mutant of Bacillus subtilis 168 in which spore germination is blocked at a late stage. J Gen Microbiol 124, 243-253.

805. Warburg, R. J., Mahler, I., Tipper, D. J. \& Halvorson, H. O. (1984). Cloning the Bacillus subtilis 168 aro $C$ gene encoding dehydroquinase. Gene 32, 57-66.

806. Ward, J. B., Jr \& Zahler, S. A. (1973). Genetic studies of leucine biosynthesis in Bacillus subtilis, J Bacteriol 116, 719-726.

807. Abe, A., Koide, H., Kohno, T. \& Watabe, K. (1995). A Bacillus subtilis spore coat polypeptide gene, cotS. Microbiology 141, 1433-1442.

808. Wawrousek, E. F. \& Hansen, J. N. (1983). Structure and organization of a cluster of six tRNA genes in the space between tandem ribosomal RNA gene sets in Bacillus subtilis. J Biol Chem 258, 291-298.

809. Wawrousek, E. F., Narasimhan, N. \& Hansen, J. N. (1984). Two large clusters with thirty-seven transfer RNA genes adjacent to ribosomal RNA gene sets in Bacillus subtilis: sequence and organization of trrnD and trrnE gene clusters. $J$ Biol Chem 259, 3694-3702.

810. Webb, C. D., Decatur, A., Teleman, A. \& Losick, R. (1995). Use of green fluorescent protein for visualization of cellspecific gene expression and subcellular protein localization during sporulation in Bacillus subtilis. J Bacteriol 177, 59065911.

811. Weinrauch, Y., Guillen, N. \& Dubnau, D. A. (1989). Sequence and transcription mapping of Bacillus subtilis competence genes $\operatorname{com} B$ and $\operatorname{com} A$, one of which is related to a family of bacterial regulatory determinants. $J$ Bacteriol 171, 5362-5375.

812. Weinrauch, Y., Penchev, R., Dubnau, E., Smith, I. \& Dubnau, D. (1990). A Bacillus subtilis regulatory gene product for genetic competence and sporulation resembles sensor protein members of the bacterial two-component signal-transduction systems. Genes Dev 4, 860-872.

813. Weng, M., Nagy, P. L. \& Zalkin, H. (1995). Identification of the Bacillus subtilis pur operon repressor. Proc Natl Acad Sci US A 92, 7455-7459.

814. Wetzstein, M. \& Schumann, W. (1990). Nucleotide sequence of a Bacillus subtilis gene homologous to the grpE gene of $E$. coli located immediately upstream of the dnaK gene. Nucleic Acids Res 18, 1289.

815. Wetzstein, M., Völker, V., Dedio, J., Löbau, S., Zuber, P., Schiesswohl, M., Herget, C., Hecker, M. \& Schumann, W. (1992). Cloning, sequencing and molecular analysis of the dnaK locus from Bacillus subtilis. J Bacteriol 174, 3300-3310.

816. Whalen, M. B. (1995). Direct submission to EMBL/ GenBank/DDBJ - U38819.

817. Whiteman, P., Marks, C. \& Freese, E. (1980). The sodium effect of Bacillus subtilis growth on aspartate. J Gen Microbiol 119, 493-504.
818. Widom, R. L., Jarvis, E. D., LaFauci, G. \& Rudner, R. (1988). Instability of rRNA operons in Bacillus subtilis. J Bacteriol 170, 605-610.

819. Wilhelm, M. (1984). The cloning of Bacillus subtilis xylose isomerase xylulokinase in Escherichia coli genes by IS5mediated expression. EMBO J 3, 2555-2560.

820. Wilhelm, M. \& Hollenberg, C. P. (1985). Nucleotide sequence of the Bacillus subtilis xylose isomerase gene: extensive homology between the Bacillus and Escherichia coli enzyme. Nucleic Acids Res 13, 5717-5722.

821. Williams, G. \& Smith, I. (1979). Chromosomal mutants causing resistance to tetracycline in Bacillus subtilis. Mol Gen Genet 177, 23-29.

822. Williams, M. T. \& Young, F. E. (1977). Temperate Bacillus subtilis bacteriophage $\phi 3 \mathrm{~T}$ : chromosomal attachment site and comparison with temperate bacteriophage $\phi 105$ and SPO2. $J$ Virol 21, 522-529.

823. Willimsky, G., Bang, H., Fischer, G. \& Marahiel, M. A. (1992). Characterization of $\operatorname{csp} B$, a Bacillus subtilis inducible cold shock gene affecting cell viability at low temperatures. $J$ Bacteriol 174, 6326-6335.

824. Winters, P., Caldwell, R., Enfield, L. \& Ferrari, E. (1996). The ampS-nprE $\left(124^{\circ}-127^{\circ}\right)$ region of the Bacillus subtilis 168 chromosome: sequencing of a $27 \mathrm{~kb}$ segment and identification of several genes in the area. Microbiology 142 (in press).

825. Wipat, A., Carter, N., Brignell, S. C., Guy, B. J., Piper, K., Sanders, J., Emmerson, P. T. \& Harwood, C. R. (1996). The dnaB-phe $A\left(256^{\circ}-240^{\circ}\right)$ region of the Bacillus subtilis chromosome containing genes responsible for stress responses, the utilization of plant cell walls and primary metabolism. Microbiology 142 (in press).

826. Wise, A. A. \& Price, C. W. (1995). Four additional genes in the sigB operon of Bacillus subtilis that control activity of the general stress factor sigma $B$ in response to environmental signals. J Bacteriol 177, 123-133.

827. Wolf, M., Geczi, A., Simon, O. \& Borriss, R. (1995). Genes encoding xylan and $\beta$-glucan hydrolysing enzyme in Bacillus subtilis: characterization, mapping and construction of strains deficient in lichenase, cellulase and xylanase. Microbiology 141, 281-290.

828. Wood, H. E., Devine, K. M. \& McConnell, D. J. (1991). Characterisation of a repressor gene $(x r e)$ and a temperaturesensitive allele from the Bacillus subtilis prophage, PBSX. Gene 96, 83-88.

829. Wray, L. V. \& Fisher, S. H. (1994). Analysis of Bacillus subtilis but operon expression indicates that histidine-dependent induction is mediated primarily by transcriptional antitermination and that amino acid repression is mediated by two mechanisms: regulation of transcription initiation and inhibition of histidine transport. J Bacteriol 176, 5466-5473.

830. Wray, L. V., Atkinson, M. R. \& Fisher, S. H. (1994). The nitrogen-regulated Bacillus subtilis nrg $A B$ operon encodes a membrane protein and a protein highly similar to the Escherichia coli glnB-encoded PII protein. J Bacteriol 176, 108-114.

831. Wray, L. V., Ferson, A. E. \& Fisher, S. H. Unpublished data.

832. Wu, J.-J., Howard, M. G. \& Piggot, P. J. (1989). Regulation of transcription of the Bacillus subtilis spoll $A$ locus. $J$ Bacteriol 171, 692-698.

833. Wu, J.-J. \& Piggot, P. J. (1990). Regulation of late expression of the Bacillus subtilis spoII $A$ locus: evidence that it is cotranscribed with the gene for a putative penicillin-binding 
protein. In Genetics and Biotechnology of Bacilli, vol. 3, pp. 321-327. Edited by A. T. Ganesan \& J. A. Hoch. New York: Academic Press.

834. Wu, J.-J., Schuch, R. \& Piggot, P. J. (1992). Characterization of a Bacillus subtilis sporulation operon that includes genes for a RNA polymerase sigma-factor and for a putative DD-carboxypeptidase. J Bacteriol 174, 4885-4892.

835. Wu, X.-C., Nathoo, S., Pang, A. S.-H., Carne, T. \& Wong, S.L. (1990). Cloning, genetic organization, and characterization of a structural gene encoding bacillopeptidase $\mathrm{F}$ from Bacillus subtilis. J Biol Chem 265, 6845-6850.

836. Xu, G. L., Kapfer, W., Walter, J. \& Trautner, T. A. (1992). BsuBI, an isospecific restriction and modification system of PstI : characterization of the BsuBI genes and enzymes. Nucleic Acids Res 20, 6517-6523.

837. Yamada, Y., Ohki, M. \& Ishikura, H. (1983). The nucleotide sequence of Bacillus subtilis tRNA genes. Nucleic Acids Res 11, 3037-3045.

838. Yamamoto, J., Shimizu, M. \& Yamane, K. (1991). Molecular cloning and analysis of nucleotide sequence of the Bacillus subtilis lys $A$ gene region using $B$. subtilis phage vectors and a multi-copy plasmid, pUB110. Agric Biol Cbem 55, 1615-1626.

839. Yamane, K., Kumano, M. \& Kurita, K. (1996). The $25^{\circ}-36^{\circ}$ region of the Bacillus subtilis chromosome: determination of the sequence of a $146 \mathrm{~kb}$ segment and identification of 112 genes. Microbiology 142 (in press).

840. Yang, M., Galizzi, A. \& Henner, D. (1983). Nucleotide sequence of the amylase gene from Bacillus subtilis. Nucleic Acids Res 11, 237--249.

841. Yang, M. Y., Ferrari, E. \& Henner, D. J. (1984). Cloning of the neutral protease gene of Bacillus subtilis and the use of the cloned gene to create an in vitro-derived deletion mutation. $J$ Bacteriol 160, 16-21.

842. Yang, M., Ferrari, E., Chen, E. \& Henner, D. J. (1986). Identification of the pleiotropic sacQ gene of Bacillus subtilis. $J$ Bacteriol 166, 113-119.

843. Yang, M., Shimotsu, H., Ferrari, E. \& Henner, D. J. (1987). Characterization and mapping of the Bacillus subtilis prt $\mathrm{R}$ gene. J Bacteriol 169, 434-437.

844. Yanouri, A., Daniel, R. A., Errington, J. \& Buchanan, C. E. (1993). Cloning and sequencing of the cell division gene $p b p B$, which encodes penicillin-binding protein 2B in Bacillus subtilis. $J$ Bacteriol 175, 7604-7616.

845. Yasbin, R. E., Cheo, D. \& Bayles, K. W. (1991). The SOB system of Bacillus subtilis: a global regulon involved in DNA repair and differentiation. Res Microbiol 142, 885-892.

846. Yasumoto, K., Liu, H., Jeong, S. M., Ohashi, Y., Kakinuma, S., Tanaka, K., Kawamura, F., Yoshikawa, H. \& Takahashi, H. (1996). Sequence analysis of a $50 \mathrm{~kb}$ region between $s p o 0 H$ and $r r n$ on the Bacillus subtilis chromosome. Microbiology 142 (in press).

847. Yazdi, M. A. \& Moir, A. (1990). Characterization and cloning of the gerC locus of Bacillus subtilis 168. J Gen Microbiol 136, 1335-1342.

848. Ye, R., Rehemtulla, S. N. \& Wong, S. L. (1994). Glucitol induction in Bacillus subtilis is mediated by a regulatory factor, GutR. J Bacteriol 176, 3321-3327.

849. Ye, R. Unpublished data.

850. Ying, C. \& Ordal, G. W. (1989). Nucleotide sequence and expresion of $c h e F$, an essential gene for chemotaxis in Bacillus subtilis. J Bacteriol 171, 1631-1637.
851. Ying, C., Scoffone, F., Albertini, A. M., Galizzi, A. \& Ordal, G. W. (1991). Properties of the Bacillus subtilis chemotaxis protein CheF, a homolog of the Salmonella typhimurium flagellar protein FliJ. J Bacteriol 173, 3584-3586.

852. Yon, J. R., Sammons, R. L. \& Smith, D. A. (1989). Cloning and sequencing of the gerD gene of Bacillus subtilis.J Gen Microbiol 135, 3431-3445.

853. Yoshida, K., Sano, H., Miwa, Y., Ogasawara, N. \& Fujita, Y. (1994). Cloning and nucleotide sequencing of a $15 \mathrm{~kb}$ region of the Bacillus subtilis genome containing the iol operon. Microbiology 140, 2289-2298.

854. Yoshida, K.-I., Sano, H., Seki, S., Oda, M., Fujimura, M. \& Fujita, Y. (1995). Cloning and sequencing of a $29 \mathrm{~kb}$ region of the Bacillus subtilis genome containing the but and wap $A$ loci. Microbiology 141, 337-343.

855. Yoshida, K. (1995). Direct submission to EMBL/GenBank/ DDBJ - D45911.

856. Yoshida, K., Seki, S., Fujimura, M., Miwa, Y. \& Fujita, Y. (1995). Cloning and sequencing of a 36-kb region of the Bacillus subtilis genome between the gnt and iol operons. DNA Res 2, 61-69.

857. Yoshikawa, H. \& Doi, R. H. (1990). Sequence of the Bacillus subtilis spectinomycin resistance gene region. Nucleic Acids Res 18, 1647.

858. Yoshikawa, H. (1995). Direct submission to EMBL/ GenBank/DDBJ - D50303.

859. Yoshikawa, H. (1995). Direct submission to EMBL/ GenBank/DDBJ - D50302.

860. Young, F. E., Smith, D. \& Reilly, B. E. (1969). Chromosomal location of genes regulating resistance to bacteriophage in Bacillus subtilis. J Bacteriol 98, 1087-1097.

861. Young, M. (1975). Genetic mapping of sporulation operons in Bacillus subtilis using a thermosensitive sporulation mutant. $J$ Bacteriol 122, 1109-1116.

862. Young, M. (1976). Use of temperature-sensitive mutants to study gene expression during sporulation in Bacillus subtilis. $J$ Bacteriol 126, 928-936.

863. Yu, J., Hederstedt, L. \& Piggot, P. J. (1995). The cytochrome bc complex (menaquinone:cytochrome $c$ reductase) in Bacillus subtilis has a nontraditional subunit organization. J Bacteriol 177, 6751-6760.

864. Yudkin, M. D. \& Turley, L. (1980). Suppression of asporogeny in Bacillus subtilis: allele-specific suppression of a mutation in the spoII A locus. J Gen Microbiol 121, 69-78.

865. Yuki, S. (1975). The chromosomal location of the structure gene for amylase in Bacillus subtilis. Jpn J Genet 50, 155-157.

866. Zahler, S. A., Benjamin, L. G., Glatz, B. S., Winter, P. F. \& Goldstein, B. J. (1976). Genetic mapping of als $A$, alsR, thy $A$, kau $A$, and citD markers in Bacillus subtilis. In Microbiology 1976, pp. 35-43. Edited by D. Schlessinger. Washington, DC: American Society for Microbiology.

867. Zahler, S. A., Korman, R. Z., Rosenthal, R. \& Hemphill, H. E. (1977). Bacillus subtilis bacteriophage SP $\beta$ : localization of the prophage attachment site, and specialized transduction. J Bacteriol 129, 556-558.

868. Zahler, S. A. (1978). An adenine-thiamin auxotrophic mutant of Bacillus subtilis. J Gen Microbiol 107, 199-201.

869. Zahler, S. A., Najimudin, N., Kessler, D. S. \& Vandeyar, M. A. (1990). $\alpha$-Acetolactate synthesis by Bacillus subtilis. In Biosynthesis of Branched Chain Amino Acids, pp. 25-42. Edited by 
Z. Barak, D. M. Chipman \& J. V. Schloss. Weinheim \& New York: Verlagsgesellschaft.

870. Zahler, S. A. Unpublished data.

871. Zeigler, D. R., Burke, B. E., Pfister, R. M. \& Dean, D. H. (1987). Genetic mapping of cadmium resistance mutations in Bacillus subtilis. Curr Microbiol 16, 163-165.

872. Zhang, J., Fitz-James, P. C. \& Aronson, A. I. (1993). Cloning and characterization of a cluster of genes encoding polypeptides present in the insoluble faction of the spore coat insoluble fraction of Bacillus subtilis. J Bacteriol 175, 3757-3766.

873. Zhang, J. \& Aronson, A. (1994). A Bacillus subtilis bgl A gene encoding phospho- $\beta$-glucosidase is inducible and closely linked to a NADH dehydrogenase-encoding gene. Gene 140, $85-90$.

874. Zheng, L. B. \& Losick, R. (1990). Cascade regulation of spore coat gene expression in Bacillus subtilis. J Mol Biol 212, $645-660$.

875. Zuberi, A. R., Ying, C., Parker, H. M. \& Ordal, G. W. (1990).
Transposon Tn917lac Z mutagenesis of Bacillus subtilis: identification of two new loci required for motility and chemotaxis. $J$ Bacteriol 172, 6841-6848.

876. Zuberi, A. R., Ying, C., Bischoff, D. S. \& Ordal, G. W. (1991). Gene-protein relationships in the flagellar hook-basal body complex of Bacillus subtilis: sequences of the $f g B, f g C, f g G$, $f i E$ and $f i F$ genes. Gene 101, 23-31.

877. Zuberi, A. R., Bischoff, D. S. \& Ordal, G. W. (1991). Nucleotide sequence and characterization of a Bacillus subtilis gene encoding a flagellar switch protein. $J$ Bacteriol 173, 710-719.

878. Zukowski, M., Miller, L., Cogswell, P. \& Chen, K. (1988). Inducible expression system based on sucrose metabolism genes of Bacillus subtilis. In Genetics and Biotechnology of Bacilli, vol. 2, pp. 17-22. Edited by A. T. Ganesan \& J. A. Hoch. San Diego, CA: Academic Press.

Received 22 April 1996; revised 4 July 1996; accepted 9 July 1996 